\title{
Differences in hemodynamic stability between hemodialysis and hemofiltration: identification of possible pathogenetic factors
}

Citation for published version (APA):

van Kuijk, W. H. M. (1995). Differences in hemodynamic stability between hemodialysis and hemofiltration: identification of possible pathogenetic factors. [Doctoral Thesis, Maastricht University]. Datawyse / Universitaire Pers Maastricht. https://doi.org/10.26481/dis.19951214wk

Document status and date:

Published: 01/01/1995

DOI:

10.26481/dis.19951214wk

Document Version:

Publisher's PDF, also known as Version of record

Please check the document version of this publication:

- A submitted manuscript is the version of the article upon submission and before peer-review. There can be important differences between the submitted version and the official published version of record.

People interested in the research are advised to contact the author for the final version of the publication, or visit the DOI to the publisher's website.

- The final author version and the galley proof are versions of the publication after peer review.

- The final published version features the final layout of the paper including the volume, issue and page numbers.

Link to publication

\footnotetext{
General rights rights.

- You may freely distribute the URL identifying the publication in the public portal. please follow below link for the End User Agreement:

www.umlib.nl/taverne-license

Take down policy

If you believe that this document breaches copyright please contact us at:

repository@maastrichtuniversity.nl

providing details and we will investigate your claim.
}

Copyright and moral rights for the publications made accessible in the public portal are retained by the authors and/or other copyright owners and it is a condition of accessing publications that users recognise and abide by the legal requirements associated with these

- Users may download and print one copy of any publication from the public portal for the purpose of private study or research.

- You may not further distribute the material or use it for any profit-making activity or commercial gain

If the publication is distributed under the terms of Article 25fa of the Dutch Copyright Act, indicated by the "Taverne" license above, 
Differences in hemodynamic stability between hemodialysis and hemofiltration:

identification of possible pathogenetic factors 
(1) WHM van Kuijk, Mastrich 1995

CIP-DATA KONINKIUKE BIBLIOTHEEK, DEN HAAG

Kuijk, Willibrordus Hendrikus Maria wan

Differences in hemodynamic stability between themodialysis and hemofiftration : identification of possible pathogenetic fictors / Willibrordus Hendrikus Maria wan Kuijk. - Mastricht: Universitaire Pers Maastricht. - III. Thesis Rijksuniversiteit Limburg Maastricht, - Wirh ref. With summary in Dutch.

ISEN $90-5278.208 .3$

Subject headings: hemodlalysis / hemofiltration.

The studies in this thesis as well as printing of this thesis were made possible by financial support of Gambro AB, Sweden 


\title{
Differences in hemodynamic stability between hemodialysis and hemofiltration:
}

\section{identification of possible pathogenetic factors}

\section{PROEFSCHRIFT}

\author{
ter verkrijging van de graad van doctor \\ aan de Rijksuniversiteit Limburg te Maastricht, \\ op gezag van de Rector Magnificus, Prof. Mr. M.J. Cohen, \\ volgens het besluit van het College van Dekanen, \\ in het openbaar te verdedigen \\ op donderdag 14 december 1995 om $\$ 4.00$ uur
}

door

Willibrordus Hendrikus Maria van Kuijk

geboren op 16 november 1965 te Waalwijk

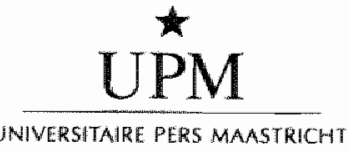




\section{Promotor}

Prof. dr. J.P. wan Hooff

\section{Co-promotor}

Dr. K.M.L. Leunissen

\section{Beoordelingscommulssie}

Prof dr. P.J.E.H.M. Kitslaar, voorzitter

Prof. dr. C. Baldamus (University of Cologne, Germany)

Prof dr. I. Bergström (Karolinska Institute, Stockholm, Sweden)

Mw. Prof. dr. M.P. van Dieijen-Visser

Prof. dr. H.A.J. Struijker Boudier 
Voor mijn onders 



\section{Contents}

Chapter 1: Introduction 9

Chapter 2: Vascular reactivity during hemodialysis and isolated ultrafiltration: thermal influences $\mathbf{3 3}$

Chapter 3: Vascular reactivity during combined ultrafiltration-hemodialysis: influence of dialysate sodium $\mathbf{5 3}$

Chapter 4: Vascular reactivity during combined ultrafiltration-hemodialysis: influence of dialysate derived contaminants 67

Chapter 5: Influence of changes in ionized calcium on cardiovascular reactivity during hemodialysis $\mathbf{8 1}$

Chapter 6: Critical role of the extracorporeal blood temperature in the hemodynamic response during hemofilltration $\mathbf{9 5}$

Chapter 7: Summary and concluding remarks 109

Chapter 8: Samenvatting 115

Dankwoord 121

Curriculum vitae 125 



\section{Chapter 1}

\section{Introduction}

WHM van Kuijk and KML Leunissen

(part of this chapter will be published in Blood Purification) 


\section{General Introduction}

One of the main goals of dialysis therapy in patients with end-stage renal fallure, is removal of excess fluid that has accumulated in the inter-dialytic period. In this respect hemodynamic instability with symptomatic hypotension will remain one of the most important complications in dialysis therapy especially as the number of elderly, cardiovascular compromised patients on dialysis is still increasing. Although recent data are lacking, the incidence of hypotensive episodes is still reported to be around $20 \%$. Symptomatic hypotension is not only a burden for the patient, it also implicates expensive interventions leading to less effective treatment. Extra treatments are even necessary for certain patients in order to achieve dryweight. Therefore, it is of the utmost importance to optimize dialysis therapy with respect to blood pressure stability.

Already in the late seventies, Bergström and Quellhorst showed that blood pressure was better maintained when fluid was withdrawn during either isolated ultrafiltration or hemofiltration as compared to combined ultrafiltrationhemodialysis ${ }^{1-3}$. These observations have been confirmed in clinical trials comparing hemofiltration with acetate buffered combined ultrafiltrationhemodialysis ${ }^{4.5}$. As compared to bicarbonate buffered combined ultrafiltrationhemodialysis, the hemodynamic advantage of hemofiltration is probably smaller ${ }^{\text {th. }}$. Identifying factors responsible for these differences in hemodynamic instability is therefore of importance since this provides means for further optimalisation of dialysis therapy and fluid removal tolerance. Theoretically, differences in hemodynamic stability could be based on differences in plasma volume preservation and cardiovascular reactivity or both. These mechanisms are playing a central role in blood pressure regulation during dialysis therapy. The pathophysiology of both mechanisms will now be discussed especially in relation to different dialysis strategies.

\section{Dialysis strategies}

The dialysis strategies discussed and used in the present thesis are combined ultrafiltration-hemodialysis (UF+HD), isolated ultrafiltration (I-UF) and hemofiltration (HF). In UF+HD, which is the most widely used form of dialysis therapy, diffusion is the main driving force for molecular transport. Diffusion takes place across a membrane with a predefined cut-off point. The extracorporeal circuit consists of an afferent (arterial) and afferent (venous) line with countercurrent flow of blood and dialysate through a dialyzer. Controlled ultrafiltration is obtained by inducing a net negative pressure across the dialysis membrane towards the dialysate 
compartment. With a high small molecular clearance, clearance of middle molecules is relatively low in UF $+\mathrm{HD}$. In $\mathrm{i}-\mathrm{UF}$ the same extracorporeal circuit is used as in UF +HD. However, in the absence of dialysate, molecular transport and consequenty clearance is negligible in i-UF. The ultrafiltration volume is limited to a maximum of 2 liters per hour. In HF, convection is the main driving force for molecular transport. In the absence of dialysate, clearance results from ultrafiltrating large amounts of plasmawater across a membrane (10-30 liter per hour). In addition, a sterile substition fluid, resembling dialysate, is infused either before (pre-diution) or after (post-dilution) the hemofilter. The rate of ultrafiltration and substition are balanced. A main advantage of $H F$ is the larger clearance of middle molecules. Dry-weight is defined as the post-dialytic weight at which the patient has an optimal fluid status.

\section{Plasma Volume Preservation}

\section{Pathophysiology}

Since fluid is directly withdrawn from the intravascular compartment during dialysis, plasma volume (PV) initially declines and as a result, the intracapillary hydrostatic pressure decreases while the colloid-osmotic pressure (COP) increases. These changes in the capillary Starling-equilibrium induce a refill of plasma volume at the capillary level from the extravascular spaces, i.e. the interstitial and intracellular compartments.

Table L.1 Factors influencing plasma wolume preservation

\begin{tabular}{ll}
\hline Positive & Negative \\
\hline $\begin{array}{l}\text { Optimal fuid staus } \\
\text { high venous conpliance } \\
\text { high-sodium dialysis } \\
\text { bicabonate dialysis } \\
\text { moderate ultrafiltration rate }\end{array}$ & hypovolemia \\
\hline
\end{tabular}

The process of plasma volume preservation (PVP) is influenced by a number of factors. (table 1.1). First of all, the patient's fluid status is important. Refill is better with well hydrated extravascular spaces, a phenomenon that is related to the fimite compliance of the interstitial compartment. Overhydration leads to an increase in interstitial pressure thereby improving refill". It has been shown that ultrafiltration below dry-weight resulting in depletion of the extravascular spaces 
leads to an exponential decline in plasma volume ${ }^{12}$. Therefore, adequate estimation of dry-weight is of the utmost importance ${ }^{13}$. PVP is also influenced by changes in plasma osmolality. Plasma osmolality decreases during diallysis as a result of hypertonic fluid loss, thus impairing refill. The decrease in osmolality can be partially compensated with higher dialysate sodium concentrations $(>140$ mmol/l/ $)^{14}$. It has been shown that at dialysate sodium concentrations above 145 mmol/l, refill of the intravascular compartment is improved by inducing a transcellular fluid shift to the extracellular compartment ${ }^{15}$. These results have been confirmed in a more recent study using conductivity techniques ${ }^{16}$. Another factor influencing PVP concerns the used buffer substrate. Acetate impairs PVP at the capillary level by inducing arteriolar vasodilation thus increasing the intracapillary hydrostatic pressure. Bicarbonate has been shown to be more favourable in this respect, especially in patients with compromised left ventricular function ${ }^{17.18}$.

Recently an inverse relation $(r=-0.66 ; p<0.025)$ between PVP and venous compliance was found by Kooman et al.. The relation is explained by a higher postcapillary pressure for a given level of plasma volume when venous compliance is reduced. As a result, hydrostatic pressure over the capillary wall will be higher and refill from the interstitium will be impaired ${ }^{19}$.

It is obvious that the decline in plasma volume is the resultant of (dis)balance between net ultrafiltration and PVP. Plasma volume declines progressively at ultrafiltration rates considerably exceeding the rate of PVP ${ }^{11,20}$.

\section{Differences between dialysis treatments}

According to the first publications on better hemodynamic stability with i-UF, the apparent advantage of $\mathrm{i}$-UF over UF + HD was attributed to differences in PVP that would arise from differences in plasma osmolality ${ }^{21}$. However, Rodriguez et al. found no significant differences in the decrement in PV (serial hematocrit) and the increase in COP, when comparing two hours i-UF with two hours UF +HD (sodium $135 \mathrm{mmol} / \mathrm{l}$ ) ${ }^{\sharp}$. Fleming et al, measured vascular refilling in ten patients during 30 minutes $\mathrm{i}-\mathrm{UF}$ and 30 minutes UF +HD (acetate, sodium $140 \mathrm{mmol} / \mathrm{l}$ ), sequentially performed within one dialysis session at an ultrafiltration rate of 1.2 $1 /$ hr. Changes in blood volume were measured with an optical monitor (infrared light absorption) that was clipped on the arterial line. After i-UF, the ultrafiltrate was reinfused, followed by an equilibration period of \pm 30 minutes to achieve a comparable fluid status at the start of UF $+H D$. They also found no differences in vascular refilling between the two treatment modalities although confirming the better tolerance to a decline in blood volume during $\mathrm{i}-\mathrm{UF}^{22}$.

Differences in PVP, however, do seem to play a role with regard to differences in blood pressure stability between UF +HD and HF. De Vries et al. have found a smaller decrease in blood volume (BV) $(-1.69 \mathrm{vs}-2.25 \% / \mathrm{hr}$, serial erythrocyte 
count) together with a more pronounced fluid shift from the intra to the extra-cellular compartment during HF as compared to UF+HD (bicarbonate) (conductivity measurements). The ultrafiltration rate and dialysate sodium in both treatments were profiled in a similar way; first two hours: $2 / 3$ of total UF-volume with sodium $138 \mathrm{mmol} / 1$, third and fourth hour: $1 / \mathrm{s}$ of total UF-volume with sodium $146 \mathrm{mmol} / \mathrm{l}$. The authors explained the difference by a reduced clearance of urea in HF with a concomitant smaller decrease in plasma osmolality. Olthof et al. have confirmed these results ${ }^{24}$.

\section{Cardiovascular Reactivity}

\section{Pathophysiology}

Due to disbalance in ultrafiltration and PVP, plasma volume normally declines during dialysis therapy and without adequate cardiovascular compensatory mechanisms, blood pressure would decrease. When intravascular volume declines under normal physiologic conditions, arterial blood pressure is maintained by an increase in either total peripheral resistance (TPR) or cardiac output.

A decline in intravascular volume is primarily sensed by low pressure receptors, located in the atria and pulmonary veins. A decrease in arterial blood pressure is sensed by baroreceptors which are mainly located in the carotid sinuses and in the wall of the aortic arch. In the resting state both sets of receptors tonicly inhibit the vasomotor centre, located in the medullary part of the autonomic nervous system. Deactivation of either one or both sets of receptors results in a decrease in their inhibitory output which will lead to an increase in sympathetic output from the vasomotor centre to the cardiovascular system. As a result, heart rate and myocardial contractility both increase while splanchnic and limb blood flow decrease. In addition, plasma renin activity increases ${ }^{25,26}$.

It has been shown in both human and animal studies that as compared to changes in heart rate and myocardial contractility, changes in vascular tone are far more important in maintaining arterial blood pressure during experimental hypovolemia ${ }^{27-29}$. Cardiac factors determine the limits of cardiac function. The actual output and consequently the arterial blood pressure are mainly regulated by the peripheral circulation ${ }^{30}$.

Changes in TPR are especially important in maintaining arterial blood pressure at the pre-capillary level. However, according to Guyton, changes in arterial blood pressure are particularly buffered by changes in cardiac output, thereby pointing at the main determinant of cardiac output: cardiac filling ${ }^{30}$. Right ventricular filling is mainly regulated by changes in venous tone. The venous system contains with minimal sympathetic activity a large blood volume reserve of hemodynamically 
inactive or 'unstressed' blood which accounts for $60 \%$ of the total blood volume. When blood wolume declines, "unstressed' blood can become hemodynamically active by active, sympathetically mediated venous constriction. In addition, "unstressed" blood is also temporarily mobilised by passive venous constriction. Passive recoil of the veins occurs when, as a result of an increase in pre-capillary resistance, the transmural venous distending pressure decreases. This is also known as the deJager-Kroch phenomenon ${ }^{31,32}$. Especially in dialysis patients, adequate right ventricular filling is of utmost importance since diastolic ventricular compliance is often reduced in uremic patients with an incidence of left ventricular hyperirophy of about $70 \%$ in non-diabetics ${ }^{33}$.

\section{Differences between dialysis strategies}

Baldamus et all. studied the acute hemodynamic (thermodilution) and sympathetic response in two groups of eight stable hemodialysis patients during i-UF, HF (acetate) and UF +HD with both acetate and bicarbonate buffering. Each patient served as his or her own control and was studied at the same individual pretreatment fluid status with a sodium concentration of $140 \mathrm{mmol} / 1$ in both dialysate and substitution fluid. To compensate for a higher ultrafiltrable fraction of total calcium in comparison to ionized calcium, the calcium concentrations in dialysate and substitution fluid were respectively 1.40 and $1.75 \mathrm{mmol} / 1$. In addition, small molecule clearances were matched. Their results show that although cardiac index (CI) decreased significantly during i-UF and HF, MAP was best preserved during these treatments as a result of a significant increase in TPR which was associated with an increase in plasma noradrenaline while heart rate (HR) remained unchanged. In contrast, the HR associated smaller decrease in CI during UF + HD resulted in a significant decrease in MAP: during UF+HD with bicarbonate buffering TPR remained more or less unchanged while with acetate, TPR tended to decrease. Moreover, no significant changes in plasma noradrenaline were observed during UF H HD irrespective of the buffer used ${ }^{34}$.

Kooman et al. showed that together with an impaired response in TPR, venous reactivity is also impaired during UF +HD. Using venous-occlusion plethysmography they measured changes in both forearm vascular resistance and venous tone in 12 stable hemodialysis patients during sequential $\mathrm{i}-\mathrm{UF}$ (45 min.) and UF + HD (45 min., bicatbonate, sodium 141 and calcium $1.75 \mathrm{mmol} / 1,37.5^{\circ} \mathrm{C}$ ). The ultrafiltration rate was fixed at $1.0 \mathrm{l} / \mathrm{hr}$ while the order of treatments was randomized. Their results show that peripheral resistance and venous tone increased only during $\mathrm{i}$-UF while in several patients venodilation accurred during $\mathrm{UF}+\mathrm{HD}^{35}$.

Fox et al. studied in a cross-over format the hemodynamic response during 
UF $+H D$ and HF using thoracic electrical biompedance. Both treatments were matched with respect to membrane type (AN69), the dialysate and substitution fluid composition and temperature (acetate, sodium 144 and calcium $1.75 \mathrm{mmol} / \mathrm{l}$, $37.0^{\circ} \mathrm{C}$ ). Stroke index $(\mathrm{SI})$ and TPR decreased significantly during UF + HD while $\mathrm{CI}$ and $\mathrm{HR}$ increased. HF was associated with a comparable decrease in SI. However, the increase in HR during HF was significantly less as compared to UF + HD while both CI and TPR remained stable. Plasma noradrenaline increased comparably during both treatments ${ }^{36}$.

In general, the results obtained by Baldamus et al., Kooman et al. and Fox et al. are in agreement with the results obtained by others ${ }^{37-44}$. Consequently, it may be concluded that ultrafiltration induced decline in plasma volume is well buffered during both i-UF and HF by the following mechanisms:

1. TPR increases in order to maintain arterial blood pressure at the pre-capillary side while temporarily mobilising "unstressed' blood by passive venous constriction.

2. Venous tone increases in order to maintain cardiac filling and output by the mobilisation of "unstressed" blood. However, venous tone has not been directly measured yet during $\mathrm{HF}$.

In contrast, during UF +HD with bicarbonate buffering, both arteriolar and venous reactivity are impaired. As a result, heart rate will increase in order to maintain cardiac output as much as possible (table 1.2). The hemodynamic effects of a decline in plasma volume during acetate buffered UF +HD are even amplified due to direct the vasodilatory capacity of acetate.

Table 1.2 Differences between dialysis strategies: hemodynamics

\begin{tabular}{|c|c|c|c|}
\hline & $U E+M D$ & $\mathrm{HF}$ & $1 \backsim U \mathrm{~F}$ \\
\hline arterial blood pressure & unstable & stable & sabule \\
\hline peripheral resistance & $=/ 4$ & it & $\|$ \\
\hline venous tone & $=/ 4$ & $? ?$ & \# \\
\hline catceholamines & $=$ & $\uparrow$ & $\Uparrow$ \\
\hline
\end{tabular}

\section{Disparity in vascular reactivity: pathogenetic factors}

The foregoing discussion points towards differences in vascular reactivity as main determinant of differences in blood pressure stability during different treatments modalities whille differences in plasma volume preservation seem to play a minor 
role. When applying, for example, the results obtained by de Vries et al, to a dialysis treatment of four hours, the difference in PVP between UF +HD and HF seeme to be relatively small: a decrease in blood volume of respectively $-9.0 \%$ and $-6.8 \%{ }^{23}$. On the other hand, reproducible differences in both arteriolar and venous reactivity have been found in a number of hemodynamic studies when comparing $U F+H D$ with either $\mathrm{i}-\mathrm{UF}$ or $\mathrm{HF}^{34-36}$. However, the mechanisms responsible for these differences in hemodynamics are still poorly understood. Identification of the factors involved will improve our understanding of the pathophysiology of hemodynamic instability during dialysis therapy and may provide us with new tools to prevent the occurrence of this complication.

The following discussion will focus on factors (table 1.3) which might be of importance when studying the interaction between the dialysis treatment and cardiovascular responses. In addition, the role of the autonomic nervous system will be discussed.

Table 1.3 Differences between diallysiss strategies: parhogenetic factors

\begin{tabular}{|c|c|c|c|}
\hline & $\mathrm{UF}+\mathrm{HD}$ & $\mathrm{HF}$ & $\mathrm{i} \sim \mathrm{UF}$ \\
\hline extracorporeal temperarure & $=/ \uparrow$ & $\downarrow$ & $\downarrow \downarrow$ \\
\hline osmolality & $\downarrow \downarrow$ & $\downarrow$ & $=$ \\
\hline \multicolumn{4}{|l|}{ bio-incompatibility } \\
\hline membrane & hilgh & low & high \\
\hline dialysate/infusate & high & low & \\
\hline \multicolumn{4}{|l|}{ clearance } \\
\hline small molecules & high & low & \\
\hline middle mollecules & low & high & \\
\hline lotall $\mathrm{CO}_{2}$ & $\uparrow \uparrow$ & $\uparrow \uparrow$ & $=/ 1$ \\
\hline Calciom & $\uparrow$ & $\uparrow$ & $=$ \\
\hline
\end{tabular}

\section{Extracorporeal blood temperature}

Blood cools during extracorporeal circulation in $\mathrm{i}-\mathrm{UF}$ in the absence of dialysate and infusate. Maggiore et all found a difference of $2.0^{\circ} \mathrm{C}$ in blood temperature between the arterial and venous line in $\mathrm{i}-\mathrm{UF}^{45}$. In HF, extracorporeal blood cooling is compensated by heat transfer from the substitution fluid to blood. However, depending upon the infusate temperature and as a result of the relatively large extracorporeal circuit and a low infusate flow $( \pm 100 \mathrm{ml} / \mathrm{min}$ in post-dilution HF) compensation is only partial. According to Maggiore, blood cools down during extracorporeal circulation by about $0.7^{\circ} \mathrm{C}$ in $\mathrm{HF}^{46}$ In contrast, cooling of blood in 
the extracorporeal circuit during UF $+\mathrm{HD}$ is (over)compensated by heat transfer across the dialysis membrane from dialysate $(500 \mathrm{~m} / \mathrm{min})$ to blood. Lindholm et al. found that at a dialysate temperature of $37.0^{\circ} \mathrm{C}$ the blood temperature increased from $35.8^{\circ} \mathrm{C}$ in the arterial line to $36.9^{\circ} \mathrm{C}$ in the venous line. A dialysate temperature of $36.0^{\circ} \mathrm{C}$ resulted in comparable blood temperatures in the arterial and venous lines ${ }^{47}$.

Differences in thermal balance between different dialysis treatments are even more stressed by the observation that only UF + HD is associated with an increase in core body temperature or in the blood temperature measured in the arterial line in the range of 0.7 to $1.0^{\circ} \mathrm{C}$ during four hours treatment at a dialysate temperature in the range of 37.0 to $38.0^{\circ} \mathrm{C}^{45.47}$. Although the observed increase in temperature might be partially explained by the presence of dialysate derived contaminants in $\mathrm{UF}+\mathrm{HD}^{48}$, Maggiore et al. found an increase in core body temperature of $1.0^{\circ} \mathrm{C}$ also during HF (sterile substitution fluid) in which blood reentering the patient had a comparable temperature as in UF $+\mathrm{HD}$ with a dialysate temperature of $38.0^{\circ} \mathrm{C}^{46}$.

Most authors who studied the relation between the dialysate temperature and cardiovascular stability during UF $+\mathrm{HD}$ found an improvement in hemodynamic stability when dialysate temperature was lowered to about $35.0^{\circ} \mathrm{C} 47.49$. A better increase in total peripheral resistance ${ }^{50-52}$ and myocardial contractility ${ }^{53}$ in association with higher levels of plasma noradrenaline $e^{52,54}$ are probably responsible for these observations. Only Maggiore et al. has actually compared UF + HD with both $\mathrm{i}-\mathrm{UF}$ and $\mathrm{HF}$ in relation to the extracorporeall blood temperature measuring arterial blood pressure and heart rate. They found a reversal of hemodynamic stability in both i-UF and HF when blood reentering the patient was warmed to a comparable temperature as in UF+HD. However, at equivalent changes in the extracorporeal blood temperature, both $\mathrm{i}-\mathrm{UF}$ and $\mathrm{HF}$ did afford some advantage over UF +HD with respect to hemodynamic stability; tachycardia was still more pronounced during UF+HD while in contrast to $\mathrm{HF}$, symptomatic hypotension occurred during cold UF $+H^{45,46}$. In agreement, Fox et al, also found a qualitatively different cardiovascular response berween HF and UF +HD with both treatments matched for dialysate and infusate temperature ${ }^{36}$. However, the results of both studies are confounded by the fact that in UF+HD acetate was used as at buffer while Fox et al. did not directly measure extracorporeal blood temperatures.

\section{Osmolality}

Traditionally, isomosmolality was thought to be the main factor responsible for better hemodynamic stability during i-UF compared to UF $+H^{\prime}$. In our opinion and to our knowledge, direct evidence is still lacking whether changes in plasma osmolality influence cardiovascular reactivity during dialysis. It is important to 
realise that the decrease in plasma osmolality during UF $+H D$ is the result of a decrease in plasma urea together with changes in the concentration of different electrolytes, especially sodium which is a tonicly active substance ${ }^{55}$. Osmolality as a blood pressure stabilising factor should thus always be related to PVP.

Vascular reactivity during UF $+H D$ is probably not influenced by a decrease in plasma osmolality as a result of small molecule clearance. Daugirdas et al. found no differences in hemodynamics in acutely uremic dogs, comparing urea-free and urea-supplemented dialysate (bicarbonate) ${ }^{56}$. Wehle et al. have also shown that in isovolemic HD, adding of urea to dialysate to minimise the fall in plasma osmolality did not prevent a reduction in blood pressure or a decrease in total peripheral resistance ${ }^{57}$. Moreover, different authors have still demonstrated a qualitatively different cardiovascular response between UF $+\mathrm{HD}$ and HF with both treatments matched for small molecule (urea) clearance and changes in plasma osmolality $^{34,36.58}$.

Concerning plasma osmolality in relation to the diallysate sodium concentration, many authors have shown that blood pressure stability during UF+HD is improved with higher dialysate sodium concentrations, especiaily in acetate buffered dialysis $^{39-63}$. The improved hemodynamic stability that was stated before at higher dialysate sodium concentrations seems mainly the result of a better preservation of plasma volume ${ }^{14,16}$. In a non-uremic dog model, Daugirdas et al. could not find any adverse effects of hyponatric dialysate $(90 \%$ of the plasma sodium concentration, bicarbonate) on peripheral resistance as compared to isonatric UF+HD whille ultrafiltration was better tolerated during the latter treatment. The hemodynamic data, although not directly measured, suggest that venous capacitance was also unaffected $^{62}$. However, influence of dialysate sodium concentration on vascular reactivity is suggested by the results obtained by Schultze et al.. They found a significant larger increase in plasma $\mathrm{PGE}_{2}$ while blood pressure was significantly lower after low-sodium UF +HD (126 mmol/l) as compared to high-sodium UF +HD $(140 \mathrm{mmol} / \mathrm{l})$. The authors speculate that low-sodium dialysate might contribute to hypotension due to $\mathrm{PGE}_{2}$ induced vasodilation ${ }^{63}$.

Henrich et al. studied the blood pressure and heart rate response in six dialysis patients during regular UF $+\mathrm{HD}, \mathrm{i}-\mathrm{UF}$ and iso-osmolar $\mathrm{UF}+\mathrm{HD}$ as well as during an orthostatic manoeuvre performed directly after these treatments at comparable decrements in body weight (2.1-3.2\%). Iso-osmolality was achieved by hypertonic mannitol infusion $(25 \%, 0.16 \mathrm{~g} / \mathrm{kg} / \mathrm{hr})$ while in another dialysis session isotonic mannitol $(5 \%)$ was infused in a volume five times the volume used in hypertonic dialysis. Plasma osmolality remained stable only during i-UF and UF +HF with hypertonic mannitol infusion. During the different treatments, no significant changes in supine blood pressure were observed. However, on assumption of the upright posture, blood pressure decreased significantly only after both regular 
UF +HD and UF+HD with iso-tonic mannitol infusion and not after i-UF and hypertonic UF $+H D$. The authors suggest a direct effect of plasma osmolality on vascular reactivity since a comparable increase in hematocrit and plasma proteins during hypertonic and isotonic mannitol $U F+H D$ are indicative of a comparable decline in plasma volume ${ }^{64}$.

\section{Dialysate derived contaminants}

Differences in cardiovascular reactivity might also be related to the presence or absence of a yet unidentified vaso-active agent during either treatment. With (1) vascular reactivity being non-physiological in UF $+H D$, (2) a negligible molecular clearance in i-UF and (3) assuming a common underlying mechanism responsible for the disparity in hemodynamics between UF+HD and both $\mathrm{i}-\mathrm{UF}$ and HF, the most likely possibility is a vasodilator or a vasoconstrictor-inhibitor produced only during UF + HD and not during $\mathrm{i}-\mathrm{UF}$ and HF. Alternatively, a small molecular vasoconstrictive agent might be produced during all three treatment modalities that is not cleared during i-UF and to a lesser extent during HF as compared to UF $+H D$. The finding, however, of a distinct difference in hemodynamics between UF $+H D$ and HF despite matching for small molecule clearances makes the latter possibility less likely ${ }^{34}$.

In this respect, an interesting theory that has attained much attention since its publication in 1983 is formulated in the well known 'Interleukin Hypothesis". The authors suggested that hemodynamic instability during UF +HD could be related to the release of Interleukin-1 by blood mononuclear cells after stimulation by $\mathrm{C} 5 \mathrm{a}$ and or by pyrogenic materials derived from dialysate. The better hemodynamic stability, as observed during i-UF and HF would then reflect the absence of dialysate (and contaminants) in both treatment modalities and the use of more biocompatible membranes in $\mathrm{HF}^{65}$.

Since the publication of the 'Interleukin Hypothesis', the effects of uremia and hemodialysis on the production of especially IL-1 and TNF but also of IL-6 and IL-8 by peripheral mononuclear cells have been studied extensively ${ }^{66}$. It is now generally accepted that monocytes of patients on hemodialysis are in a state of activation, i.e. they have an elevated cytokine content and they are 'primed" to produce cytokines in larger amounts after in-vitro stimulation by lipopolysaccharides (LPS) in comparison with monocytes from normal controls ${ }^{67.71}$. Conflicting data exist, however, whether plasma levels of circulating cytokines are elevated in patients on hemodialysis and whether they increase during the hemodialysis procedure ${ }^{72.75}$. Complement activation (C5a) during (cuprophane) hemodialysis probably only results in mRNA synthesis while dialysate derived endotoxins are necessary for cytokine synthesis and release ${ }^{76.77}$. In-vitro studies 
have shown that fragments of LPS are indeed able to pass most dialysis membranes used in daily clinical practice ${ }^{78-60}$. Studies with radiolabelled $\mathbb{L P S}$ even suggest that the complete LPS particle can pass dialysis membranes of different origins ${ }^{81}$. Membrane transfer of cytokine inducing substances at lower, clinical more relevant concentrations of endotoxins, could however not be demonstrated ${ }^{82}$.

The relevance of the mentioned observations with respect to hemodynamic instability remains to be established. Both $I L-1$ and TNF as well as LPS are known to induce hypotension at certain plasma levels when directly injected in humans with both cytokines acting synergistically ${ }^{* 3}$. Although the degree of pyrogen exposition during hemodialysis is rather small, low grade monocyte stimulation in relation to dialysate derived contaminants might be responsible for impairing the normal physiologic response to a decline in plasma volume as observed during UF + HD. However, for their biological action, both IL-1 and TNF are dependent on the activity of their specific antagonists, namely the $I L-1$ receptor antagonist (IL-IRa) and the soluble TNF receptor (sTNFR), which have both been found elevated in hemodialysis patients ${ }^{84.85}$. In addition, LPS activity is determined by the activity of both lipopolysaccharide binding protein (LBP) and bactericidall permeability increasing protein (BPI). BPI has been shown to increase gradually during hemodialysis ${ }^{86}$. Finally, the acute effect of monocyte stimulation on vascular reactivity during hemodialysis is probably also limited by sequestration of activated monocytes in the pulmonary vasculature ${ }^{87}$.

\section{Buffer substrate and acid-base status}

Correction of uremic acidosis is one of the main objectives of dialysis therapy. Influx of buffer substrate or changes in acid-base balance may play a role in the impaired hemodynamic response during UF $+\mathrm{HD}$ as compared to $\mathrm{i}-\mathrm{UF}$. The latter is associated with bicarbonate loss as a result of convective transport. Until the eighties mainly acetate was used as a buffer in dialysate ${ }^{8 *}$. However, acetate has direct vasodilatory capacities ${ }^{39}$, induces hypoxemia ${ }^{90.91}$ and may impair myocardial contractility ${ }^{92}$. Especially in high efficiency dialysis, when acetate load may exceed the metabolic capacity of muscles and liver, the adverse effects of acetate become apparent $^{8 *}$. In this respect, the advantage of bicarbonate as a buffer in reducing intradialytic morbidity has been documented in several studies, especially in patients who are prone to developing symptomatic hypotension or with dialysate sodium concentrations of about $130 \mathrm{mmol} / \mathrm{t}^{68,90,91,93-95}$.

Most probably, a decrease in total peripheral resistance during UF+HD, as reported by different authors is explained by the use of acetate. Baldamus et al. found that only in acetate buffered UF +HD, total peripheral resistance tended to decrease during the whole treatment, while in bicarbonate buffered UF+HD total 
peripheral resistance first tended to increase after which it tended to decrease back to the baseline level. In addition, acetate buffered UF+HD was associated with a significant larger increase in heart rate as compared to bicarbonate buffered $\mathrm{UF}+\mathrm{HD}^{34}$. Thus, although bicarbonate has most probably no direct adverse effect on hemodynamics, the results obtained by both Baldamus et al. and Kooman ef al. show that arteriolar and venous reactivity remain impaired during bicarbonate $\mathrm{UF}+\mathrm{HD}$ as compared to both $\mathrm{i}-\mathrm{UF}$ and $\mathrm{HF}^{34,35}$. Moreover, HF is still associated with a significant increase in total peripheral resistance even when acetate is used as a buffer in the substitution fluid ${ }^{34}$.

\section{Calcium}

Calcium ions play a critical role in the contractile process of both cardiac and vascular smooth muscle cells as well as in the release of catecholamines from adrenergic nerves ${ }^{96,97}$. Therefore, changes in ionized calcium are potentially important denominators of the cardiovascular response during different dialysis strategies.

A dialysate calcium concentration in the range of $1.50-1.75 \mathrm{mmol} / 1$ results in an increase of the plasma ionized calcium concentration of about $0.20 \mathrm{mmol} / \mathrm{l}$ while with a dialysate calcium concentration of $1.25 \mathrm{mmol} / \mathrm{I}$ in UF +HD, plasma ionized calcium remains more or less unchanged ${ }^{9 \%}$. The increase has been shown to be dependent on the degree of acidosis correction with a negative correlation between changes in ionized calcium and changes in total $\mathrm{CO}_{2}(\mathrm{r}=-0.70 ; \mathrm{p}<0.001)^{99}$.

In a number of studies arterial blood pressure during UF+HD was indeed found to be positively correlated with changes in ionized calcium ${ }^{99.103}$. In this respect, an increase in left ventricular contractility has been a consistent finding ${ }^{100,102,103}$. Fellner et al. could not find a relation between the level of plasma ionized calcium and both total vascular resistance and left ventricular end-diastolic dimensions, measured echocardiographically in eight dialysis patients after dialysis with three different dialysate calcium concentrations $(0.5,1.75 \text { and } 2.5 \mathrm{mmol} / \mathrm{l})^{103}$. Although they only performed post-dialytic echographies, these results suggest that the peripheral vascular response during UF $+H D$ is not directly related to changes in plasma ionized calcium. In the study of Kooman et al, peripheral vascular tone remained unchanged during $U F+H D$ despite a significant increase in plasma ionized calcium ${ }^{35}$. These results are in contrast with the observation that under normal physiologic conditions acute hypercalcemia (serum total calcium from 2.2 to $3.2 \mathrm{mmol} / 1$ in three hours) results in an increase in systemic vascular resistance ${ }^{97}$. Therefore, measurement of peripheral vascular reactivity during dialysis at different levels of plasma ionized calcium seems necessary. 


\section{Autonomic Nervous System}

A treatment specific dystunction of the autonomic nervous system (ANS) has been suggested to play a role in the disparative hemodynamic response during different forms of dialysis therapy. Bergstrom extensively reviewed the relation between the ANS and blood pressure control in dialysis therapy. It might be concluded on the basis of plasmal catecholamine levels that UF +HD is indeed associated with an impairment of the ANS function although conflicting data exist. UF+HD induces a variable response of plasma noradrenaline while in contrast, both i-UF and HF are associated with a more marked increase. However, the noradrenaline response to different autonomic stimuli is probably not impaired by $U F+H D^{104}$. These results, however, should be considered with caution since plasma catecholamine levels are only weak denominators of regional sympathetic activity, especially in uremic patients ${ }^{105,106}$. Factors that may influence efferent sympathetic activity during dialysis are the extracorporeal blood temperature ${ }^{52.54}$, changes in plasma ionized calcium $^{97}$ and the presence of dialysate derived contaminants ${ }^{83}$.

Zucchelli et al concluded that UF +HD is associated with an acute dysfunction of the baroreceptors on the basis of a normal cold pressor and diving test after both $\mathrm{UF}+\mathrm{HD}$ and $\mathrm{HF}$ and an abnormal Valsalva ratio and baroreceptor reflex sensitivity index after UF $+H D$. Moreover lower levels of plasma noradrenaline were found after UF $+\mathrm{HD}$ in comparison with HF. Pre-treatment autonomic function tests were comparable to controls ${ }^{107}$. At variance with this, Baldamus et al. found a normalisation of baroreflex sensitivity during (isovolemic) HF which remained impaired during (isovolemic) $\mathrm{HD}^{108}$. So, although both studies point at an alteration of the ANS function at the level of the afferent part of the baroreflex arc, they are not completely conclusive.

A technique that may improve our knowledge about the role of the ANS in the disparative hemodynamic response during different forms of dialysis therapy in relation to different factors is microneurography. With this technique it is possible to measure efferent, post-ganglionic muscle nerve sympathetic activity directly ${ }^{109}$. Such measurements have already been performed in the interdialytic period in nephrectomized and non-nephrectomized normotensive and hypertensive uremic patients as well as during dialysis comparing stable with hypotensive prone patients ${ }^{10.111}$. The latter study showed that acute hypotension during UF +HD is related to an acute decrease in both calf-vascular resistance and peripheral sympathetic nerve activity"1. 


\section{Conclusion}

Hemodynamic instability is still an important problem in dialysis therapy. Maintenance of blood pressure during dialysis is related to an optimal preservation of plasma volume as well as to adequate cardiovascular compensating mechanisms. In this respect, it is distinctly established that on the basis of an impaired vascular response, blood pressure is less stable during UF $+H D$ as compared to both i-UF and HF. However, the mechanisms responsible for these differences in vascular reactivity are still poorly understood.

Differences in the extracorporeal blood temperature seem to be at least partially responsible. However, only few comparative studies have yet been performed, while most studies are confouncled by the fact that acetate was used as a buffer in UF $+\mathrm{HD}$. Based on measurements of blood pressure, heart rate and prostaglandins it is suggested that the relatively large decline in plasma osmolality could also lead to an impairment of the vascular response during UF+HD. In addition, vascular reactivity could also be influenced by changes in acid-base status. Ionized calcium has been shown to be an important determinant of the blood response during dialysis therapy by influencing myocardial contractility. However, it is unknown whether vascular reactivity is also influenced by changes in ionized calcium. Finally, the clinical relevance of bioincompatibility factors with respect to hemodynamics remains to be established.

\section{Aim of the Study}

The aim of the present study is to identify factors that could be responsible for the impaired vascular response during UF $+\mathrm{HD}$ as compared to $\mathrm{i}-\mathrm{UF}$ and $\mathrm{HF}$. The role of the following factors in the vascular response during dialysis therapy was studied under completely standardised conditions:

- extracorporeal blood temperature

- plasma osmolality

- dialysate derived contaminants

- plasma ionized calcium

The first study compares $\mathrm{i}-\mathrm{UF}$ and $\mathrm{UF}+\mathrm{HD}$ in relation to differences in extracorporeal blood temperature.

1. Examination of the role of the extracorporeal blood temperature in the disparity in vascular reactivity between $\mathrm{i}-\mathrm{UF}$ and UF+HD (bicarbonate). 
To be able to study the role of the other factors separately, vascular reactivity was studied during UF $+\mathrm{HD}$ in relation to a single factor;

2. Establishing the role of changes in plasma osmolality, the presence of dialysate derived contaminants and changes in ionized calcium in the vascular response during $\mathrm{UF}+\mathrm{HD}$ (bicarbonate).

Based on the results of these first four studies a comparison was made between $U F+H D$ and HF in relation to the factor that appeared to be the most important:

3. Study the role of the extracorporeal blood temperature in the disparity in vascular reactivity between $\mathrm{UF}+\mathrm{HD}$ (bicarbonate) and pre-dilution HF (bicarbonate). 


\section{References}

1 Bergström J, Asaba H, Fürst P, Oulès R: Dialysis, ultrafiltration and blood pressure. Proc EDTA 1976; 13: 293-305.

2 Bergström J: Ultrafiltration without dialysis for removal of fluid and solutes in uremia. Clin Nephrol 1978; 9: 156-164.

3 Quellhorst $\mathbb{E}$, Doht B, Schueneman B: Hemofiltration: treatment of renal failure by ultrafiltration and substitution. I Dial 1977; 1: 529-543.

4 Baldamus CA, Quellhorst E: Outcome of long-term hemofiltration.

Kidney Int 1985; 17: \$41-\$46.

5 Henderson LW: Heterogeneity of the cardiovascular response to hemofiltration. Kidney Int 1986; 29: $901-907$.

6 Keshaviah P, Berkseth $R$, Ilstrup $K$, McMichael C, Collins A: Reduced treatment time: hemodiallysis (HD) versus hemofittration (HF).

Trans Am Soc Artif Intern Organs 1985; 31: 176-182.

7 Malberti $F$, Surian M, Colussi $G$, Mineti $L$ : Acid-base status and dialysis symptoms in different forms of renal replacement therapy.

Kidney Int 1988; 33: S117-S119.

8 Rodriguez M, Pederson JA, Llach F: Effects of dialysis and ultrafiltration on osmolality, colloid osmotic pressure, and vascular refilling rate.

Kidney Int $1985 ; 28: 808-813$.

9 Leunissen KML, Noordzij TC, wan Hooff JP. Pathophysiologic aspects of plasma volume preservation during dialysis and ultrafiltration.

Contrib Nephrol 1990; 78: 201-211.

10 de Vries PMM: Plasma volume changes during hemodialysis.

Sem Dial $1992 ; 5: 42-47$.

11 Mann H, Stiller S, Schallenberg U, Thömmes A: Optimizing dialysis by variation of ultrafiltration rate and sodium concentration controlled by continuous measurement of circulation blood volume. Contrib Nephrol 1989; 74: 182-190.

12 de Vries J-PPM, Kouw PM, van der Meer NJM, Olthof CG, Oe LP, Donker AIM, de Vries PMIM: Non-invasive monitoring of blood wolume during hemodialysis: Its relation with post-dialytic dry weight. Kidney Int 1993; 44: 851-854.

13 Leunissen KML, Kouw P, Kooman JP, Cheriex EC, de Vries PMM, Donker AJM, van Hooff JP: New techniques to determine fluid status in hemodialyzed patients. Kidney Int 1993; 43: S50-S56.

14 Fleming SI, Wilkinson JS, Greemwood RN, Aldridge C, Baker LRI, Cattell WR: Effect of dialysate composition on intercompartmental fluid shift.

Kidney Int 1987; 32: $267-273$.

15 Chanard J, Brunois JP, Toupance O, Roujoulkeh $H$, Milcent T: Effect of sodium dialysate concentration on the extracellular fluid distribution during hemodialysis. Contrib Nephrol 1984:41:371-375.

16 de Vries PMIJ: Fluid balance during haemodialysis and haemofiltration: The effect of dialysate sodium. Nephrol Dial Transplant 1990; 5 suppl 1: 158-161. 
17 Hsu CH, Schwarz RD, Somermeyer MG, Raj A: Bicarbonate hemodialysis: Influence on plasma refilling and hemodynamic stabiliry,

Nephron $1984: 38: 202-208$.

18 Leunissen KML, Cheriex EC, Janssen J, Teule GJJ, Mooy MV, Ramentol M, van Hooff JP: Influence of left ventricular function on changes in plasma volume during acetate and bicarbonate dialysis. Nephrol Dial Transplant 1987; 2: 99-103.

19 Kooman JP, Wijnen JAG, Drátjer P, van Bortel LMAB, Gladziwa U, Peltenburg HG, Struyker-Boudier HAJ, van Hooff JP, Leunissen KML: Compliance and reactivity of the peripheral venous system in chronic intermittent hemodialysis. Kidrey Int 1992; 41: 1041\%1048.

20 Fachald $\mathrm{P}$ : Effects of ultrafiltration on body fluid volunes and transcapillary colloid osmotic gradient in hemodialysis patients.

Contrib Nephrol 1989; 74: 170-175.

21 Keshaviah P. Shapiro FL: A critical examination of dialysis induced hypotension. Am J Kidney Dis 1982; 11: 290-301.

22 Fleming SJ, Wilkinson JS, Aldridge C, Greenwood RN, Baker LRI, Cattell WR: Blood volume changes during isolated ultrafiltation and combined ultrafiltrationdialysis. Nephrol Dial Transplant 1988; 3: 272-276.

23 de Vries PMJM, Othof CG, Solf A, Schuenemann B, Oe PL, Quellhorst $\mathbb{E}$, Schneider H, Donker AJM: Fluid balance during haemodialysis and haemofiltration: The effect of dialysate sodium and a variable ultrafiltration rate.

Nephrol Dial Transplant 1991;6: $257-263$.

24 Olthof CG, de Vries PMJM, Kouw PM, De PL, Gerlag PGG, Schneider H, Donken AJM: The recovery of the fluid balance after hemodialysis and hemofiltration. Clin Nephrol 1992; 37: 135-139.

25 Hirsch AT, Levenson DJ, Cutler SS, Dzau VJ, Creager MA: Regional vascular responses to prolonged lower body negative pressure in nomal subjects.

Am J Physiol 1989; 257: H219-H225.

26 Berdeaux A, Duranteau J, Pussard E, Edouard A, Gudicelli J-F: Baroreflex control of regional vascular resistances during simulated orthostatism.

Kidney Int $1992 ; 41: 529 \$ 33$.

27 Thinte TH, Vaner SF: Cardiac dynamics during hemorthage: relative unimportance of adrenergic inotropic responses. Cinc Res 1982; 50:705-713.

28 Usioda E, Nuwayhid B, Kleinman G, Tabsh K, Brinkman III CR, Assali NS: The contribution of the $\beta$-adrenergic system to the cardiovascular response to hypovolemia. Am J Obstet Gynecol 1983; 147:423-429.

29 Sander-Jansen $K$, Mehken J, Stadeager C, Christensen NJ, Fahrenkrug $\mathbb{J}$, Schwartz TW. Warberg $J$, Bie $P$ : Increase in vagal activity during hypotensive lower-body negative pressure in humans. Am J Physiol 1988: 255: R149-R156.

30 Guyton AC, Jones CE. Coleman. TG (ed.): Circulatoty physiology: cardiac output and its regulation. Philadelphia London Toronto, W.B. Saunders Company, 1973 , 556. 
31 Rothe CF: Venous system: Physiology of capacitance wessels; in Shepherd JT, Abboud FM (ed.): Handbook of Physiology. Bethesda, American Physiological Society, 1983, 3, Peripheral circulation and organ blood flow pp. 397-452

32 Greenway CV, Laut WW: Blood volume, the venous system, preload, and cardiac output. Can J Physiol Pharmacol 1986; 64: 383-387.

33. Foley RN, Parfrey PS, Harnett ID: Left ventricular hypertrophy in dialysis patients. Sem Dial 1992; $5: 3441$.

34 Baldamus CA, Enst W, Frei U, Koch.KM: Sympathetic and hemodynamic response to volume removal during different forms of renal replacement therapy. Nephron 1982; 31 : 324-332.

35. Kooman JP, Gladziwa U, Böcker $G$, van Bortel LMAB, wan Hooff JP, Leunissen KML: Role of the venous system in hemodynamics during ultrafiltration and bicarbonate dialysis. Kidney Int 1992; 42: 718-726.

36 Fox SD, Henderson LW: Cardiovascular response during hemodialysis and hemofilltration: thermal, membrane, and catecholamine influences.

Blood Purif 1993; 11: 224-236.

37 Wehle B, Asaba H, Castenfors J, Fürst P, Gunnarsson B, Shaldon S, Bergström J: Hemodynamic changes during sequential ultrafultration and dialysis.

Kidney Int 1979; 15:411-418.

38 Shaldon S, Deschodt G, Beau MC, Claret G, Mion H, Mion C: Vascular stability during high flux haemofiltration (HF). Proc EDTA 1979; 16: 695-697.

39 Hampl H, Paeprer H, Unger V, Fischer C, Resa I, Kessel M: Hemodynamic changes during hemodialysis, sequential ultrafiltration, and hemofiltration.

Kidney Int 1980; 18: S83-S88.

40 Chaignon M, Tzuoh Chen W, Tarazi RC, Bravo EL, Nakamoto S: Effect of hemodialysis on blood volume distribution and cardiac output.

Hypert $1981 ; 3$ : $327-332$.

41 Kinet J-P, Soyeur D, Balland $N$, Saint-Remy $M$, Collignon P, Godon J-P: Hemodynamic study of hypotension during hemodialysis.

Kidney Int 1982; $21: 868-876$.

42 Baldamus CA, Ernst W, Lysaght MJ, Shaldon S, Koch KM: Hemodynamics in hemofiltration. Int J Artif Organs 1983; 6: 27-31.

43 Bradley JR, Evans DB, Gore SM, Cowley AJ: Is dialysis bypotension caused by an abnormality of venous tone? BMJ 1988; 296:1634-1637.

44 Bradley JR, Evans DB, Cowley AJ: Comparison of vascular tone during combined haemodalysis with ultrafiltration and during ultrafiltration followed by haemodialysis: a possible mechanism for dialysis hypotension.

BMI $1990 ; 300: 1312$.

45 Maggiore $Q$, Pizzarelli F. Zoccali C, Sisca $S$, Nicoló F: Influence of blood temperature on vascular stability during hemodialysis and isolated ultrafiltration.

Int J Artif Organs 1985; 8: 175-178. 
46 Maggiore Q, Pizzarelli F. Sisca S, Zoccalli C, Parlongo S, Nicolò F, Creazzo G: Blood temperature and vascular stability during hemodialyis and hemofiltration. Trans Am Soc Artif Intern Organs 1982; 28: 523.527.

47 Lindholm $T$, Thysell H, Yamamoto $Y$, Forsberg B, Gullberg CA: Temperature and vascular stability in hemodialysis. Nephron $1985 ; 39: 130-133$.

48 Dinatrello $\mathrm{CA}$ : Pathogenesis of fever during hemodialysis.

Contrib Nephrol 1983; 36:90-99.

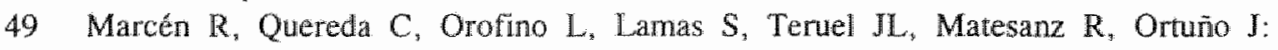
Hemodialysis with low-temperature dialysate: A long-term experience.

Nephron 1988; 49: 29-32.

50 Coli U, Landini S, Lucatello S, Fracasso A, Morachiello P, Righetto F, Scanferla $F$, Onesti $G$, Bazzato $G$ : Cold as cardiovascular stabilizing factor in hemodialysis: hemodynamic evaluation. Trans Am Soc Artif Intern Organs 1983; 29: 71-75.

51 Bazzato $\mathrm{G}$, Coli U, Landimi $S$, Lucatello $S$, Fracasso $A$, Morachiello P, Righetto $F$, Scanferla $\mathrm{F}$ : Temperature monitoring in dialysis-induced lyypotension.

Kidney Int $1985 ; 28:$ S161-\$165.

52 Jost CMT, Agarwal R, Khair-El-Din T, Grayburn PA, Victor RG, Henrich WL: Effects of cooler temperature dialysate on hemodynamic stability in "problem" dialysis patients. Kidney Int 1993; 44: 606-612.

53 Levy FL, Grayburn PA, Foulks CJ, Brickner ME, Henrich WL: Improved left ventricular contractility with cool temperature hemodialysis.

Kidney Int 1992; $41: 961965$.

54 Mahida BH, Dumler F, Zasuwa G, Fleig G, Levin NW: Effect of cooler dialysate on serum catecholamines and blood pressure stability.

Trans Am Soc Artif Intern Organs 1983; 24: 384-389.

55. Gennari FJ: Serum osmolality: Uses and limitations.

N Engl J Med 1984; 310: 102-105.

56 Daugirdas JT, Ing TS, Chen W-T, Vestal RE, Hano JE, Al-Kudsi RR: Ultrafiltration hemodynamics in conscious, uremic dogs: Effect of a decreasing plasma urea level. Mineral Electrolyte Metab 1985; 11: 79-84.

57 Wehle B. Asaba H, Castenfors J, Gunnarsson B, Bergstrón J: Influence of dialysate composition on cardiovascular function in isovolemic haemodialysis.

Proc EDTA 1981; 18: 153-159.

58 Shaldon $S$ : Role of small molecule removal in the controll of treatment morbidity with haemodialysis and haemofiltration. Proc EDTA 1981; 18: 249-255.

59 Henrich WL, Woodard TD. McPhaul JJ: The chronic efficacy and safety of high sodium dialysate: double-blind, crossover study.

Am J Kidney Dis 1982; 2: 349-353.

60 Cybulsky AVE, Matni A, Hollomby DJ: Effects of high sodium dialysate during maintenance hemodialysis. Nephron $1985 ; 41: 57-61$.

61 Sadowski RH, Allred EN, Jabs K: Sodium modeling ameliorates intradialytic and interdialytic symptoms in young hemodialysis patients.

J Am Soc Nephrol 1993; 4: 1192-1198. 
62 Daugirdas JT, Purandare VV, Ing TS, Chen WT, Popli S, Hano JE, Klok MA: Ultrafiltration hemodynamics in an animal model: effect of a decreasing plasma sodium level. Trans Am Soc Artif Intern Organs 1984; 30: 603-609.

63 Schultze G, Maiga M, Neumayer H-H, Wagner $K$, Keller F, Molzahn M, Nigam S: Prostaglandin $\mathrm{E}_{2}$ promotes hypotension on low-sodium hemodialysis.

Nephron 1984; $37: 250-256$.

64 Henrich WL, Woodard TD, Blachley JD, Gomez-Sanchez C, Pettinger W, Cronin RE: Role of osmolality in blood pressure stability after dialysis and ultrafiltration. Kidney Int $1980 ; 18: 480-488$.

65 Henderson LW, Koch KM, Dinarello CA, Shaldon S: Hemodialysis hypotension: The interteukin-1 hypothesis. Blood Purif 1983; 1: 3 8.

66 Dinarello $\mathrm{CA}$ : Interleukin-1 and tumor necrosis factor and their naturally occurring antagonists during hemodialysis. Kidney Int 1992; 42: S68-S77.

67 Blumenstein M. Schmidt B, Wand RA, Ziegler-Heitbrock HWL, Gurland HJ: Altered interleukin-1 production in patients undergoing hemodialysis.

Nephron $1988 ; 50: 277-281$.

68 Herbelin A, Ureña $P$, Nguyen AT, Zingraff J, Descamps-Latscha B: Influence of first and longwerm dialysis on uremia-associated increased basal production of interleukin 1 and tumor necrosis factor $\alpha$ by circulating monocytes.

Nephrol Dial Transplant 1991; 6:349-357.

69 Pertosa G, Tarantino EA, Gesualdo L, Montinaro V, Schena FP: C5b-9 generation and cytokine production in hemodialyzed patients.

Kidney Int 1993; 43: S221-\$225.

70 Ryan JJ, Beynon HLC, Rees AJ, Cassidy MD: In vitro production of tumor necrosis factor by monocytes cultured from dialysis patients.

Kidney Int 1993; 43: S226-S229.

71 Haeffner-Cavaillon N, Cavaillon J-M, Ciancioni C, Bacle F, Delons S, Kazatchkine MD: In vivo induction of interleukin-1 during hemodialysis.

Kidney Int $1989 ; 35 ; 1212-1218$.

72 Bingel M, Lonnemann G, Koch KM, Dinarello CA, Shaldon S: Plasma interteukin1 during hemodialysis: the influence of dialysis membranes.

Nephron $1988 ; 50: 273-276$.

73 Tetta $C$, Camussi $G$, Turello E, Salomone $M$, Aimo G, Priolo G, Segoloni $G$, Vercellone A: Production of cytokines in hemodialysis.

Blood Purif 1990; 8: 337-346.

74 Herbelin A, Nguyen AT, Zingraff J, Urena P, Descamps-Iatscha B: Influence of uremia and hemodialysis on circulating interleukin-1 and tumor necrosis factor $\alpha$. Kidney Int 1990; $37: 116-125$.

75 Miyazaki T, Niwa T, Sato M, Kambe F, Maeda K, Seo H: Plasma Interleukin 8 levels are increased by hemodialysis. Blood Purif 1994; 12: 135-140.

76 Schindler S, Lonneman G, Shaldon S, Koch KM, Dinarello CA: Transcription, not synthesis, of interleukinm 1 and tumor necrosis factor by complement.

Kidney Int 1990; 37 : 85-93. 
77 Schindler R, Linnenweber $S$, Schulze $M$, Oppermann M, Dinarello CA. Shaldon S, Koch KM: Gene expression of interleukin-1B during hemodialysis.

Kidney Int 1993; 43: 712-721.

78 Evans $\mathrm{RC}$, Holmes $\mathrm{CJ}$ : In vitro study of the transfer of cytokine-inducing substances across selected high-fux hemodialysis membranes.

Blood Purif 1991; 9: 92-101.

79 Lonnemann $\mathrm{G}$ : Dialysate bacteriological quality and the permeability of dialyzer membranes to pyrogens. Kidney Int 1993; 43: \$195-\$200.

80 Urena $P$, Herbelin $A$, Zingraff $J$, Lair $M$, Khoa Man $N$, Descamps-Latscha $B$, Drieke $\mathrm{T}$ : Permeability of cellulosic and non-cellulosic membranes to endotoxin subunits and cytokine production during in-vitro haemodialysis.

Nephrol Dial Transplant 1992; 7: 16-28.

81 Laude-Sharp $M$, Caroff $M$, Simard $L$, Pusineri $C$, Kazatchkine MD, HaeffnerCavaillon $\mathrm{N}$ : Induction of $\mathrm{IL-1}$ during hemodialysis: transmembrane passage of intact endotoxins. Kidney Int 1990; 38: 1089-1094.

82 Kumano $K$, Yokota $S$, Nambu M. Sakai $T$ : Do cytokine-jnducing substances penetrate through dialysis membranes and stimulate monocytes?

Kidney Int 1993; 43: \$205-\$208.

83 Dinarello CA: Cytokines: agents provocateurs in hemodialysis?

Kidney Int 1992; 41: 683-694.

84 Pereira BJG, Shapiro I, King AJ, Falagas ME, Strom JA, Dinarello CA: Plasma levels of IL-1 $\beta$, TNE $\alpha$ and their specific inhibitors in undialyzed chronic renal failure, CAPD and hemodialysis patients. Kidney Int 1994; 45:890-896.

85 Leeuwenberg JFM, Mat O, Abramowicz D, Gastaldello R, Tielemans C, Bumman WA: Increased plasma levels of soluble tumor necrosis factor-receptors in uraemic patients: effects of dialysis, type of membrane, and anticoagulation method.

Nephrol Dial Transplant 1994; 9: 1125-1129.

86 Schindler R, Marra MN, McKelligon BM, Lonnemann G, Schulzeck P, Schulze M, Oppermann M, Shaldon $S$ : Plasma levels of bactericidal/permeability-increasing protein (BPI) and lipopolysaccharide-binding protein (LBP) during hemodialysis. Clin Nephrol 1993; 40: 346-351.

87 Engeberts 1. Francot GIM, Leunissen KML, Haenen B, Ceska M, van der Linden CI, Buturman WA: Effect of homodialysis on peripheral blood monocyte tumor necrosis factor- $\alpha$, interleukin-6, and interteukin-8 secretion in vitro.

Nephon 1994: 66:396-403.

88 Leunissen KML. Kooman JP, van Kuijk WHM, van Hooff JP. Bicarbonate dialysis: a review and future perspectives. Sem Dial 1994; 7: 186-191.

89 Liang CS, Lowenstein JM: Metabolic control of the circulation. Effects of acetate and pyruvate. J Clin Invest 1978; 62:1029-1038.

90 Hakim RM, Pontzer M-A, Tilton D, Lazanus IM, Gotheb MN: Effects of acetate and bicarbonate dialysate in stable chronic dialysis patients.

Kidney Int $1985 ; 28: 535-540$. 
91. Herrero JA, Trobo II, Tomente J, Torrabo $A$, Tomero $F_{*}$ Cruceyra $A$, Cononel $F_{\text {, }}$ Barrientos A: Hemodialysis with acetate, DL-lactate and bicarbonate: a hemodynamic and gasometric study. Kidney lnt 1994; 46:1167-1177.

92 Leunissen KML, Hoomtje SJ, Fiers H, Dekkers WT, Mulder AW: Acetate versus bicarbonate hemodialysis in critically ill patients. Nephron 1986; 42: 146-151.

93 Henrich WL, Woodard TD, Meyer BD, Chappell TR, Rubin Lil: High sodium bicarbonate and acetate hemodialysis: double-blind crossover comparison of hemodynamic and ventilatory effects. Kidney Int 1983; $24: 240-245$.

94 Velez RL, Woodard TD. Herrich WL: Acetate and bicarbonate hemodialysis in patients with and without autonomic dysfunction. Kidney Int 1984; 26: 59-65.

95 Collins $A$, Keshaviah $P$, Berkseth $R$, Ilstrup $\mathbb{K}$, McMichael C. Ebben I: Short efficient hemodialysis with reduced symptoms. Kidney Int 1985; $27: 158$.

96 Rubin RP: Neurotransmitter substances and hormones.

Pharmacol Rev $1970 ; 22: 389-428$.

97 Marone C, Beretta-Picolli C, Weidmann P: Acute hypercalcenic hypertension in man: role of hemodynamics, catecholamines and renin.

Kidney Int 1980; 20: $92-96$.

98 Argiles A, Kerr PG, Canaud B, Flavier JL, Mion C: Calcium kinetics and the longterm effects of lowering dialysate calcium concentration.

Kidney Int $1993 ; 43: 630-640$.

99 Leunissen KML, van den Berg BW, van Hooff JP: Ionized calcimm plays a pivotal role in controlling blood pressure during haemodialysis.

Blood Purif $1989 ; 7: 233-239$.

100 Henrich WL, Hunt JM, Nixon JV: Increased ionized callium and left ventricular contractility during hemodialysis. N Engl J Med 1984; 310:19-23.

101 Maynard JC, Cruz C, Kleenekoper M, Lewin NW: Blood pressure response to changes in serum ionized calcium during hemodialysis.

Ann Intern Med 1986; 104: 358-361.

102 Lang RM. Fellner SK, Neumann A, Bushinsky DA, Borow KM: Left ventricular contractility varies directly with blood ionized calcium.

Ann Intern Med 1988; 108: 524-529.

103 Feliner SK, Lang RM, Neumann A, Spencer KT, Bushinsky DA, Borow KM: Physiological mechanisms for calcium-induced changes in systemic arterial pressure in stable dialysis patients. Hypert 1989; 13:213-218.

104 Bergstrom $\mathrm{J}$ : Catecholamines and control of blood pressure during hemodialysis and hemofiltration. Kidney Int 1.988; 34: S110-S114.

105 Esler MD, Hasking GI, Willett IR, Leonard PW, Jennings GL: Noradrenaline release and sympathetic nervous system activity. J Hypert 1985; 3: 1.17-129.

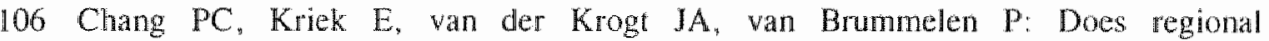
norepinephrine spillover represent local sympathetic activity?

Hypert $1991 ; 18: 56-66$. 
107 Zucchelli P, Santoro A, Sturani A, Degli Esposti E, Chiarini C, Zuccalà A: Effects of hemodialysis and hemofiltration on the autonomic control of circulation.

Trans Am Soc Artif Intern Organs 1984; 30: 163-167.

108 Baldamus CA, Mantz P, Kachel HG, Koch KM, Schoeppe W: Baroreflex in patients undergoing hemodialysis and hemofiltration.

Contrib Nephrol 1984; 41: 409-414.

109 Vallbo $A B$, Hagbarth $\mathrm{K}-\mathrm{E}$, Torebjörk HE, Wallin BG: Somatosensory, proprioceptive, and sympathetic activity in human peripheral nerves.

Physiol Rev 1979; 59: 919-957.

110 Converse RL, Jacobsen TN, Toto RD, Jost CMT, Cosentino F, Fouad-Tarazi F, Victor RG: Sympathetic overactivity in patients with chronic renal failure.

N Engl J Med 1992; 327: 1912-1918.

111 Converse RL, Jacobsen TN, Jost CMT, Toto RD, Grayburn PA, Obregon TM, Fouad-Tarazi F, Vicior RG: Paradoxical withdrawal of reflex vasoconstriction as a cause of hemodialysis-induced hypotension. J Clin Invest 1992; 90: 1657-1665. 


\section{Chapter 2}

Vascular reactivity during hemodialysis and isolated ultrafiltration: thermal influences

WHM van Kuijk, AJ Luik, PW de Leeuw, JP van Hooff, FHM Nieman, HML Habets, KML Leunissen

(Parts of this chapter will be published in Nephrology Dialysis and Transplantation) 


\section{Abstract}

\section{Background}

The present study was performed to assess the role of the extracorporeal bllood temperature in the disparitive cardiovascular response between isolated ultrafiltration and combined ultrafiltration-hemodialysis.

\section{Methods}

In twelve stable dialysis patients (21-77 years), blood pressure and heart rate (Finapres) as well as forearm vascular resistance and venous tone (strain-gauge plethysmography) were measured during one hour isolated ultrafiltration and one hour combined ultrafiltration-hemodiallysis (bicarbonate, sodum $141 \mathrm{mmol} / \mathrm{l}$ ) at a fixed ultrafiltration rate of $0.9 \mathrm{l} / \mathrm{hr}$. In addition, blood pressure and heart rate were measured during the following two dialysis hours as well as during 22 post-dialytic hours with ambulatory blood pressure monitors. Serving as his or her own control, each patient was studied at two different dialysate temperatures: 37.5 and $35.0^{\circ} \mathrm{C}$.

\section{Results}

At a dialysate temperature of $35.0^{\circ} \mathrm{C}$, extracorporeal blood cooling during combined ultrafiltration-hemodialysis was comparable to isolated ultrafiltration. The cardiovascular response in isolated ultrafiltration was characterized by a significant increase in both forearm vascular resistance and venous tone while heart rate even decreased. As a result, blood pressure remained unchanged or even increased. In contrast, during combined ultrafiltration-hemodialysis at a dialysate temperature of $37.5^{\circ} \mathrm{C}$, the increase in forearm vascular resistance was only small and insignificant while venous tone decreased significantly. Heart rate tended to increase. Combined ultrafiltration-hemodialysis at a dialysate temperature of $35.0^{\circ} \mathrm{C}$ was also associated with a small increase in forearm valscular resistance. However, venous tone remained stable while heart rate decreased. Arterial blood pressure was significantly higher at a dialysate temperature of $35.0^{\circ} \mathrm{C}$ only during the last two dialysis hours. There was no rebound drop in blood pressure in the post-dialytic period after cold dialysis.

\section{Conclusion}

We conclude that differences in cardiovascular reactivity between isolated ultrafiltration and combined ultratiltration-hemodialysis are only partially explained by differences in the extracorporeal blood temperature. In addition, especially venous reactivity is improved by lowering the dialysate temperature. Cold dialysis is a safe method to improve hemodynamic stability in combined ultrafiltration-hemodialysis without adverse effects on postodialytic blood pressure. 


\section{Introduction}

Symptomatic hypotension is still the most important complication in dialysis therapy and although our insight in the underlying mechanisms has increased substantially during the past two decades, many controversies still exist. One important problem that remains unresolved are the differences in cardiovascular reactivity during different forms of dialysis therapy ${ }^{1.2}$.

Under normal conditions, the cardiovascular response to a decline in plasma volume mainly includes an increase in both total peripheral resistance and venous tone which results in a centralisation of blood volume, thus maintaining adequate cardiac filling and outpu, ${ }^{3,4}$. It is well recognised that these vascular responses are well preserved when fluid is withdrawn during either hemofiltration or isolated ultrafiltration while during combined ultrafiltration-hemodialysis vascular reactivity is impaired ${ }^{5.6}$. However, as only few comparative studies have yet been performed, it is unknown which factors are actually responsible for impaired vascular reactivity during combined ultrafiltration-hemodialysis in comparison to hemofiltration and isolated ultrafiltration.

It has been shown by many investigators that blood pressure stability during combined ultrafiltration-hemodialysis can be improved by using colder dialysate $\left( \pm 35.0^{\circ} \mathrm{C}\right)^{7,8}$ which is probably mediated through a better increase in total peripheral resistance ${ }^{9-11}$ and cardiac contractility ${ }^{12}$ in association with higher levels of plasma noradrenaline ${ }^{11,13}$. However, only Maggiore and co-workers studied blood pressure stability in relation to the extracorporeal blood temperature, comparing combined ultrafiltration-hemodialysis with both hemofiltration and isolated ultrafiltration. Measuring mean arterial blood pressure and heart rate, they found that changes in the two parameters were almost comparable between treatments at equivalent changes in the extracorporeal blood temperature and concluded that differences in cardiovascular stability between treatments are mainly due to opposite changes in the extracorporeal blood temperature ${ }^{14.15}$.

The present study was performed to further assess the relative role of the extracorporeal blood temperature in the differences in cardiovascular stability between combined ultrafiltration-hemodialysis and isolated ultrafiltration. In order to make a more pathophysiological comparison possible, changes in blood pressure and heart rate as well as changes in forearm vascular resistance and venous tone were measured during isolated ultrafiltration and during both warm and cold combined ultrafiltration-hemodialysis. In addition, blood pressure was also measured in the post-dialytic period to study whether cold dialysis resulted in rebound hypotension. 


\section{Subjects and methods}

\section{Subjects and dialysis}

Twelve patients ( 3 women, 9 men) on chronic intermittent hemodialysis signed an informed consent for participation in the study that had been approved by the Ethics Committee of the Maastricht University Hospital. The patient group had a mean age of 51 years (range 21-77) and the mean time on hemodialysis was 3.0 years (range $0.1-21$ ). They were all stable patients who rarely suffered from intradialytic hypotension. Exclusion criteria were severe coronary (NYHA If or more) or valvular heart disease, compromised left ventricular function (ejection fraction $30 \%$ or less) and diabetes mellitus. By adjusting fluid intake, patients were instructed to achieve a predialysis weight at two kilograms above their dry-weight which was estimated by echography of the inferior caval vein ${ }^{16}$. All vasoactive medication was stopped 48 hours before the study which resulted in hypertension in patient number 11. In addition, patients were not allowed to smoke or drink caffeine containing beverages during 12 hours preceding the study.

All patients were studied on the regular day of his or her dialysis schedule after an overnight fast. The first two dialysis hours consisted of one hour isolated ultrafiltration (i-UF) and one hour combined ultrafiltration-hemodialysis (UF + HD) (protocol A) followed by two hours UF+HD (protocol B). Each patient served as his or her own control and was studied once at a dialysate temperature of 37.5 and once at a dialysate temperature of $35.0^{\circ} \mathrm{C}$, respectively warm $\mathrm{UF}+\mathrm{HD}$ and cold $\mathrm{UF}+\mathrm{HD}$. The determination of the dialysate temperature in cold UF +HD was based on preliminary experiments. At a dialysate temperature of $35.0^{\circ} \mathrm{C}$, blood in the venous line had the same temperature during $\mathrm{UF}+\mathrm{HD}$ as measured during $\mathrm{i}$-UF, indicating a comparable degree of extracorporeal blood cooling. To assure that differences in cardiovascular reactivity between i-UF and UF HD would not arise from large differences in plasma volume, patients were randomly selected to start with either UF (UF-UF $+H D, n=6)$ or UF +HD (UF + HD-UF, $n=6$ ).

Dialysis was performed with a Gambro AK-100 module using hemophane membranes (GFS-16; Gambro, Sweden). The composition of dialysate was: sodium $14.1 \mathrm{mmol} / \mathrm{l}$, potassium $2.0 \mathrm{mmol} / \mathrm{l}$, bicarbonate $34 \mathrm{mmol} / \mathrm{l}$, acetate $3 \mathrm{mmol} / \mathrm{l}$, calcium $1.75 \mathrm{mmol} / 1$, magnesium $0.5 \mathrm{mmol} / 1$ and chloride $108 \mathrm{mmol} / 1$. Blood flow was $250 \mathrm{ml} / \mathrm{min}$ and dialysate flow was $500 \mathrm{ml} / \mathrm{min}$.

\section{Methods}

The study started with the insertion of the dialysis needles after which patients were in supine rest for 30 minutes. All studies were performed in a temperature controlled room at at room temperature of about $23^{\circ} \mathrm{C}$. The luminal blood 
temperature was measured in the arterial and venous line with needle thermometers (Hewlett-Packard $78214 \mathrm{C}$ temperature monitor). Connectors with a built-in adaptor were placed in the arterial and venous line under sterile conditions at a distance of about 15 centimetres from the patient. There was no direct contact between blood and thermometer.

\section{Protocol A}

Protocol A was performed during the first two dialysis hours consisting of sequential $\mathrm{i}-\mathrm{UF}$ and $U F+\mathrm{HD}$ at a fixed ultrafiltration rate of $0.9 \mathrm{l} / \mathrm{hr}$. All hemodynamic measurements were performed before (pre-treatment) and every 15 minutes during dialysis.

Arterial blood pressure (BP) and heart rate (HR) were measured with the Finapres method (Finapres, Ohmeda 2300, Lameris, The Netherlands). The mean values of 3 minutes were calculated. With the Finapres device, arterial blood pressure and heart rate are measured beat to beat at zero transmural pressure by the use of a small finger cuff that is equipped with an infrared photoplethysmograph ${ }^{17}$. The Finapres cuff was applied to the third finger.

Vascular reactivity was studied at the non-fistula arm that was positioned just above heart level using strain-gauge plethysmography as described by Whitney (Periflow; Janssen Scientific Instruments, Beerse, Belgium) ${ }^{18}$. Changes in forearm vascular and sympathetic tone have been shown to correlate well with the systemic hemodynamic and sympathetic response during unloading of cardiopulmonary or baroreceptors ${ }^{19-21}$. An inflatable cuff was applied to the upper arm while the mercury-filled strain gauge was positioned at the thickest part of the forearm. In addition, an antecubital vein was cannulated (Venflon, $1 \mathrm{~mm}$ ø) for the recording of direct intravenous pressure (Hewlett-Packard $78205 \mathrm{C}$ pressure monitor). The pressure dome was positioned at the level of the right atrium approximately 5 centimetres under the sternal angle.

Changes in venous tone (VT) (active venous constriction) were estimated by recording the pressure/volume ratio $(\mathrm{mm} / \mathrm{Hg} / \mathrm{ml} / 100 \mathrm{ml}$ ) at a cuff pressure of 40 $\mathrm{mmHg}$. Pressure was applied until both intravenous pressure and arm volume had reached a plateau. During venous occlusion and after obtaining a plateau, the intravenous distending pressure is determined by the cuff pressure. Therefore, changes in venous tone are primarily related to volume changes. In addition, at a transmural pressure of about $40 \mathrm{mmHg}$, changes in volume only reflect active venous constriction whereas the contribution of passive venous constriction as a result of elastic recoil of the venous wall is negligible ${ }^{22}$. \& Pressure and $\&$ volume were estimated directly after the deflation of the upper arm cuff to minimize the influence of capillary filtration on assessing * volume. The coefficient of variation 
of consecutive measurements is $11.9 \%$.

The measurement of forearm blood flow is based on the measurement of the initial volume change during three heart beats after initiating venous occlusion. Measurement of forearm blood flow by venous occlusion plethysmography has been shown to correlate well with electromagnetic flow measurements ${ }^{23}$. The coefficient of variation of consecutive flow measurements is $14 \%{ }^{24}$. To measure forearm blood flow (FBF), the upper arm cuff was rapidly inflated, $5 \mathrm{msec}$ after the R-top of the electrocardiogram, at a cuff pressure of $50 \mathrm{mmHg}$. The inflation/deflation ratio was 3:2 heart beats. Due to the presence of the Finapres cuff, the hand circulation was not occluded. Forearm blood flow was measured during four minutes and estimated with a computerized integrator. The mean value of the last two minutes was calculated. Forearm vascular resistance (FVR) was calculated by dividing mean arterial pressure by forearm blood flow $(\mathrm{mmHg} / \mathrm{ml} / 100 \mathrm{ml} / \mathrm{sec})$.

Prior to dialysis and after both 1 hour $\mathrm{U}-\mathrm{UF}$ and 1 hour UF+HD, blood was withdrawn for the estimation of: sodium, potassium, ionized calcium, total $\mathrm{CO}_{2}$ and osmolality (Wescor, vapour pressure osmometer). In addition, blood was withdrawn in ice-chilled tubes and directly centrifuged at a temperature of $4^{\circ} \mathrm{C}$ for the estimation of plasma catecholamines (HPLC, fluorescence detection) $)^{25}$. Changes in plasma volume were calculated with the serial hematocrit (Hct) method using the formula ${ }^{26}$ :

$$
\text { plasmavolume }=\frac{100}{\left(100-H C t_{\text {biroro }}\right)} \times \frac{100\left(H C t_{\text {before }}-H C t_{\text {aftar }}\right)}{H C t_{\text {arter }}}
$$

\section{Protocol B}

Nine patients participated in protocol B that was performed during the last two dialysis hours as well as during 22 post-dialysis hours. The dialysate temperature was maintained at the initial level while patients were ultrafiltrated to their dry-weight. Arterial BP and HR were measured non-invasively with Spacelabs 90207 oscillometric ambulatory blood pressure monitors ${ }^{27}$. BP was measured every 15 minutes during daytime $(7 \mathrm{a} . \mathrm{m} .-11 \mathrm{p} . \mathrm{m}$.) and every 30 minutes during nightime (1l p.m. -7 a.m.).

\section{Statisticall analysis}

Changes in hemodynamic parameters within each treatment as well as differences between treatments were analysed by repeated measurements MANOVA (SPSS-PC version) ${ }^{28}$. If the sphericity of the variance-covariance matrix appeared to be violated, degrees of freedom in the univariate MANOVA tests were corrected by 
the Greenhouse-Geisser epsilon to avoid Type 1 error in testing the F-ratio. All laboratory parameters were analysed by Friedmans ANOVA and if appropriate, by the Wilcoxon's signed-rank test. All values are expressed as mean \pm SD.

\section{Results}

\section{Blood temperature}

The uncorrected blood temperatures are presented in figure 2.1a-d. During i-UF, blood cooled down during circulation through the extracorporeal circuit by about $1.7^{\circ} \mathrm{C}$. In contrast, blood had a comparable temperature in the arterial and venous line during warm $U F+H D$. Cold $U F+H D$ resulted in a comparable degree of blood cooling in the extracorporeal circuit as compared to i-UF. Only during warm $\mathrm{UF}+\mathrm{HD}$ preceded by $\mathrm{i}-\mathrm{UF}$, the temperature of blood in the arterial line increased from $35.7 \pm 0.6^{\circ} \mathrm{C}$ to $36.0 \pm 0.5^{\circ} \mathrm{C}(p<0.05)$. During three consecutive hours of warm and cold $\mathrm{UF}+\mathrm{HD}$, the temperature of blood in the arterial line increased by $0.7 \pm 0.1^{\circ} \mathrm{C}(\mathrm{p}<0.05)$ and $0.4 \pm 0.2^{\circ} \mathrm{C}(\mathrm{p}<0.05)$ respectively while the temperature of blood in the venous line remained unchanged.

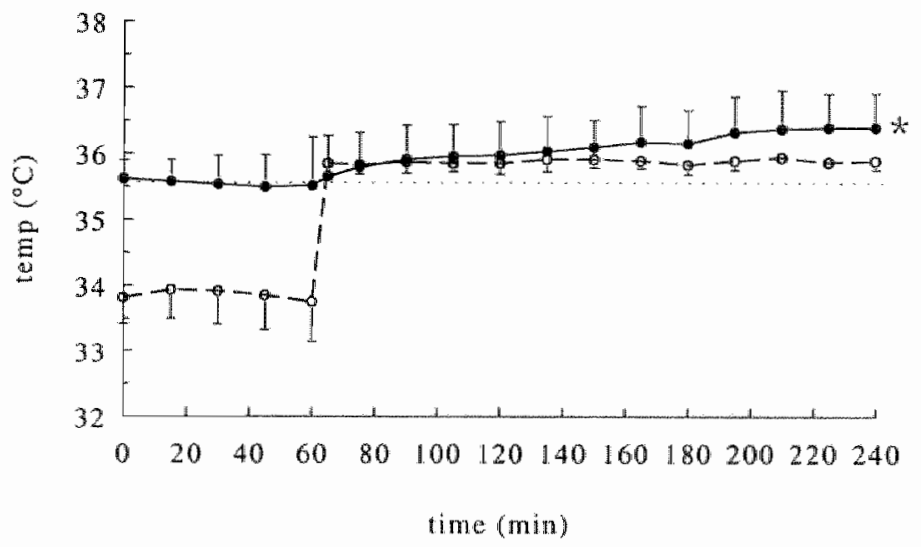

Figure 2.1a Arterial (-) and venous (- - ) blood temperature in UF-UF+HD. $37.5^{\text {t6 }} \mathrm{C},{ }^{*}=\mathrm{p}<0.05$, arterial blood temperature as compared to $1=0$ min 


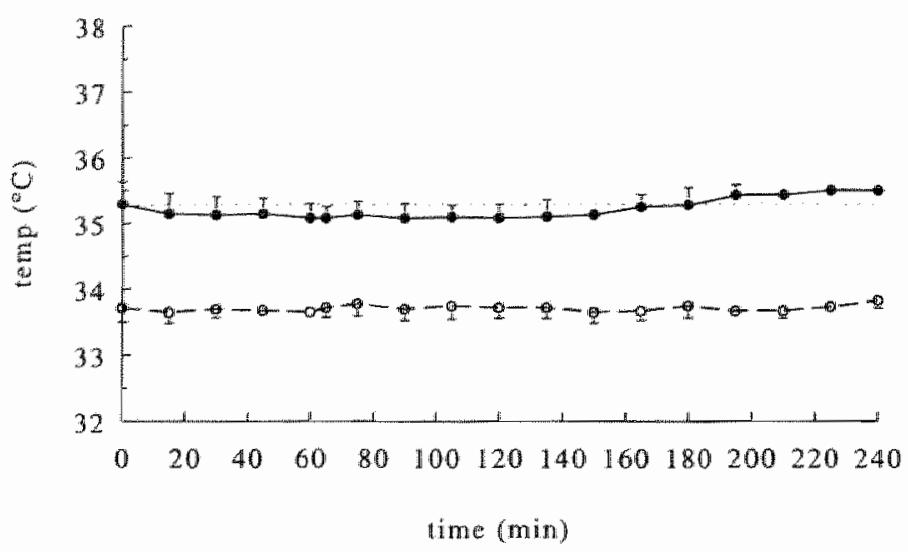

Figure 2.1b Arterial (-) and wenous (- ) blood temperature in UF-UF $+\mathrm{HD}, 35.0^{\circ} \mathrm{C}$

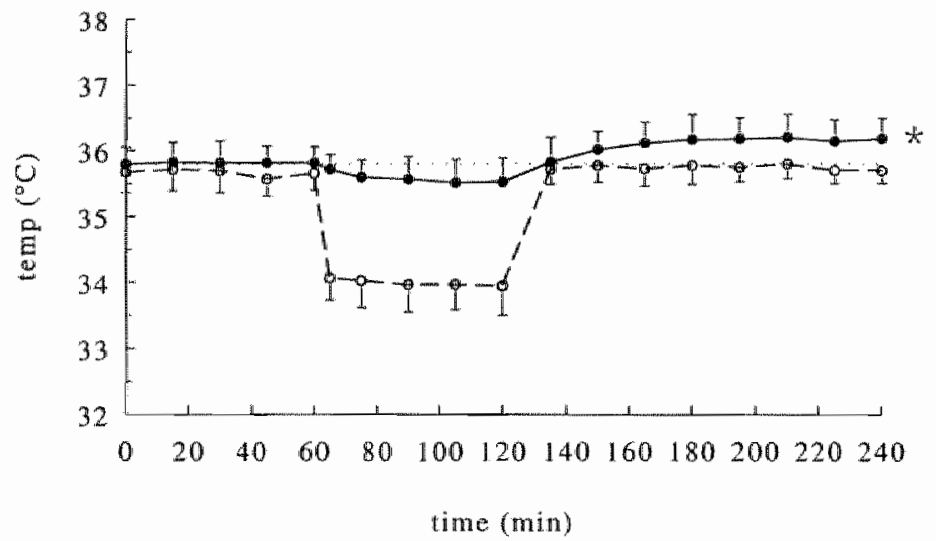

Figure 2.1c Arterial $(\longrightarrow$ and venous $(-,-)$ blood remperature in UF+HD-UF. $37.5^{\circ} \mathrm{C} ;=\mathrm{p}<0.05$, arterial blood temperature as compared to $\mathrm{i}=0 \mathrm{~min}$

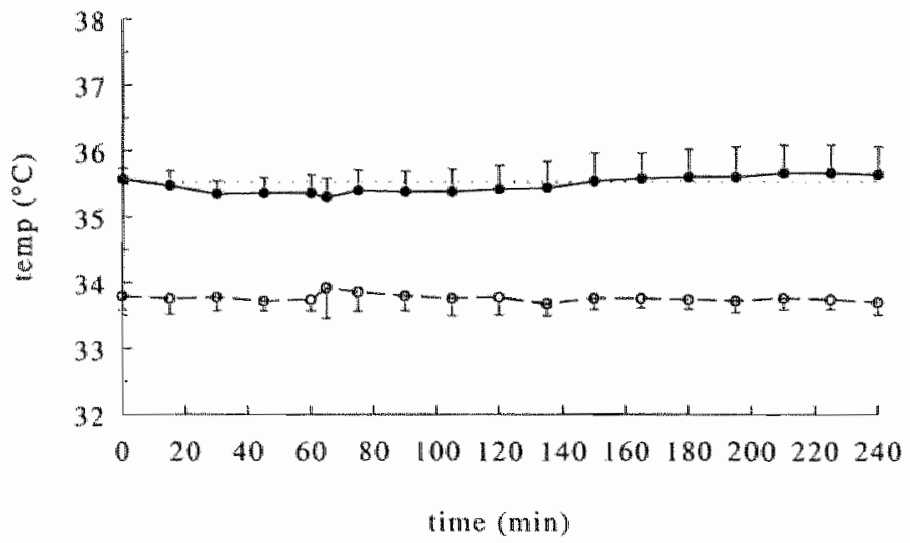

Figure 2.1d Arrerial (-) and wenous (- - ) blood temperature in UF+HD-UF, $35.0^{\circ} \mathrm{C}$ 


\section{Protocol A}

\section{Isolated ultrafiltration followed by combined ultrafiltration-hemodialysis}

The hemodynamic data are presented in figure $2.2 \mathrm{a}+\mathrm{b}$ and table 2.1 . The predialysis weights at the start of warm and cold dialysis were $71.3 \pm 11.4$ and $71.4 \pm 10.9 \mathrm{~kg}$ respectively $(\mathrm{p}=0.75)$.

I-UF was associated with an increase in both FVR and VT as well as in MAP while HR decreased. During warm UF+HD, FVR remained unchanged while VT decreased significantly even below the pre-treatment level. In addition, HR increased significantly. During cold UF $+H D$, both $V T$ and $H R$ remained unchanged with both parameters being significantly different as compared to warm $\mathrm{UF}+\mathrm{HD}$. As compared to $\mathrm{i}-\mathrm{UF}$, changes in FVR, VT, MAP and HR were significantly different only during warm UF $+H D$.

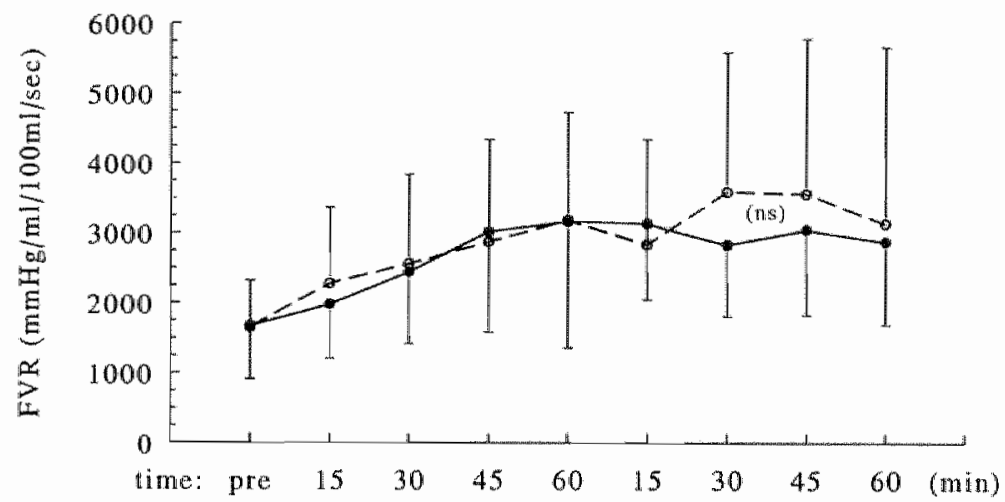

Figure $2.2 \mathrm{a}$ FVR during UF UF+HD, $37.5(\longrightarrow)$ and $35.0^{\circ} \mathrm{C}(--)$

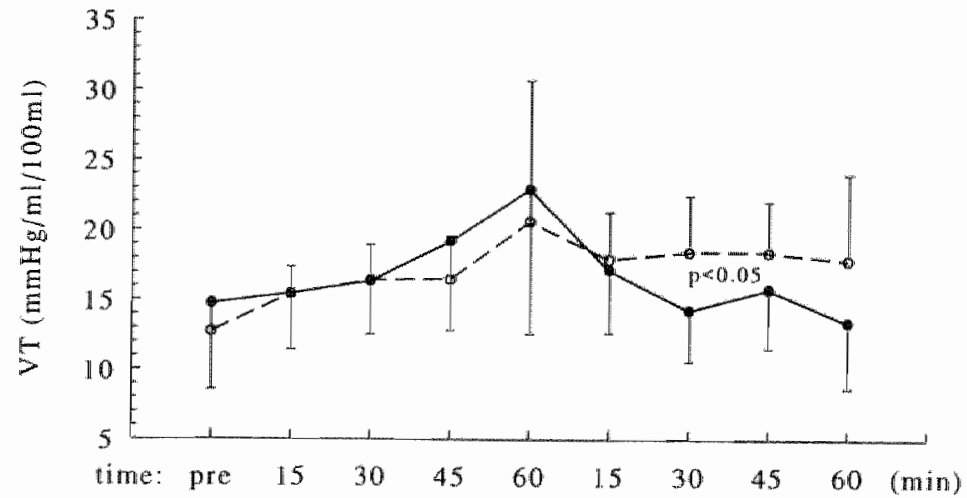

Figure 2.2b VT during UF-UF+HD, 37.5(-) and $35.0^{\circ} \mathrm{C}(--)$ 
Table 2.1 Changes in hemodynamic parameters during UF-UF+HD

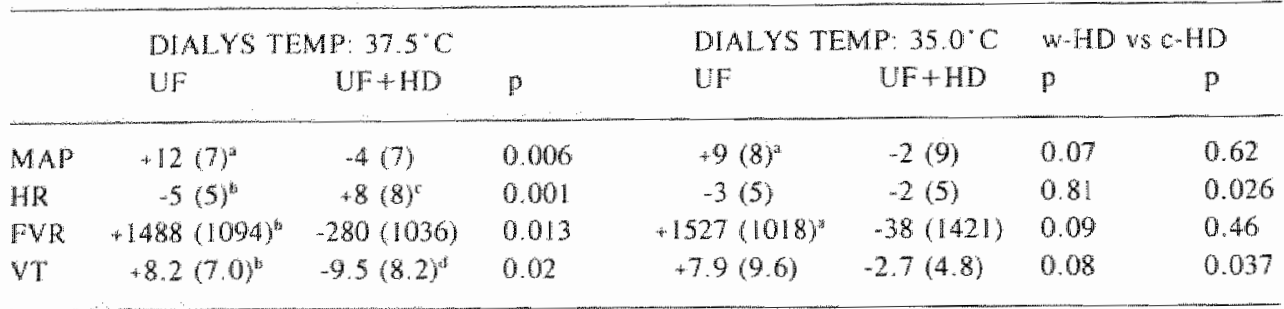

MAP (mmHg): HR (beats/min); FVR (mmHg/ml/100m/sec); VT $(\mathrm{mmHg} / \mathrm{ml} / 100 \mathrm{ml}) ;{ }^{a} \mathrm{p}<0.01$. change us pre-treatment value, " $\mathrm{p}<0.05$, change vs pre-treament value; $p<0.01$, change vs endUF value; ${ }^{2} p<0.05$, change ws end-UF value

Table 2.2 Labohtory paramerers during UF-UHa + HD

\begin{tabular}{|c|c|c|c|c|c|c|}
\hline & \multicolumn{3}{|c|}{ DIALYS TEMP: $37.5^{\circ} \mathrm{C}$} & \multicolumn{3}{|c|}{ DIALYS TEMP: $35.0^{\circ} \mathrm{C}$} \\
\hline & Pre & UF & $U F+H D$ & Pre & UF & $\mathrm{UF}+\mathrm{HD}$ \\
\hline delta PV & & $-11.9(7.8)$ & $-5.5(6.9)$ & & $-12.6(3.9)$ & $-6.2(3.0)^{t u}$ \\
\hline Sodium & $136.7(4.5)$ & $137.5(4.7)$ & $139.3(3.4)^{\mathrm{a}}$ & $137.2(3.1)$ & $137.3(2.9)$ & $139.5(2.4)^{m}$ \\
\hline Osmolality & $299.2(13.5)$ & $294.7(8.1)$ & $286.8(11.2)^{.1 \mathrm{k}}$ & $299.0(8.9)$ & $306.5(13.2)$ & $290.2(1.3 .1)^{\mathrm{h}}$ \\
\hline total $\mathrm{CO}_{2}$ & $23.8(11.3)$ & $22.8(1.8)^{\mathrm{n}}$ & $26.7(1.7)^{a b b}$ & $23.0(1.7)$ & $22.9(1.5)$ & $26.1(1.5)^{3.6}$ \\
\hline ionized $\mathrm{Ca}$ & $1.23(0.12)$ & $1.25(0.15)$ & $1.36(0.11)^{1.1 .1 .}$ & $1.17(0.14)$ & $1.21(0.14)$ & $1.30(0.13)^{\mathrm{b}}$ \\
\hline Nowdrenaline & $1.90(0.86)$ & $2.81(0.91)^{\mathrm{a}}$ & $2.10(0.79)^{\mathrm{t}}$ & $1.70(0.79)$ & $2.51(0.88)^{\mathrm{a}}$ & $2.25(0.68)^{\pi 1}$ \\
\hline Adrenaline & $0.20(0.11)$ & $0.24(0.09)$ & $0.22(0.10)$ & $0.21(0.11)$ & $0.24(0.13)$ & $0.21(0.12)$ \\
\hline
\end{tabular}

PV (\%); Sodium, total $\mathrm{CO}_{2}$ and ionized calcium (mmol/1); Osmolality (mosm/kg);

Catecholamities (nmol/1): ${ }^{a} \mathrm{p}<0.05$, compared to pre-meatment value; ${ }^{10} \mathrm{p}<0.05$. compared to UF

The laboratory data are presented in table 2.2 . Changes in plasma volume were comparable between the different treatment modalities. Only in i-UF followed by cold UF + HD, the decline in plasma volume was significantly larger during i-UF.

Probably as a result of a higher pre-treatment level, plasma ionized calcium was significantly higher after warm UF $+\mathrm{HD}$ as compared to cold UF + HD. Plasma noradrenaline increased significantly during i-UF. Although there was no significant difference in plasma noradrenaline between warm and cold UF $+\mathrm{HD}$, plasma noradrenaline remained elevated only during cold UF +HD. Plasma adrenaline remained unchanged during the different treatment modes. 
Thble 2.3 Changes in hemodynamic parameters during UF $\mathrm{HD}$-UF

\begin{tabular}{|c|c|c|c|c|c|c|c|}
\hline & \multicolumn{3}{|c|}{ DIALSTEMP. $37.5^{\circ} \mathrm{C}$} & \multicolumn{2}{|c|}{ DLALYS TEMP: $35.0^{\circ} \mathrm{C}$} & \multicolumn{2}{|c|}{ WHD VSCHD } \\
\hline & $\mathrm{UF}+\mathrm{HD}$ & UF & $\mathrm{p}$ & $U E+H D$ & Uf & $p$ & $\mathrm{p}$ \\
\hline MAP & $-1(4)$ & $+5(9)$ & 0.1 & $40(16)$ & $+4(7)$ & 0.38 & 0.87 \\
\hline $\mathrm{HR}$ & $+2(4)$ & $-3(4)$ & 0.37 & $-5(2)^{*}$ & $+1(4)$ & 0.84 & 0.001 \\
\hline $\mathrm{WWR}$ & $+511(860)$ & $.962(486)$ & 0.75 & $+921(985)$ & $+159(625)$ & 0.68 & 0,33 \\
\hline$\sqrt{T}$ & $-3.1(2.6)^{b}$ & $\div 5.2(2.7)^{\mathrm{A}}$ & 0.30 & $40.51(3.4)$ & $-0.1(4.2)$ & 0.48 & 0.031 \\
\hline
\end{tabular}

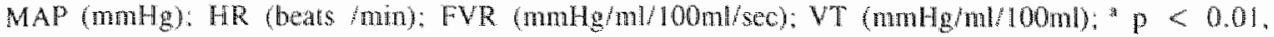
change vs pre-treament value; ${ }^{\mathrm{p}} \mathrm{p}<0.05$, change vs pre-treatment value; $\mathrm{p}<0.01$, change vs chd$U F+H D$ value: ${ }^{a} p<0.05$, change ws end $-U F+H D$ value

Table 2.4 Laboratory parameters during UF+HD-UF

\begin{tabular}{|c|c|c|c|c|c|c|}
\hline & \multicolumn{3}{|c|}{ DLALYS TEMP: $37.5^{\circ} \mathrm{C}$} & \multicolumn{3}{|c|}{ DIALYS TEMP: $35.0^{\circ} \mathrm{C}$} \\
\hline & Pre & $\mathrm{UF}+\mathrm{HD}$ & UF & $\operatorname{Pro}$ & $\mathrm{UF}+\mathrm{HD}$ & $\mathrm{UF}^{\mathrm{Z}}$ \\
\hline della PV & & $-9.5(4.9)$ & $-11.8(2.8)$ & & $-8.7(2.4)$ & $-12.4(4.4)$ \\
\hline Sodium & $136.5(1.5)$ & $139.0(3.0)$ & $138.8(1.2)^{\mathrm{n}}$ & $138.2(1.2)$ & $140.0(1.3)^{a}$ & $139.8(1.0)^{n}$ \\
\hline Osmolality & $298.3(9.6)$ & $288.7(9.7)^{\mathrm{a}}$ & $293.2(8.0)^{3}$ & $307.0(1.4 .3)$ & $298.3(12.5)^{4}$ & $294.7(12.2)^{\mathrm{a}}$ \\
\hline total $\mathrm{CO}_{2}$ & $23.7(4.5)$ & $26.7(2.5)^{3}$ & $25.2(3.5)^{\mathrm{a} .14}$ & $23.9(3.3)$ & $27,0(2.6)^{a}$ & $25.6(2.8)^{a b^{5}}$ \\
\hline ionized $\mathrm{Ca}$ & $1.19(0.11)$ & $1.29(0.09)^{4}$ & $1.28(0.10)^{2}$ & $1.19(0.11)$ & $1.30(0.12)^{8}$ & $1.30(0.12)^{9}$ \\
\hline Noradrenaline & $1.05(0.36)$ & $1.10(0.27)$ & $1.32(0.42)$ & $1.03(0.45)$ & 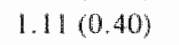 & $1.58(0.48)^{\mathrm{n} .}$ \\
\hline Adrenaline & $0.19(0.15)$ & $0.18(0.10)$ & $0.18(0.11)$ & $0.18(0.10)$ & $0.14(0.07)$ & $0.20(0.08)^{\mathrm{hi}}$ \\
\hline
\end{tabular}

PV (\%); Sodium. total $\mathrm{CO}^{2}$ and ionized calcinm (mmoll); Osmolality (mOsm/kg);

Catecholamines (nmol/1); " $p<0.05$, compared to pre-treament value: " $p<0.05$, compared to $\mathrm{UF}+\mathrm{HD}$

\section{Combined altrafiltration-hemodialysis followed by isolated ultrafiltration}

The hemodynamic data are presented in table 2.3. and figure $2.3 a+b$. The predialysis weights were comparable at the start of warm and cold dialysis: $78.3 \pm 15.2$ and $78.2 \pm 15.8 \mathrm{~kg}(\mathrm{p}=1.00)$.

Warm UF+HD was associated with a significant decrease in VT while FVR tended to increase $(p>0.05)$. Both MAP and HR remained unchanged. Cold UF HD was associated with significantly higher VT while HR decreased significantly. After both warm and cold UF+HD, changes in the different hemodynamic parameters during i-UF did not reach statistical significance. Only VT increased significantly during i-UF after warm UF + HD. There were no significant differences between $\mathrm{i}-\mathrm{UF}$ and both warm and cold UF +HD. 
The laboratory data are presented in table 2.4. Changes in plasma volume were comparable between the different treatment modes. There were no significant differences in the different laboratory parameters between warm and cold UF + HD. Both plasma noradrenaline and adrenaline increased significantly only during i-UF after cold UF+HD.

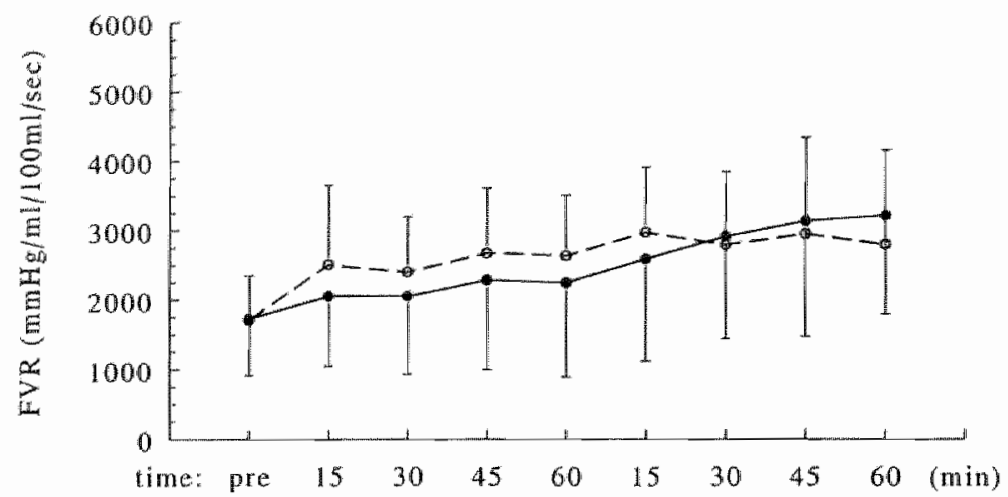

Figure 2.3a FVR during UF-UF+HD, 37.5 (-) and $35.0^{\circ} \mathrm{C}(--)$

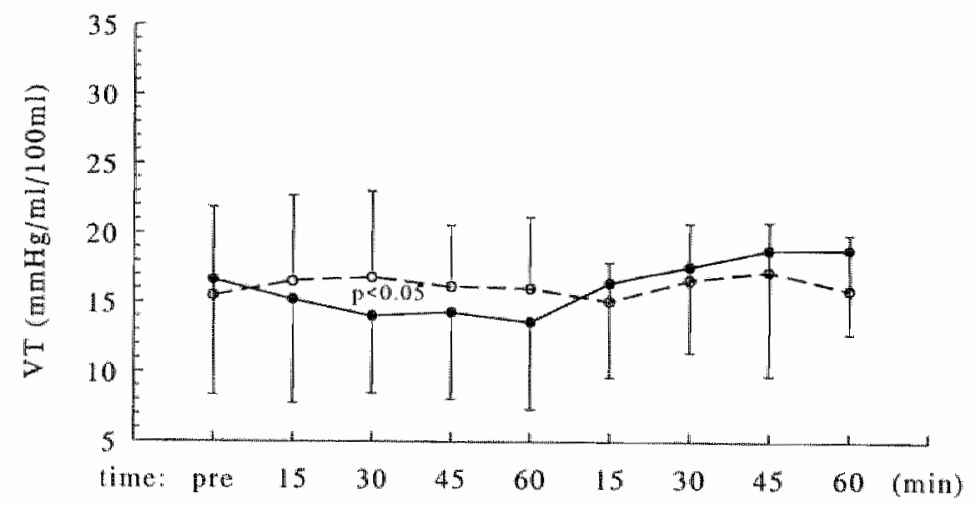

Figure 2.36 VT during UF+HD-UF, $37.5(-)$ and $35.0^{\circ} \mathrm{C}(--)$

Sub-analysis: isolated ultrafiltration (UF-UF+HD) compared to warm and cold combined ultrafiltration-hemodialysis (UF+HD-UF)

A sub-analysis of the hemodynamic data was performed comparing changes from baseline during $\mathrm{i}-\mathrm{UF}$ (first hour in UF-UF $+\mathrm{HD}$ ) with changes from baseline during warm and cold UF + HD (first hour in UF +HD-UF). In $\mathrm{i}-\mathrm{UF}$, the mean values of the hours preceding warm and cold UF+HD were used for analysis. 
There were no statistically significant differences in MAP and FVR between i-UF and both warm and cold UF+HD. However, changes in HR and VT were significantly different comparing i-UF with warm UF $+\mathrm{HD}$ (respectively $-4 \pm 5 \mathrm{vs}$ $+2 \pm 4$ beats $/ \mathrm{min}, \mathrm{p}<0.05$ and $+8.0 \pm 8.2 \mathrm{vs}-3.1 \pm 2.6 \mathrm{mmHg} / \mathrm{ml} / 100 \mathrm{ml}, \mathrm{p}<0.01)$. Furthermore, while changes in HR were comparable (respectively $-4 \pm 5$ vs $-5 \pm 2$ beats $/ \mathrm{min}, \mathrm{p}>0.05$ ), changes in VT were significantly different between UF and cold UF $+\mathrm{HD}$ (respectively $+8.0 \pm 8.2 \mathrm{vs}+0.5 \pm 3.4 \mathrm{mmHg} / \mathrm{ml} / 100 \mathrm{ml}, \mathrm{p}<0.05$ ).

\section{Protocol B}

The predialysis weights in warm and cold UF+HD in this sub-group of nine patients were respectively $75.5 \pm 11.8$ and $75.2 \pm 12.1 \mathrm{~kg}$ (ns). The ultrafiltration rates were respectively $0.4 \pm 0.3$ and $0.3 \pm 0.2 \mathrm{l} / \mathrm{hr}$ (ns) while the post-dialysis weights were respectively $73.0 \pm 11.7$ and $73.2 \pm 11.7 \mathrm{~kg}$ (ns). MAP was significantly higher in cold UF + HD during both dialysis hours (mean difference $+8 \pm 8 \mathrm{mmHg}, \mathrm{p}<0.05$ ) (figure 2.4a). While differences in diastolic BP did not reach statistical significance systolic $B P$ was significantly higher during the last dialysis hour $(+11 \pm 12 \mathrm{mmHg}, p<0.05)$. In addition, HR was significantly lower in cold UF + HD during the first dialysis hour $(-10 \pm 9$ beats $/ \mathrm{min}, \mathrm{p}<0.05$ ) (figure 2.4b). Although MAP tended to be higher during the first four post-dialysis hours, there were no significant differences in either BP or HR in the post-dialytic period between warm and cold $U F+H D$. None of the patients developed reactive hypotension after cold UF + HD.

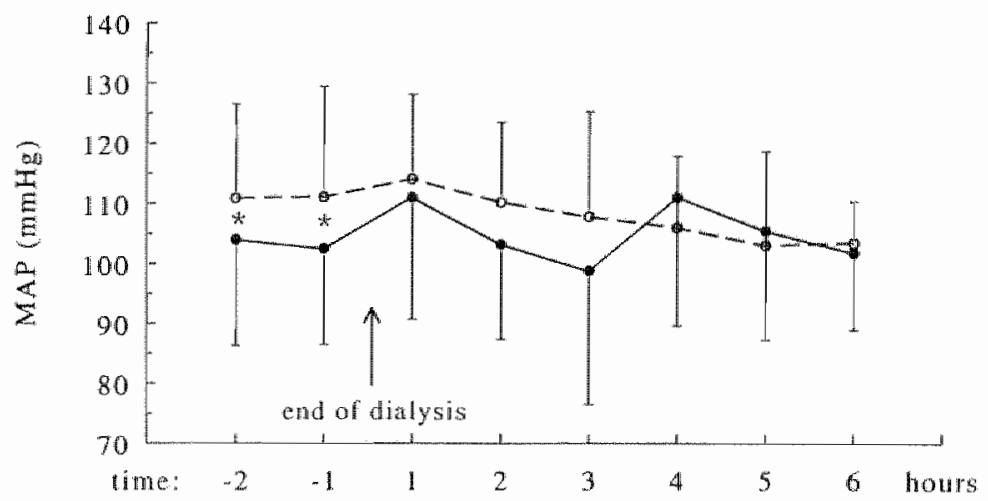

Figure 2.4a Mean anterial BP during and after UF +HD, 37.5 (- - ) and $35.0^{\circ} \mathrm{C}(--) ; * \mathrm{p}<0.05$ 


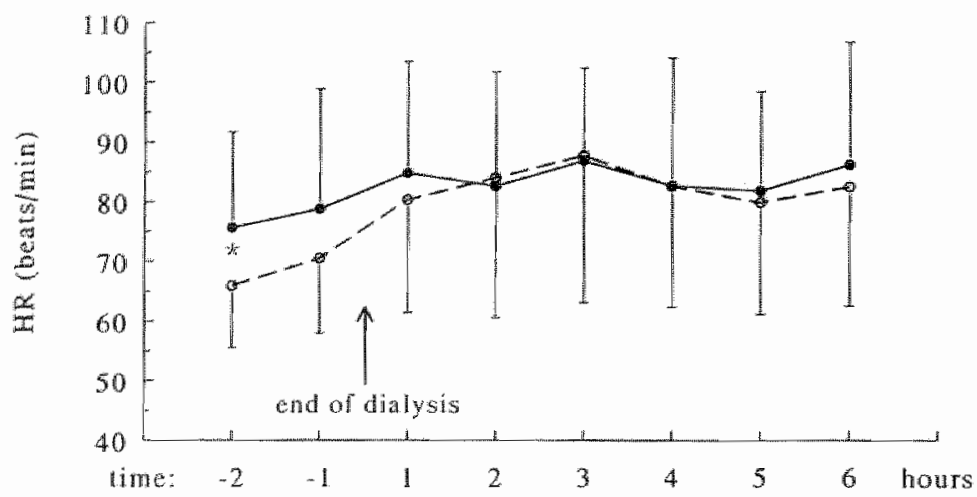

Figure 2.41 Heart rate during and after UF+HD, $37.5(-)$ and $35.0^{\circ} \mathrm{C}(-\ldots)$

$* \mathrm{p}=<0.05$

\section{Discussion}

In the present study, vascular reactivity was measured during both $\mathrm{i}-\mathrm{UF}$ and warm $\mathrm{UF}+\mathrm{HD}\left(37.5^{\circ} \mathrm{C}\right)$ as well as during cold $\mathrm{UF}+\mathrm{HD}\left(35.0^{\circ} \mathrm{C}\right)$ to study the role of the extracorporeal blood temperature in the disparitive hemodynamic response between isolated ultrafiltration and combined ultrafiltration-hemodialysis. In addition, the effect of cold dialysis on post-dialytic blood pressure was studied.

The main conclusion in the present study is that differences in the extracorporeal blood temperature are only partially responsible for differences in vascular reactivity between $\mathrm{I}-\mathrm{UF}$ and $\mathrm{UF}+\mathrm{HD}$. In addition, especially venous reactivity is improved during UF +HD when a comparable degree of blood cooling as during i-UF is achieved. Finally, cold dialysis does not result in rebound hypotension in the post-dialytic period.

During i-UF blood cooled down in the extracorporeal circuit by about $1.7^{\circ} \mathrm{C}$. In contrast, LF +HD at a dialysate temperature of $37.5^{\circ} \mathrm{C}$ blood was associated with a comparable temperature of blood in the arterial and venous line, indicating that extracorporeal blood cooling was exactly counterbalanced by heat transfer from dialysate to blood. At a dialysate temperature of $35.0^{\circ} \mathrm{C}$, extracorporeal blood cooling was comparable between UF $+\mathrm{HD}$ and $\mathrm{i}-\mathrm{UF}$.

The increase in temperature of blood in the arterial line by $0.3^{\circ} \mathrm{C}$ during one hour warm UF + HD (in UF-UF+HD) suggests that in protocol A, warm UF + HD was already associated with net heat gain. Three hours UF + HD resulted in an even larger increase in blood temperature, especially at a dialysate temperature of $37.5^{\circ} \mathrm{C}$. These results are in agreement with studies in which an increase in core body temperature or arterial blood temperature in the range of 0.7 to $1.0^{\circ} \mathrm{C}$ was 
demonstrated after four hours UF $+\mathrm{HD}$ at dialysate temperatures ranging between 37.0 and $38.0^{\circ} \mathrm{C}^{7.14 .15}$. In our experiments, however, heat gain is probably not only explained by net heat load at the dialyser level as even cold UF+HD was associated with a small but significant increase in the arterial blood temperature. Possible mechanisms that might be important in this respect are a decline in heat loss due to constriction of the skin vascular bed or an increase in internal heat generation due to the induction of a pyrogenic reaction, reflecting an interaction between blood and the non-sterile dialysate ${ }^{29}$.

With respect to the cardiovascular and laboratory data, both groups (UF-UF + HD and UF +HD-UF) were analyzed separately as statistical analysis revealed a significant effect of the specific order on some cardiovascular data. Only in the sub-analysis, a between-group comparison was made. In i-UF followed by warm UF $+H D$, changes in all four hemodynamic parameters were significanty different between the two treatments showing an adequate increase in FVR and VT during $\mathrm{i}-\mathrm{UF}$ with vascular reactivity being impaired during UF $+\mathrm{HD}$. However, at a dialysate temperature of $35.0^{\circ} \mathrm{C}$ these differences did not reach statistical significance. In UF +HD followed by $\mathrm{i}-\mathrm{UF}$, differences in hemodynamics between the two treatments were less pronounced irrespective of the dialysate temperature. The data suggest that vascular reactivity was disturbed during i-UF when preceded by $U F+H D$, especially after cold $U F+H D$. Although this might be a physiologic adaptation to a more stable circulation during cold $U F+H D$, vascular reactivity during i-UF might also be disturbed as a result of ongoing effects of the first UF +HD hour. Possible factors in this respect are the decrease in plasma osmolality ${ }^{30}$ or exposition to dialysate derived contaminants ${ }^{31}$. In order to exclude order effects in comparing i-UF with UF $+H D$, a sub-analysis was performed showing a statistically significant difference in VT between the two treatments at both dialysate temperatures. Differences in FVR were not significant

The use of colder dialysate mainly affected venous reactivity. In both ireatment sequences, VT was significantly higher during cold UF +HD as compared to warm UF $+H D$. Furthermore, in contrast to warm UF $+H D, H R$ decreased during cold UF +HD which is probably related to a better maintenance of VT, improving venous return, together with an increase in left ventricular contractility during cold UF + HD as observed by Levy et al. ${ }^{12}$. A delayed decrease in plasma $\alpha$-ANP during cold UF +HD as compared to warm UF + HD as recently reported by Hegbrant et al. is also in agreement with our observations ${ }^{32}$. We found no significant difference in FVR during UF $+\mathrm{HD}$ at the two dialysate temperatures although in both treatment sequences, mean FVR did tend to be higher during cold $\mathrm{UF}+\mathrm{HD}$. 
In protocol $A$, cold $U F+H D$ was not associated with a significantly higher blood pressure as compared to warm UF +HD. However, when patients were further ultrafiltrated to their dry-weight in protocol B arterial blood pressure was significantly higher during cold dialysis while HR contimued to be lower as observed in protocol A. Special attention was given to the post-dialytic period as rewarming of patients after cold dialysis might lead to rebound hypotension. However, none of the patients developed post-dialytic hypotension while blood pressure even tended to be somewhat higher after cold UF $+H D$ up to four hours after dialysis.

Plasma noradrenaline increased significantly only during i-UF in our experiments which might indicate that UF $+\mathrm{HD}$ is associated with an impairment of sympathetic reactivity. Furthermore, our results suggest that efferent sympathetic activity was unaffected by the extracorporeal blood temperature as plasma noradrenaline was not significantly different comparing warm with cold UF $+\mathrm{HD}$, which is at variance with the results of prior studies ${ }^{13,15}$. Moreover, these results make it less likely that improved venous reactivity during cold UF $+\mathrm{HD}$ is explained by an increase in the overall sympathetic output from the vasomotor centre ${ }^{3,34}$. However, we should bear in mind that plasma noradrenaline is only a weak indicator of sympathetic activity ${ }^{35}$. A possible explanation for improved venous reactivity in cold UF +HD might be a more specific decrease in venous capacitance of the skin vascular bed ${ }^{34}$. In addition, it has been shown that the vascular response to adrenergic stimulation increases when the peripheral blood temperature decreases ${ }^{36}$.

Overall, our results confirm the results obtained by other investigators ${ }^{5,6}$ showing that both vascular and sympathetic reactivity are impaired during combined ultrafiltration-hemodialysis as compared to isolated ultrafiltration. In addition, they show that at equivalent changes in the extracorporeal blood temperature, especially venous reactivity is still better during isolated ultrafiltration as compared to combined cold ultrafiltration-hemodialysis. Therefore, we conclude that disparity in vascular reactivity between isolated ultrafiltration and combined ultrafiltrationhemodialysis is only partially explained by differences in the extracorporeal blood temperature. Possible factors that might contribute to impaired vascular reactivity during combined ultrafiltration-hemodialysis and that cannot be excluded in the present study are a decrease in plasma osmolality ${ }^{30}$ or the induction of cytokine production by monocytes in the presence of dialysate derived contaminants ${ }^{31.37}$. Differences in plasma ionized calcium are probably not responsible for disparity in vascular reactivity as ionized calcium increased only during UF + HD in the present study. Finally we conclude, that lowering the dialysate temperature to $35.0^{\circ} \mathrm{C}$ does not lead to rebound hypotension in the post-dialytic period. Thus, lowering the dialysate temperature is in this respect a safe method to improve hemodynamic stability in the clinical situation. 


\section{References}

1 Henrich WL: Hemodynamic instability during hemodialysis.

Kidney Int 1986; 30:605-612.

2 Daugirdas JT: Dialysis hypotension: A hemodynamic analysis.

Kidney Int 1991; 39: 233-246.

3. Rothe CFi: Venous system: Physiology of capacitance vessels; in Shepherd IT, Abboud FM (ed.): Handbook of Physiology. Bethesda, American Physiological Society, 1983, 3, Peripheral circulation and organ blood flow, pp. $397-452$

4 Greenway CV, Laut WW: Blood volume, the venous system, preload, and cardiac output. Can J Physiol Phamacol 1986; 64: 383-387.

5 Baldamus CA, Enst $W$, Frei $U$, Koch.KM: Sympathetic and hemodynamic response to volume removal during different forms of renal replacement therapy. Nephron 1982; $31: 324-332$.

6 Kooman JP, Gladziwa U, Bocker G, van Bortel LMAB, van Hooff JP, Leunissen KML: Role of the venous system in hemodynamics during ultrafiltration and bicarbonate dialysis. Kidney Int 1992; 42:718 726 .

7 Lindholm T, Thysell H, Yamamoto Y, Forsberg B, Gullberg CA: Temperature and vascular stability in hemodialysis. Nephron 1985; 39: 130-133.

8 Marcén R, Quereda $C$, Orofino L, Lamas S, Teruel IL, Matesanz R, Ortuño J: Hemodialysis with low-temperature dialysate: A long-term experience.

Nephron 1988; 49: 29-32.

9 Coli U, Landini S, Lucatello S, Fracasso A, Morachiello P, Righetto F, Scanferla $F$, Onesti $G$, Bazzato $G$ : Cold as cardiovascular stabilizing factor in hemodialysis: hemodynamic evaluation. Trans Am Soc Artif Intern Organs 1983; 29: $71-75$.

10 Bazzato $G$, Coli U, Landini S, Lucatello S, Fracasso A, Morachiello P, Righetto F, Scanferla F: Temperature monitoring in dialysis-induced hypotension.

Kidney Int 1985; 28: S161-S165.

11 Jost CMT, Agarwal R, Khair-EJ-Din T, Grayburn PA, Victor RG, Henrich WL: Effects of cooler temperature dialysate on hemodynamic stability in "problem" dialysis patients. Kidney Int 1993; 44: 606-612.

12 Lewy $\mathbb{F L}$, Graburn PA, Foulks CJ, Brickner ME. Hentich WL: Improved left ventricular contractility with cool temperature hemodialysis.

Kidney Int 1992; 41: 961-965.

13 Mahida BH, Dumler $F$, Zasuwa G, Fleig G, Levin NW: Effect of cooler dialysate on serum catecholamines and blood pressure stability.

Trans Am Soc Artif Intern Organs 1983; 24; 384-389.

14 Maggiore $Q$, Pizzarelli F, Sisca $S$, Zoccalli $C$, Parlongo $S$, Nicolò F, Creazzo G: Blood temperature and vascular stability during hemodialyis and hemofiltration. Trans Am Soc Artif Intern Organs 1982; 28: 523-527. 
15 Maggiore Q, Pizzarelli $F$, Zoccali $C$, Sisca $S$, Nicoló F: Influence of blood temperature on vascular stability during hemodialysis and isolated ultrafiltration.

Int J Artif Organs 1985; 8: 175-178.

16. Leunissen KML, Kouw $\mathrm{P}$, Kooman JP, Cheriex $\mathrm{EC}$, de Vries PMJM, Donker AJM, wan Hooff JP: New techniques to determine fluid status in hemodialyzed patients. Kidney Int 1993; 43: $550-556$.

17 Penàz J: Photolelectric measurement of blood pressure, volume and flow in the finger. Digest 10th Int Conf Med Biol Engng 104, Dresden 1973.

18 Whitney RJ: The measurement of volume changes in human limbs.

J Physiol 1953; 121:1-27.

19 Berdeaux A, Duranteau J, Pussard E, Edouard A, Giudicelli J-F: Baroreflex control of regional vascular resistances during simulated orthostatism.

Kidney Int $1992 ; 41: \$ 29-\$ 33$.

20 Tripathi A, Mack $G$, Nadel ER: Peripheral vascular reflexes elicited during lower body negative pressure. Aviat Space Environ Med 1989; 60: 1187-1193.

21 Baily RG, Prophet SA, Shenberger JS, Zelis. R, Sinoway LI: Direct neurohumoral evidence for isolated sympathetic nervous system activation to skeletal muscle in response to cardiopulmonary barorecptor unloading. Circ Res 1990; 66: 1720-1728.

22 Oberg $B$ : The relationship between active constriction and passive recoil at various. distending pressures. Acta Plrysiol Scand 1967; 71: 233-247.

23 Jageneau AH: Noninvasive diagnosus in the management of cardiovascular disedses. Amsterdam, New York, London, North Holland Biomedical Press, 1981, 169-229.

24 Houben AJHM (1993): Early (micro)circulatory haemodynamic changes in type I diabetes mellitus. Ph.D. Dissertation, University of Limburg, Maastricht, The Netherlands. $144 \mathrm{p}$.

25 van der Hoorn FA, Boomsma F, Man in 't Veld AJ, Schalenkamp MA: Determination of catecholamines in human plasma by high-performance liquid chromatography: comparison between a new method with fluorescence detection and

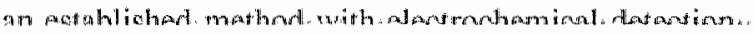

J Chromatogr 1989; 487: 17-28.

26 Van Beamont $W$ : Evaluation of hemoconcentration from hematocrit measurements. $J$ of Appl Physiol 1972; 32: 712-713.

27 O'Brien E, Mee F. Atkins N, O'Mally K: Accuracy of the Spacelabs 90207 determined by the British Hypertension Society protocol.

J Hypert 1991; 9: 573-574.

28 Stevens J: Chapter 13.7; Should we use the univariate or the multivariate approach?; in: Applied multivariate statistics for the social sciences. Hillsclale, New Jersey, Lawrence Enlbaum Associates, Publishers, 1992, pp. 454-456.

29 Dinarello CA: Pathogenesis of fever during hemodialysis.

Contrib Nephrol 1983; 36: 90-99.

30 Henrich WL, Woodard TD, Blachley ID, Gomez-Sanchez C. Pettinger W, Cronin RE: Role of osmolalicy in blood pressure stability after dialysis and ultrafiltration. Kidney Int 1980: 18: $480-488$. 
31 Henderson LW, Koch KM, Dinarello CA, Shaldon S: Hemodialysis hypotension: The interlenkin-1 hypothesis. Blood Purif 1983; 1:3-8.

32 Hegbrant $\mathfrak{J}$, Thysell $\mathrm{H}$, Mårtensson L, Nielsen $\mathrm{AL}$, Lindberg FL: Delayed decrease in plasma levels of atrial natriuretic peptide during cold hemodialysis.

Nephron 1994; 68: 427-432.

33 Johnson JM: Nonthermoregulatory control of human skin blood flow. J of Appl Physiol 1986; 61: 1613-1622.

34 Rowell BR: Cardiovascular adjustment to thermal stress; in Shepherd JT, Abboud FM (ed.): Handbook of Physiology, sect 2, Cardiovascular system, vol 3, Peripheral circulation and organ blood flow. Bethesda , American Physiological Society, 1983, 3, pp. 967-1023

35 Esler MD, Hasking GI, Willett IR, Leonard PW, Jennings GL: Noradrenaline release and sympathetic nervous system activity. J Hypert 1985; 3: 117-129.

36 Vanhoutte PM: Physical factors of regulation; in Bohr DF, Somlyo AP (ed.): Handbook of Physiology, sect 2, Cardiovascular System, vol 2, Vascular smooth muscle. Bethesda, American Physiological Society, 1980, 2, pp. 443-474

37 Beasly D, Brenner BM: Role of nitric oxide in hemodialysis hypotension. Kidney Int 1992; 42: S96-S100. 


\section{Chapter 3}

\section{Vascular reactivity during combined ultrafiltration- hemodialysis: influence of dialysate sodium}

WHM van Kuijk, JJJM Wirtz, W Grave, F de Heer, PPCA Menheere, JP van Hooff, KML Leunissen 


\section{Abstract}

\section{Background}

It is well known that vascular reactivity is impaired during combined ultrafilltrationhemodialysis as compared to isolated ultrafiltration and hemofiltration which might be related to differences in plasma osmolality. Therefore, vascular reactivity was studied during combined ultrafiltration-hemodialysis in relation to sodium related differences in plasma osmolality/tonicity.

\section{Methods}

With each patient serving as his or her own control, nine stable dialysis patients (23-71 years) were studied during two hours of combined ultrafiltration-hemodialysis (bicarbonate, UF-rate $1.0 \mathrm{~J} / \mathrm{hr}$ )) att iwo different dialysate sodium concentrations: 134 and $144 \mathrm{mmol} / 1$. Before dialysis as well as every twenty minutes during dialysis, blood pressure (Dinamap), heart rate (EKG) and forearm vascular resistance and venous tone (strain-gauge plethysmography) were measured. Relative blood volume was monitored continuously with an optical reflection method (Haemoguard 2000) while before and after dialysis blood was obtained for the estimation of plasma prostaglandin $\mathbb{E}_{2}\left(\mathrm{PGF}_{2}\right)$.

\section{Results}

High-sodium dialysis resulted in a significantly higher post-dialysis plasma sodium concentration $(139.9$ vs $135.0 \mathrm{mmol} / \mathrm{l} ; \mathrm{p}<0.01)$ while the decrease in relative blood volume was significantly smaller as compared to low-sodium dialysis $(-8.4 \mathrm{ws}-1.8 .4 \%$; $p<0.01)$. There were no significant differences in the different hemodynamic parameters between the two treatment modalities. Both high-and low-sodium dialysis were associated with a significant increase in forearm vascular resistance while venous tone remained unchanged. Although there was no significant difference in plasma PGE between the two treatment modalities, $\mathrm{PGE}_{2}$ increased significantly only during low-sodium dialysis. We found no relation between changes in $\mathrm{PGE}_{2}$ and vascular reactivity.

\section{Conclusions}

We conclude that vascular reactivity during combined ultrafiltration-hemodialysis is not directly influenced by sodium related changes in plasma tonicity. Although not studied directly, the reported improved hemodynamic stability with high-sodium dialysis is probably only mediated through a better preservation of plasma volume. Finally, an increase in plasma $\mathrm{PGE}_{2}$ as observed during low-sodium dialysis does not lead to a decrease in vascular tone. 


\section{Introduction}

Hemodynamic instability with symptomatic hypotension is still the most important complication in dialysis therapy. During ultrafiltration, maintenance of blood pressure is related to both optimal preservation of plasma volume as well as to adequate cardiovascular compensating mechanisms to buffer the decline in plasma volume ${ }^{1.2}$. In this respect it is well recognised that vascular reactivity is inpaired during combined ultrafiltration-hemodialysis as compared to both isolated ultrafiltration and hemofiltration ${ }^{3-5}$. However, the mechanisms responsible for this impaired vascular response are still not well understood. In a recent study and in agreement with Maggiore et al. we concluded that impaired vascular reactivity during combined ultrafiltration-hemodialysis as compared to isolated ultrafiltration is only partially explained by differences in the extracorporeal blood temperature which indicates that additional factors should play a role ${ }^{6,7}$.

Traditionally, the relatively large decrease in plasma osmolality during combined ultrafiltration-hemodialysis as result of hypertonic fluid loss is considered to disturb the hemodynamic response during this treatment ${ }^{8.9}$. It has been shown that counterbalancing changes in osmolality by the use of higher dialysate sodium concentrations or by the infusion of hypertonic mannitol result in a better hemodynamic stability ${ }^{10-12}$. Although this improvement is at least partially explained on the basis of a better preservation of plasma volume, results obtained by Henrich et al. suggest a direct effect of plasma osmolality on vascular reaciivity ${ }^{13}$. Schultze et al. suggested that increased levels of plasma $\mathrm{PGE}_{2}$ may contribute to hemodynamic instability in low-sodium dialysis by inducing vasodilation ${ }^{14}$. However, the conclusions in both studies are based on measurements of blood pressure and heart rate only.

In the present study therefore, peripheral vascular reactivity was measured during high-and low-sodium dialysis to study the role of sodium related changes in plasma osmolality in the hemodynamic and response during combined ultrafilltration-hemodialysis.

\section{Subjects and methods}

\section{Subjects and dialysis}

Nine patients on chronic intermittent hemodialysis signed an informed consent for participation in the study that had been approved by the Ethics Committee of the $\mathrm{St}$ Laurentius Hospital. All patients were hemodynamically stable patients who rarely suffered from intradialytic hypotension. Exclusion criteria were severe coronary (NYHA II or more) or valvular heart disease, compromised left ventricular 
function (ejection fraction $30 \%$ or less) and diabetes mellitus.

One woman and eight men were studied with a mean age of 46 years (range 23-71) and a mean time on hemodialysis of 46 months (range 12-53). Patients served as their own control and were studied according to their individual dialysis schedule. By adjusting fluid intake, patients were instructed to achieve a pre-diallysis weight of 2.0 kilograms above their dry-weight that was estimated by echography of the inferior caval vein ${ }^{15}$. All vasoactive medication was stopped 48 hours before the study while patients were not allowed to smoke or drink caffeine containing beverages during 12 hours preceding the study. None of the patients used non-steroidal anti-inflammatory drugs.

Measurements were performed during two dialysis treatments consisting of two hours combined ultrafiltration-hemodialysis that only differed in the dialysate sodium concentration: 134 and $144 \mathrm{mmol} / 1$ (by measurement of conductivity). The order of the dialysate sodium concentration was randomised while the ultrafiltration rate was $1.0 \mathrm{l} / \mathrm{hr}$ in all treatments. Dialysis was performed with a Gambro AK-100 module using hemophane membranes (GFS-16; Gambro, Sweden). The composition of dialysate was: sodium 134 or $144 \mathrm{mmol} / \mathrm{l}$, chloride 112 or 104 mmol/l, potassium $2.0 \mathrm{mmol} / 1$, bicarbonate $34 \mathrm{mmol} / 1$, acetate $3 \mathrm{mmol} / 1$, calcium $1.75 \mathrm{mmol} / \|$ and magnesium $0.5 \mathrm{mmol} / \mathrm{l}$. The dialysate temperature was $37.5^{\circ} \mathrm{C}$. Blood flow was $250 \mathrm{ml} / \mathrm{min}$ and dialysate flow was $500 \mathrm{ml} / \mathrm{min}$.

\section{Methods}

Arterial blood pressure (BP) was measured with an automatic blood pressure monitor (Dinamap $1486 \mathrm{SX}$, Critikon Inc., USA). The mean value of four consecutive measurements was calculated. Heart rate (HR) was obtained from an electrocardiogram. The mean value of two minutes was calculated. Forearm vascular resistance (FVR) and venous tone (VT) were measured as described in chapter 2. The hand circulation was occluded from one minute prior to as well as during flow measurements. All measurements were performed before and every 20 minutes during dialysis.

Changes in relative blood volume (BV) were measured continuously and non-invasively by means of an optical reflection method which operates at a wavelength of $950 \mathrm{~nm}$. The optical sensor was clipped on the arterial line (Haemoguard 2000, Sanofi Sante). The amount of reflected light has been shown to correlate well with the erythrocyte concentration $(r=0.94 ; p<0.001)^{16}$. The baseline value was obtained after two minutes of extracorporeal circulation at a blood flow of $250 \mathrm{ml} / \mathrm{min}$ without ultrafiltration to exclude the influence of saline (recirculation) present in the extracorporeal circuit at the start of dialysis. 
Before as well as after two hours UF+MD, blood was withdrawn for the estimation of: sodium (selective electrode), potassium, honized calcium, total $\mathrm{CO}_{2}$, urea, osmolality (Wescor, vapour pressure osmometer) and colloid osmotic pressure. In addition, blood was withdrawn in ice-chilled nubes and directly centrifuged at a temperature of $4^{\circ} \mathrm{C}$ for the estimation of plasma catecholamines (HPLC, fluorescence detection).

\section{Prostaglandin $\mathbb{E}_{2}$}

For the estimation of plasma Prostaglandin $\mathbb{E}_{2}\left(\mathrm{PGE}_{2}\right)$ blood was withdrawn in ice-chilled tubes (EDTA) and directly centrifuged (15 min at $2000 \mathrm{~g}$ ) at a temperature of $4^{\circ} \mathrm{C}$ for the estimation of $\mathrm{PGE}_{2}$. All samples were stored at $-70^{\circ} \mathrm{C}$ until analysis. $P G E_{2}$ was determined by RIA using a commercially available PGE $_{2}$ assay system (Amersham International PLC, Amersham, UK). In brief, the assay is based upon competition between the methyl oximate derivative of unlabelled $\mathrm{PGE}_{2}$ and ${ }^{125} \mathrm{~J}$ labelled metlyyl oximate derivative of $\mathrm{PGE}_{2}$ for a limited quantity of binding sites on a rabbit antibody specific for the methyl oximate derivative of $\mathrm{PGE}_{2}$. Separation of the bound and free derivative of $\mathrm{PGE}_{2}$ was achieved by reaction of the bound fraction with a donkey antirabbit antibody bound to magnetizable polymer particles. After application of a strong magnetic field the separation was effected by decantation of the supernatant after which the remaining radioactivity was counted. The activity of the standards provicled in the kit was plotted against their assigned values. The concentrations of the unknown samples were determined by interpolation from the standard curve.

Crossreactivity $(\%)$ at $50 \%$ displacement of the tracer was $100 \%$ for $\mathrm{PGE}_{2}$ and about $60 \%$ for 8-iso-PGE . $_{2} \mathrm{PGE}_{2}$ and $20 \mathrm{OH} \mathrm{PGE}_{2}$ cross react for about $5 \%$. All other substances known to interfere cross reacted to a percentage below $0.01 \%$. In our laboratory, the sensitivity of the assay was $2.7 \mathrm{pg} / \mathrm{ml}$. The precision of the assay was better than $7 \%$ at the level of $25 \mathrm{pg} / \mathrm{ml}$, better that $4 \%$ at the level of $100 \mathrm{pg} / \mathrm{ml}$ and better than $3 \%$ at the level of $400 \mathrm{pg} / \mathrm{ml}$.

\section{Statistical analysis}

Changes in hemodynamic parameters within each treatment as well as differences between treatments were analyzed by repeated measurements MANOVA (SPSS-PC version). If the sphericity of the variance-covariance matrix appeared to be violated, degrees of freedom in the univariate MANOVA tests were corrected by the Greenhouse-Geisser epsilon to avoid Type 1 error in testing the F-ratio. All laboratory parameters were analyzed by Friedman's ANOVA and if appropriate by Wilcoxon's signed-rank test. All values are expressed as mean $\pm S D$. 


\section{Results}

The mean pre-dialysis weights at the start of high- and low-sodium UF+HD were respectively $76.7 \pm 11.1$ and $76.6 \pm 11.3 \mathrm{~kg}$ (ns). The laboratory data are shown in table 3.1. In both low- and high-sodium UF+HD, the dialysate sodium concentration was respectively hypo- and hypernatric in comparison to the pre-dialysis plasma sodium level in eight patients while the concentration was isonatric in one patient in both treatment modalities. During high-sodium UF +HD, plasma sodium tended to increase $(p=0.076)$ while during low-sodium UF + HD plasma sodium decreased significantly. As a result, plasma sodium was significantly lower after low-sodium UF $+H D$ as compared to high-sodium $U F+H D(p<0.01)$. With comparable changes in urea, there was no significant difference in plasma osmolality between high- and low-sodium UF +HD. The increase in colloid osmotic pressure was significantly larger during low-sodium dialysis. Changes in both plasma noradrenaline and adrenaline did not reach statistical significance during both treatment modalities.

Talble 3.1 Laboratory data

\begin{tabular}{|c|c|c|c|c|c|}
\hline & \multicolumn{2}{|c|}{ Sodium $134 \mathrm{mmol} / \mathrm{l}$} & \multicolumn{2}{|c|}{ Sodium 144 mnol/1 } & \multirow{2}{*}{$\begin{array}{l}\text { changes } \\
134 \text { vs } 144\end{array}$} \\
\hline & pre & post & pre & post & \\
\hline Sodium & $137.1(2.0)$ & $135,0(2.7)^{\mathrm{a}}$ & $138.4(2.7)$ & $139.9(2.0)$ & 0.017 \\
\hline Potassium & $5.3(0.8)$ & $3.9(0.5)^{b}$ & $5.2(0.9)$ & $4.0(0.8)^{b}$ & ns \\
\hline ionized Calcium & $1.29(0.07)$ & $1.39(0.06)^{\mathrm{a}}$ & $1.30(0.07)$ & $1.46(0.04)^{a}$ & nis \\
\hline total $\mathrm{CO}_{2}$ & $25.1(2.8)$ & $29.8(1.6)^{13}$ & $26.0(2.5)$ & $29.4(1.7)^{b}$ & ns \\
\hline Urea & $25.5(6.4)$ & $14.4(4.9)^{\mathrm{th}}$ & $26.0(6.7)$ & $14.5(4.3)^{b}$ & ns \\
\hline Osmolality & $298.9(14.0)$ & $285.0(9.1)^{\mathrm{a}}$ & $302.9(12.4)$ & $293.7(10.9)^{\mathrm{a}}$ & ns \\
\hline COP & $3.1(0.3)$ & $3.8(0.6)^{\prime \prime}$ & $3.0(0.3)$ & $3.4(0.4)^{\mathrm{D}}$ & 0.018 \\
\hline Noradrenaline & $1.36(0.56)$ & $1.47(0.59)$ & $1.53(0.66)$ & $1.49(0.64)$ & ns \\
\hline Adrenaline & $0.09(0.06)$ & $0.10(0.03)$ & $0.11 \quad(0.06)$ & $0.10(0.03)$ & ns \\
\hline $\mathrm{PCE}_{2}$ & $32.2(25.0)$ & $76.9(91.1)^{2}$ & $20.6(8.6)$ & $31.6(29.7)$ & nsis \\
\hline
\end{tabular}

Sodium, Potassium, ionized Calcium, iotal $\mathrm{CO}_{2}$, Lrea (mmol/); Ommolality (mOsm/kg); COP (kPa); Catcholamines (nmol/l): PGE $(\mathrm{pg} / \mathrm{ml})$; post vs pre, ${ }^{*}=\mathrm{p}<0.05$ and ${ }^{b}=\mathrm{p}<0.01 ;{ }^{*} \mathrm{n}=5$.

The individual changes in plasma $\mathrm{PGE}_{2}$ are shown in figure 3.1. One blood sample of a patient obtained after low-sodium was lost. Therefore, data of eight patients were analyzed. Plasma $\mathrm{PGE}_{2}$ increased significanily only during low-sodium UF +HD while during high-sodium UF + HD the increase did not reach statistical significance $(p=0.070)$. 
Despite a substantially larger mean increase in $P G E_{2}$ during low-sodium UF + HD, the difference between the wo treatment modalities was not statistically significant.
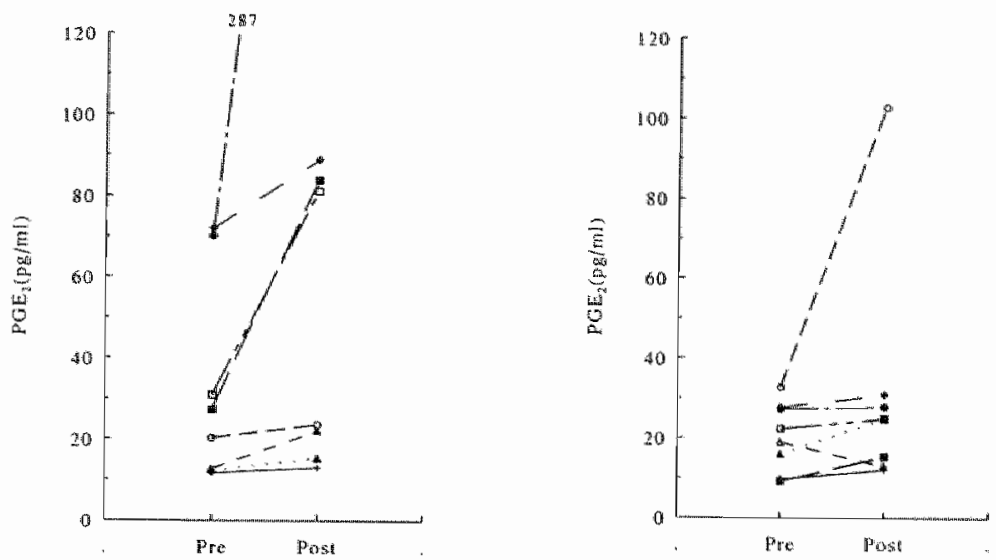

Figure 3.1 Individual changes in plasma $\mathrm{PGE}_{2}$ during low (left) and high (righ) sodium $\mathrm{UF}+\mathrm{HD}$

Changes in relative blood volume are shown in figure 3.2. Blood volume decreased to a mean value of $92 \pm 4 \%$ and $82 \pm 5 \%$ in respectively high- and lowsodium UF + HD. The difference was statistically significant $(p<0.01)$.

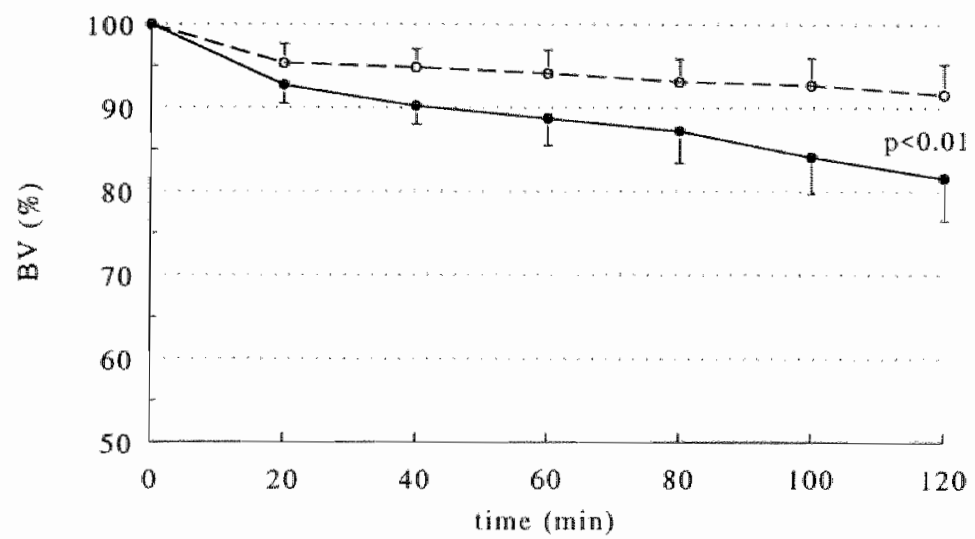

Figure 3.2 Changes in relanve blood volume during low (- -$)$ and high $(\ldots-)$ sodium UF+HD 
The hemodynamic data are shown in table 3.2 and figure $3.3 \mathrm{a}+\mathrm{b}$. During both treatments, FVR increased significantly while VT remained unchanged. There were no significant differences in FVR and VT between high- and low-sodium UF+HD.

For the group as a whole, there were no significant changes in both arterial blood pressure and heart rate during the two treatment modalities. In two patients, systolic blood pressure decreased by about $20 \mathrm{mmHg}$ only during low-sodium $U F+H D$ and remained stable during high-sodium UF $+H D$. One of these two patients became symptomatically hypotensive during the third dialysis hour after attaining the upright posture while seated.

There was no significant correlation between changes in plasma PGE 2 and changes in plasma sodium, FVR, VT or arterial blood pressure.

Table 3.2 Hemodynamic data

\begin{tabular}{|c|c|c|c|c|c|}
\hline & \multicolumn{2}{|c|}{ Sodium $134 \mathrm{mmol} / \mathrm{l}$} & \multicolumn{2}{|c|}{ Sodium 144 mmol/1 } & \multirow{2}{*}{$\begin{array}{l}\text { changes } \\
134 \text { wis } 144\end{array}$} \\
\hline & pre & post & pre & post & \\
\hline Systolic BP & $148(30)$ & $145(27)$ & $146 \cdot(26)$ & $150(31)$ & ns \\
\hline Diastolic BP & $85(13)$ & $88(13)$ & $85(11)$ & $88(17)$ & $\mathrm{ns}$ \\
\hline Mean Arterial BP & $107(19)$ & $109(18)$ & $107(16)$ & $111(23)$ & ns \\
\hline Heart Rate & $69(15)$ & $69(12)$ & $71(14)$ & $69(13)$ & ns \\
\hline FVR & $2113(741)$ & $3380(874)^{4}$ & $2057(677)$ & $3363(1033)^{x}$ & ns \\
\hline $\mathrm{VT}$ & $11.9(2.9)$ & $12.9(3.0)$ & $12.4(3.2)$ & $12.5(2.8)$ & ns \\
\hline
\end{tabular}

BP (mmHg); HR (beats/min); FVR ( $\mathrm{mmHg} / \mathrm{ml} / 100 \mathrm{ml} / \mathrm{sec}) ; \mathrm{VT}(\mathrm{mmHg} / \mathrm{ml} / 100 \mathrm{ml}) ;$ post vs pre, an $=p<0.01$

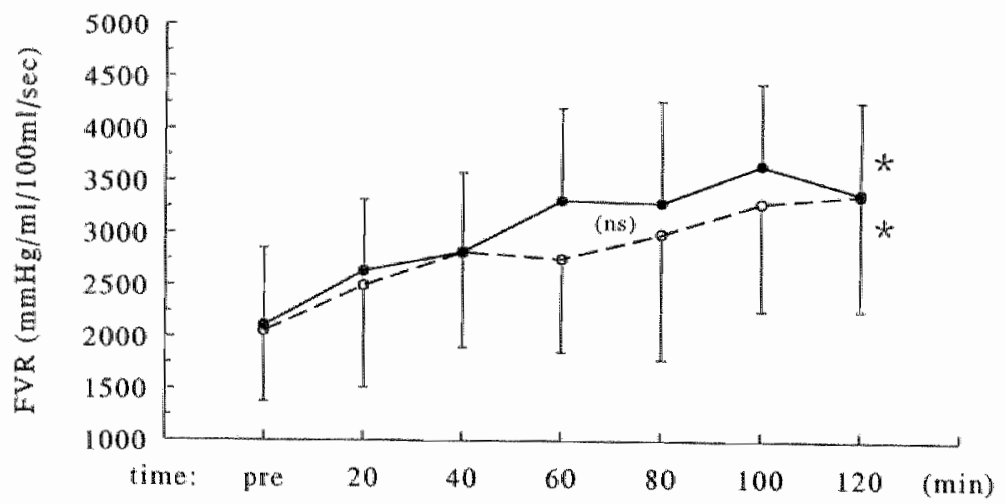

Figure 3.3a FVR during low $(-\rightarrow)$ and high $(-\rightarrow)$ sodium UF $+H D, *=p<0.01$ as compared to pre-treament value 


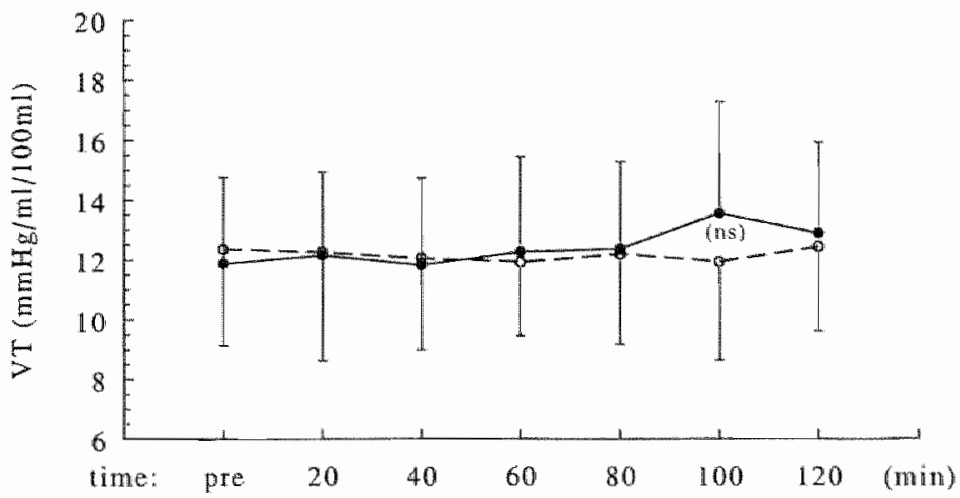

Figure 3.3b VT during low (-) and high (- $-\infty$ ) sodium UF H HD

\section{Discussion}

Peripheral vascular reactivity was studied during high- and low-sodium dialysis to investigate whether vascular reactivity during UF $+H D$ is related to changes in plasma osmolality. Our results show that both arteriolar and venous reaclivity are not influenced by sodium related changes in plasma osmolality, or better plasma tonicity. In addition, they show that improved hemodynamic stability in high-sodium dialysis as reported in previous studies is probably only mediated by an improvement in plasma volume preservation.

A model of two hours was used to study the vascular responses as Kooman et al. from our group found clear differences in both FVR and VT between isolated ultrafiltration and UF +HD within one hour. In addition, the model offers the possibility to study patients at a high UF-rate of $1 \mathrm{~J} / \mathrm{hr}$ under completely standardised conditions. Finally, changes in both plasma sodium and osmolality are most pronounced during the first two treatment hours.

Changes in plasma osmolality have been suggested to play a role in the impaired hemodynamic response during UF+HD. In this respect, only loss of tonically active substances seems to be important as adding of urea to dialysate did not improve the hemodynamic response in both humans and $\operatorname{dogs}^{17,18}$. Therefore, vascular reactivity was studied in relation to an active osmol, i.e. sodium. Two hours UF +HD at a dialysate sodium concentration of respectively 134 and 144 mmol/l resulted in a significantly different plasma sodium concentration. As changes in plasma osmolality are mainly urea related, there was no significant difference in plasma osmolality after high- and low-sodium UF + HD. However, with comparable pre-dialysis weights and the same ultrafiltration rate in both 
treatment modalities the significantly larger decrease in relative blood volume during low-sodium UF $+\mathrm{HD}$ points to an important difference in plasma tonicity. In previous studies, it has been shown that with higher dialysate sodium concentrations refill of the intravascular compartment is improved by the induction of an osmotic gradient both over the cellular as well as over the capillary wall ${ }^{19,20}$.

High-and low-sodium UF +HD were associated with a significant increase in FVR while VT remained unchanged. Moreover, there were no significant differences in these parameters between the two treatments which indicates that vascular reactivity is not directly influenced by sodium related changes in plasma tonicity. Although not significantly different, the data presented in figure 3.3a even suggest that during low-sodium UF +HD, the larger decline in blood volume was counterbalanced by a somewhat higher level of peripheral resistance.

Arterial blood pressure and heart rate were comparable between high- and low-sodium UF +HD. For the group as a whole one might expect a larger difference in blood pressure between the two treatments as the decrease in blood volume was substantially larger during low-sodium UF +HD while the increase in vascular tone was comparable to high-sodium UF +HD. These observations suggest that in these patients, selected for their relatively good cardiac function, blood pressure was adequately maintained on the basis of an increase in peripheral resistance and probably also in myocardial contractility as a result of an increase in plasma ionized calcium ${ }^{21}$, despite a lower level of venous return. In only two patients, systolic blood pressure decreased substantially during low-sodium UF +HD despite a relatively small decrease in blood volume $(-13 \%$ and $-14 \%)$. This could be related to differences in the individual cardiac status as these two patients had the lowest ejection fraction of the studied patients.

Our results are in contrast with those obtained by Henrich et al. who studied the "brook pressure response during "both regular diàlysis and isolated ultratiltration as well as during dialysis with either isotonic $(5 \%)$ or hypertonic $(25 \%)$ mannitol infusion. Plasma osmolality remained stable only during isolated ultrafiltration and dialysis with hypertonic mannitol infusion while blood pressure was best preserved during these treatments as well as during an orthostatic manoeuvre after these treatments. As the increase in both hematocrit and plasma proteins was comparable between dialysis with either isotonic or hypertonic mannitol infusion, compatible with comparable changes in plasma volume during these two treatments, the authors suggested a direct relation between changes in plasma osmolality and vascular reactivity ${ }^{1.3}$. However, vascular reactivity was not directly monitored in their study while it is our impression that differences in extracellular volume distrilbution are not conclusively excluded since data on changes in plasma volume are not presented for all treatment modalities. Moreover, at variance with our study plasma osmolality was completely counterbalanced with hypertonic mannitol 
infusion.

Release of eicosanoids during dialysis has been related to the membrane type $e^{22,23}$ as well as to the use of low-sodium dialysate ${ }^{14}$. Schultze et al. found a larger decrease in mean arterial blood pressure in association with higher levels of plasma $\mathrm{PGE}_{2}$ during low-sodium dialysis (126 mmol/l) as compared to high-sodium dialysis ( $140 \mathrm{mmol} / \mathrm{l}$ ). They hypothesized that hemodynamic instability during low-sodiun dialysis could be related to the release of vasodilating prostaglandins ${ }^{14}$. In the present study, plasma $\mathrm{PGE}_{2}$ increased significantly also only during low-sodium UF +HD while in agreement with Schultze et al. the data shown in figure 3.1 suggest a responder non-responder phenomenon. However, there were no significant differences in plasma $\mathrm{PGE}_{2}$ between high- and low-sodium UF+HD in the present study while in addition there was no relation between either the vascular or blood pressure response and changes in plasma $\mathrm{PGE}_{2}$. It is our opinion therefore, that with respect to hemodynamics the increase in plasma $\mathrm{PGE}_{2}$ during low-sodium dialysis seems to be an epi-phenomenon.

In conclusion, vascular reactivity during combined ultrafiltration-hemodialysis is not related to sodium related changes in plasma tonicity while improved hemodynamic stability with high-sodium dialysate is primarily related to a better preservation of plasma volume. This indicates that in contrast to differences in the extracorporeal blood temperature, changes in plasma osmolality probably do not play an important role in the impaired vascular response during combined ultrafiltration-hemodialysis as compared to isolated ultrafiltration and hemofiltration. Possible factors that might be important in this respect are differences in ionized calcium or biocompatibility ${ }^{2425}$. 


\section{References}

1 Daugirdas JT: Dialysis hypotension: A hemodynamic analysis.

Kidney Int 1991; 39: 233-246.

2 Rothe CF: Venous systern: Physiology of capacitance vessels; in Shepherd IT, Abboud FM (ed.): Handbook of Physiology. Bethesda, American Physiological Society, 1983, 3, Peripheral circulation and organ blood flow, pp. 397-452

3 Baldamus CA, Ernst W, Frei U, Koch.KM: Sympathetic and hemodynamic response to volume removal during different forms of renal replacement therapy. Nephron 1982; 31: 324-332.

4 Bradley JR, Evans DB, Cowley AJ: Comparison of vascular tone during combined haemodialysis with ultrafiltration and during ultrafiltration followed by haemodialysis: a possible mechanism for dialysis hypotension.

BMJ 1990; 300: 1312.

5 Kooman JP, Gladziwa U, Böcker $G_{n}$ van Bortel LMAB, van Hooff JP, Leunissen KML: Role of the venous system in hemodynamics during ultrafiltration and bicarbonate dialysis. Kidney Int 1992; 42: 718-726.

6 Maggiore $Q$, Pizzarelli $F$, Zoccali $C$, Sisca $S$, Nicolò $F$ : Influence of blood temperature on vascular stability during hemodialysis and isolated ultrafiltration.

Int J Artif Organs 1985; 8: 175-178.

van Kuijk WHM, Luik.AJ, de Leeuw PW, van Hooff JP, Nieman FHM, Habets HML, Leunissen KML: Vascular reactivity during hemodialysis and isolated ultrafiltration: thermal influences. Nephrol Dial Transplant 1995; (in press).

8 Bergström J: Ultrafiltration without dialysis for removal of fluid and solutes in uremia. Clin Nephrol 1978; 9: 156-164.

9 Palmer BF: The effect of dialysate composition on systemic hemodynamics. Sem Dial 1992; 5: 54-60.

10 Henrich WL, Woodard TD, McPhaul Jy: The chronic efficacy and safety of high sodium dialysate: double-blind, crossover study.

Am J Kidney Dis 1982; 2: 349-353.

11 Cybulsky AVE, Matni A, Hollomby DJ: Effects of high sodium dialysate during maintenance hemodialysis. Nephron 1985; 41: 57-61.

12 Aguilera D, Diab N, Faivre J-M: Influence of sodium dialysate variation on hemodynamic stability. Kidney Int 1988; 34: S187-S189.

13 Henrich WL, Woodard TD, Blachley JD, Gomez-Sanchez C, Pettinger W, Cronin RE: Role of osmolality in blood pressure stability after dialysis and ultrafiltration. Kidney Int 1980; 18: 480-488.

14 Schultze G, Maiga M, Neumayer H-H, Wagner K, Keller F, Molzahn M, Nigam S: Prostaglandin $\mathrm{E}_{2}$ promotes hypotension on low-sodium hemodialysis.

Nephron 1984: 37: 250-256. 
15 Leunissen KML. Kouw P, Kooman JP, Cheriex EC, de Vries PMM, Donker AMM, van Hooff JP: New techniques to determine fluid status in hemodialyzed patients. Kidney Int 1993; 43: $\$ 50-\$ 56$.

16 de Vries JPPM, Othof CG, Viosser $V$, Kouw PM, van Es A, Donker AJM, de Vries PMJM: Continuous measurement of blood volume during hemodialysis by an optical method. ASAIO Journal 1992; 38: M181-M185.

17 Wehle $B$, Asaba $H$, Castenfors $J$, Gunnarsson $B$, Bergström J: Influence of dialysate composition on cardiovascular function in isovolemic haemodialysis.

Proc EDTA 1981; 18: 153-159.

18 Daugirdas JT, Ing TS, Chen W-T, Vestal RE, Hano JE, Al-Kudsi RR: Ultrafiltration hemodynamics in conscious, uremic dogs: Effect of a decreasing plasma urea level. Mineral Electrolyte Metab 1985; 11: 79-84.

19 de Vries PMJM, Olthof CG, Solf A, Schuenemann B, Oe PL, Quellhorst E, Schneider H, Donker AJM: Fluid balance during haemodialysis and hacmofiltration: The effect of dialysate sodium and variable ultrafiltration rate.

Nephrol Dial Transplant 1991; 6: 257-263.

20 Kouw PM, Olthof CG, Gruteke P: Influence of high and low sodium dialysis on blood volume preservation. Nephrol Dial Transplant 1991; 6:876-880.

21. Henrich WL, Hunt JM, Nixon JV: Increased ionized calcium and left ventricular contractility during hemodialysis. $\mathbb{N}$ Engl I Med 1984; 31.0: 19-23.

22 Schultze G, Wagner K, Neumayer HH, Fizner R, Molzahn M: Effect of dialyzer membranes on in vitro generation of eicosanoids.

Int J Artif Organs 1987; 10: 275-278.

23 Mahiout A, Jörres A, Hiss R, Meinhold H, Kessel M: Effects of blood-dialyzer interaction on prostaglandins in uremic patients and in healthy man.

Nephrol Dial Transplant 1987; 2: 546-550.

24 Leunissen KML, van den Berg BW, wan Hooff IP: Ionized calcium plays a pivotal role in controlling blood pressure during haemodialysis.

Blood Purif 1989; 7: 233-239.

25 Henderson LW, Koch KM, Dinarello CA. Shaldon S: Hemodialysis hypotension: The interleukin-1 hypothesis. Blood Purif 1983; 1: 3-8. 


\section{Chapter 4}

\section{Vascular reactivity during}

combined ultrafiltrationhemodialysis: influence of dialysate derived contaminants

WHM van Kuijk, WA Buurman, PGG Gerlag, KML Leunissen

(submitted for publication) 


\section{Abstract}

\section{Background}

Hemodynamic instability and impaired vascular reactivity during combined ultrafiltrationhemodialysis have been suggested to be related to bioincompatibility factors such as dialysate derived contaminants or the dialyzer. In the present study it was investigated whether vascular reactivity could be improved by the use of sterile dialysate.

\section{Methods}

Forearm vascular resistance and venous tone (strain-gauge plethysmography) as well as arterial blood pressure (Dinamap) and heart rate (EKG) were measured in ten stable dialysis patients (28-71 years) during two hours combined ultrafiltration-hemodiallysis (bicarbonate, UF-rate $1.0 \mathrm{l} / \mathrm{hr}$ ). In addition, a dialysate sample was obtained for culture and LAL testing while blood was withdrawn for the estimation of plasma Bactericidal/Permeability Increasing Factor (BPI, ELISA) and the soluble TNF receptor p75 (sTNF-Rp75, ELIBA). Patients served as their own control, comparing dialysis with non-sterile and sterile dialysate.

\section{Results}

We observed no bacterial growth in sterile dialysate while all samples were positive in culture in non-sterile dialysis (Pseudomonas). All LAL tests were negative. BPI tended to increase during non-sterile dialysis $(p=0.063)$ and remained unchanged during sterile dialysis. In both treatments TNF-Rp75 increased significantly $(\mathrm{p}<0.01)$. There were no significant differences in hemodynamic parameters between the treatment modalities. Despite use of sterile dialysate, forearm vascular resistance remained unchanged while venous tone decreased significantly.

\section{Conclusion}

We conclude that vascular reactivity during combined ultrafiltration-hemodialysis is not improved by the use of sterile dialysate. 


\section{Introduction}

One of the main goals of dialysis therapy is withdrawal of excess fluid by ultrafiltration which might result in hemodynamic instability with symptomatic hypotension under certain conditions. When blood volume decreases, blood pressure stability is especially dependent on an adequate increase in peripheral vascular tone. In this respect, fluid withdrawal during isolated ultrafiltration and hemofiltration has been shown to result in an adequate increase in peripheral vascular tone while in contrast, peripheral vascular reactivity is impaired during combined ultrafiltration-hemodiallysis ${ }^{1,2}$. A number of factors such as differences in plasma osmolality, acid-base status or the extracorporeal blood temperature have been suggested to be responsible for these differences in vascular reactivity of which the latter seems to be most important ${ }^{3-6}$.

Henderson and colleagues hypothesized in their "Interleukin Hypothesis" that hemodynamic instability during combined ultrafiltration-hemodialysis could be related to the release of cytokines by blood mononuclear cells after stimulation by pyrogenic materials derived from dialysate or as a result of complement activation due to bioincompatibility of the dialyzer. Better hemodynamic stability as observed during isolated ultrafiltration and hemofiltration would then reflect the absence of dialysate (and contaminants) in both treatment modalities and the use of more biocompatible membranes in $\mathrm{HF}^{7}$. In this respect, dialysate contaminants are now considered to be the most important bioincompatibility factor ${ }^{8.9}$ while most dialysis membranes have been shown to be permeable for pyrogens derived from dialysate ${ }^{10,11}$. Conflicting data exist whether plasma cytokine levels increase during dialysis $^{12-14}$. However, monocytes have been shown to be stimulated by a single dialysis treatment in which dialysate derived pyrogens play an essential role.1.15. Concerning hemodynamic instability, Beasly et al. have proposed a possible role for cytokine-induced activation of nitric oxide synthesis within vascular smooth muscle cells ${ }^{16}$.

However, the clinical importance of dialysate derived contaminants with respect to hemodynamics remains to be established. In the present study therefore, we investigated whether impaired vascular reactivity as observed during combined ultrafiltration-hemodialysis could be improved by the use of pyrogen free dialysate. 


\section{Subjects and methods}

\section{Subjects and dialysis}

All patients signed an informed consent for participation in the study that had been approved by the Ethics Committee of the St. Joseph Hospital Veldhoven. Two women and eight men on intermittent hemodialysis were included with a mean age of 51 years (range 28-71) and a mean time on hemodialysis of 99 months (range 15-260). All patients were hemodynamically stable patients who rarely suffered from intradialytic hypotension. Exclusion criteria were severe coronary (NYHA II or more) or valvular heart disease, compromised left ventricular function (ejection fraction $30 \%$ or less), diabetes mellitus and a donor kidney in situ. Patients were studied on the regular day of his or her dialysis schedule. By adjusting fluid intake, patients were instructed to achieve a pre-dialysis weight at about 2.0 kilograms above their dry-weight that was estimated by echography of the inferior caval vein $^{17}$. All vasoactive medication was stopped 48 hours before the study and the patients were not allowed to smoke or drink caffeine containing beverages during 12 hours preceding the study.

Each patient served as his or her own control and was studied during two standardised dialysis treatments of two hours combined ultrafiltration-hemodialysis (UF + HD) at an ultrafiltration rate of $11 / \mathrm{hr}$ using either non-sterile (NS UF + HD) or sterile dialysate (S UF $+H D$ ). The order of treatments was randomised. Non-sterile dialysate was routinely prepared from a liquid bicarbonate component while overnight the dialysis monitor (AK-100, Gambro, Sweden) was sterilised by heat disinfection. Sterile dialysate was prepared from a Bicart module while two $1.4 \mathrm{~m}^{2}$ Polyamide (U-7000) membranes were used for filtration of dialysate (AK-100 Ultra, Gambro, Sweden). Overnight, the monitor was sterilised with peracetic acid (Dialox, Seppic, France). In all treatments, a hemophane dialyzer (GFS-16, Gambro, Sweden) was used. The composition of dialysate was: sodium $1.41 \mathrm{mmol} / \mathrm{l}$, potassium $2.0 \mathrm{mmol} / \mathrm{l}$, calcium $1.75 \mathrm{mmol} / 1$, bicarbonate $34 \mathrm{mmol} / 1$, acetate $3 \mathrm{mmol} / \mathrm{l}$, magnesium $0.5 \mathrm{mmol} / 1$ and chloride $108 \mathrm{mmol} / 1$. The dialysate temperature was $37.5^{\circ} \mathrm{C}$. Blood flow was $250 \mathrm{ml} / \mathrm{min}$ and dialysate flow was 500 $\mathrm{ml} / \mathrm{min}$.

\section{Methods}

Before each dialysis treatment a sample of $250 \mathrm{ml}$ dialysate was obtained under aseptical conditions and directly transported to the laboratory for immediate microbiological analysis. Each sample was filtrated through $0.45 \mathrm{~m} \mu$ microfilters. The microfilters were incubated for 3 days at $30^{\circ} \mathrm{C}$ on PCA-agar plates after which the number of colony forming units (CFU) per filter was estimated. In addition, 
samples of $5 \mathrm{ml}$ dialysate were obtained in pyrogen free tubes and directly frozen at $-20^{\circ} \mathrm{C}$ for LAL testing. LPS was measured with a chromogenic Limulus assay (Coatest endotoxin, Kabivitrum, Stockholm, Sweden) according to the manufacturer's instructions. The detection limit was $10 \mathrm{pg} / \mathrm{ml}$. In addition, data of routine cultures were used to estimate the bacterial content of $\mathrm{RO}$-water.

Before dialysis as well as at $t=30,60$ and 120 minutes, arterial afferent blood was obtained for the estimation of the plasma levels of Bactericidal/Permeability Increasing Factor (BPI) and the soluble TNF receptor p75 (sTNF-Rp75). Blood was withdrawn in ice-chilled tubes (EDTA) and immediately centrifuged. Plasma was obtained without disturbing the buffy-coat and stored at $-20^{\circ} \mathrm{C}$.

BPI was determined by sandwich ELISA using a human rBPI specific Mab 4E3, as described previously ${ }^{18}$. The sTNF-Rp 75 receptor was determined by an enzyme-linked immunological biological assay (ELIBA) using a mAb utr. $4^{19}$. The detection limits for BPI and STNF-Rp75 were respectively $100 \mathrm{pg} / \mathrm{ml}$ and 400 $\mathrm{pg} / \mathrm{ml}$.

Arterial blood pressure (BP) and heart rate (HR) were measured as described in chapter 3 while forearm vascular resistance (FVR) and venous tone (VT) were measured as described in chapter 2. The hand circulation was occluded from one minute before as well as during flow measurements. All hemodynamic measurements were performed before (pre-treatment) and every 20 minutes during dialysis.

Luminal blood temperatures were measured in the arterial and venous lines with needle thermometers (Hewlett-Packard $78214 \mathrm{C}$ temperature monitor). Connectors with a built-in adaptor were placed in the arterial and venous lines under sterile conditions at a distance of about 15 centimetres from the patient. There was no direct contact between blood and thermometer. Changes in relative blood volume (BV) were measured continuously and non-invasively by means of an optical reflection method which operates at a wavelength of $950 \mathrm{~nm}$. The optical sensor was clipped on the arterial line (Haemoguard 2000, Sanofi Sante) ${ }^{2 / 3}$. The baseline value was obtained after two minutes of extracorporeal circulation at a blood low of $250 \mathrm{ml} / \mathrm{min}$ without ultrafiltration to exclude the influence of saline (recirculation) present in the extracorporeal circuit at the start of dialysis.

Before as well as after two hours UF+HD, blood was withdrawn for the estimation of: sodium, potassium, total $\mathrm{CO}_{2}$, urea, osmolality (Wescor, vapour pressure osmometer) and colloid osmotic pressure (COP). In addition, blood was withdrawn in ice-chilled tubes and directly centrifuged at a temperature of $4^{\circ} \mathrm{C}$ for the estimation of plasma catecholamines (HPLC, fluorescence detection). 


\section{Statistical analysis}

Changes in hemodynamic parameters within each treatment as well as differences between treatments were analyzed by repeated measurements MANOVA (SPSS-PC version). If the sphericity of the variance-covariance matrix appeared to be violated, degrees of freedom in the univariate MANOVA tests were corrected by the Greenhouse-Geisser epsilon to avoid Type 1 error in testing the F-ratio. All laboratory parameters were analyzed by Friedmans ANOVA and if appropriate, by the Wilcoxon's signed-rank test.

\section{Results}

Samples obtained prior to S UF +HD showed no bacterial growth in culture with the exception of two samples. 4 colony forming units (CFU) were counted in both samples, identified as respectively Acinetobacter and Bacillus species. All dialysate samples were positive in culture in NS UF $+\mathrm{HD}$, identified as mainly Pseudomonas species. Due to confluence of colonies it was not possible to count the number of CFU in NS UF + HD reliably. All LAL tests were negative in both treatment modalities. RO-water contained $201 \pm 209$ CFU per $\mathrm{ml}(\mathrm{n}=30)$.

The immunological data are presented in figure 4.1a+b. Although not statistically significant, BPI tended to increase during NS UF + HD $(p=0.063$ at $\mathrm{t}=60 \mathrm{~min})$. In $\mathrm{S} U \mathrm{UF}+\mathrm{HD}, \mathrm{BPI}$ remained unchanged. The sTNF-Rp75 increased significantly in both treatments $(\mathrm{p}<0.01)$. There were no significant differences in BPI or sTNF-Rp75 between the two treatment modalities.

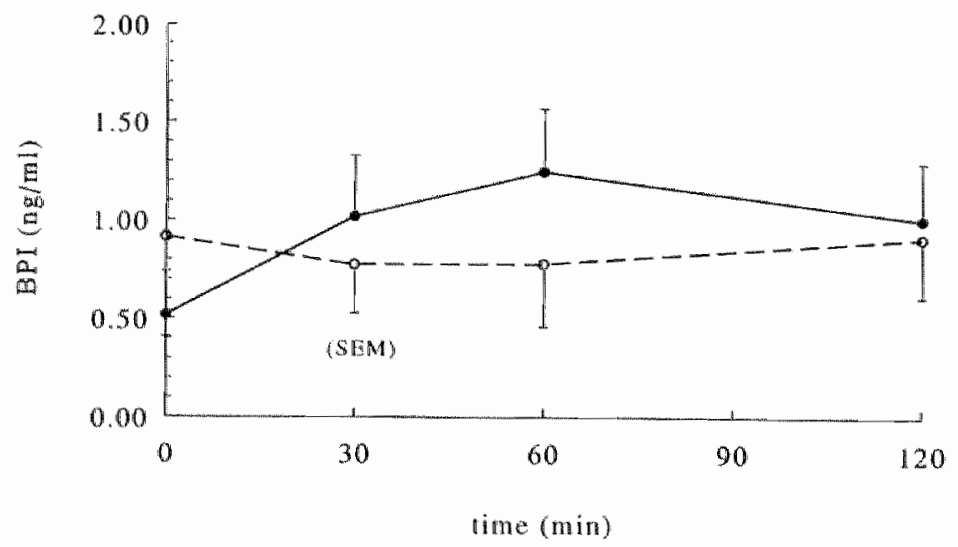

Figure 4.1a Plasma BPI during NS UF + HD $(-)$ and S UF+HD (- - ) 


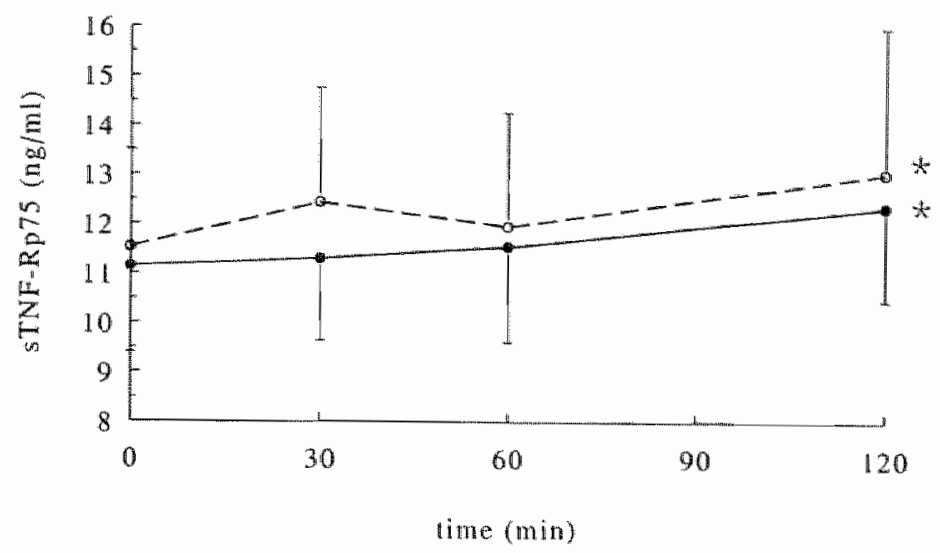

Figure 4.1b Plasma STNF-Rp75 during NS UF +HD (-) and S UF +HD (- - ); $*=\mathrm{p}<0.01$ as compared to pre-treatment level

The prediallysis weights in NS UF $+H D$ and $S$ UF $+H D$ were respectively $69.1 \pm 6.6 \mathrm{~kg}$ and $69.1 \pm 6.5 \mathrm{~kg}$ (ns). The hemodynamic data are presented in table 4.1 and figure $4.2 \mathrm{a}+\mathrm{b}$. Systolic BP decreased significantly in NS UF +HD $(-11 \pm 9$ mmHg, $\mathrm{p}<0.05)$ while diastolic and mean arterial $\mathrm{BP}$ remained unchanged. There were no significant changes in arterial $B P$ during $S U F+H D$. Heart rate increased significantly during both NS UF $+H D$ and $S U F+H D$ with respectively $6 \pm 8$ $(p<0.05)$ and $6 \pm 7(p<0.01)$ beats/min. Concerning vascular reactivity, FVR did not change significantly during both treatments. VT decreased significantly during NS UF + HD and S UF + HD with respectively $-2.4 \pm 3.6(\mathrm{p}<0.05)$ and $-3 . \| \pm 3.5$ $(p<0.01) \mathrm{mmHg} / \mathrm{ml} / 100 \mathrm{ml}$. There were no significant differences in hemodynamic parameters comparing NS-UF+HD with S UF+HD.

Table 4.1 Hemodynamic data

\begin{tabular}{|c|c|c|c|c|c|}
\hline & $\begin{array}{l}\text { NS UF + HD } \\
\text { pre }\end{array}$ & post & $\begin{array}{l}\text { SUF+HD } \\
\text { pre }\end{array}$ & posi & $\begin{array}{l}\text { changes } \\
\text { NS vs S }\end{array}$ \\
\hline Systolic BP & $151(16)$ & $141(11)^{3}$ & $149(18)$ & $144(14)$ & nis \\
\hline Diastolic $\mathrm{BP}$ & $84(8)$ & $85(9)$ & $82(10)$ & $84(11)$ & ins \\
\hline Mean Arterial BP & $111(13)$ & $108(9)$ & $110(16)$ & $105(12)$ & ns \\
\hline Heart Rate & $72(11)$ & $78(12)^{\mathrm{h}}$ & $74(13)$ & $80(14)^{\mathrm{n}}$ & ns \\
\hline FVYR & $2769(1300)$ & $3440(979)$ & $2819(1503)$ & $2993(700)$ & $n s$ \\
\hline $\mathrm{VT}$ & $17.5(5.5)$ & $15.2(3.9)^{\mathrm{b}}$ & $17.5(3.9)$ & $14.4(2.9)^{\mathrm{a}}$ & ns \\
\hline
\end{tabular}

BP (mmHg); HR (beats/min); FWR (mmHg/ml/100ml/sec); VT (mmHg/ml/100ml); post vs pre, ${ }^{*}=p<0.01, b=p<0.05$. 


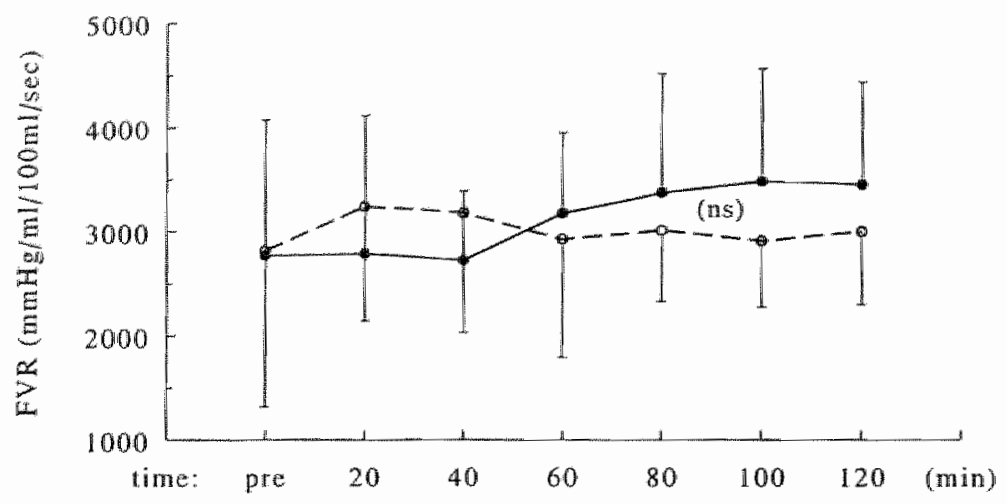

Figure 4.2a FVR during NS UF+HD (- - ) and $\mathrm{S} \mathrm{UF+HD(-.)}$

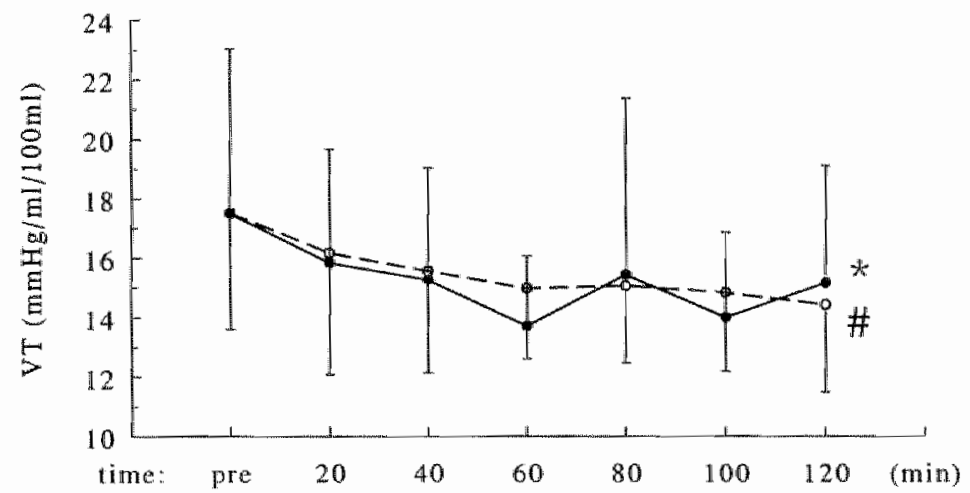

Figure 4.2b VT during NS UF+HD $(-$ and $S$ UF+HD $(-\cdots) ;=p<0.05$ $H=p<0.01$ as compared to pre-treament level

The laboratory data are presented in table 4.2 . Changes in the different laboratory parameters were comparable between NS UF+HD and S-UF+HD. Plasma adrenaline remained unchanged during both treatment modalities. During $\mathrm{NS}-\mathrm{UF}+\mathrm{HD}$, plasma noradrenaline increased significantly $(\mathrm{p}=0.050)$ while during $S-U F+H D$ the increase did not reach statistical significance $(p=0.059)$. Blood volume decreased respectively to $84 \pm 6$ and $86 \pm 7 \%$ (ns). 
Table 4.2 Laboratory data

\begin{tabular}{|c|c|c|c|c|c|}
\hline & $\begin{array}{l}\text { NS UF+HD } \\
\text { pre }\end{array}$ & post & $\begin{array}{l}\text { SUF+HD } \\
\text { pre }\end{array}$ & post & $\begin{array}{l}\text { changes } \\
\text { NS vs S }\end{array}$ \\
\hline Sodium & $137.7(2.5)$ & $140.2(1.6)^{a}$ & $138.1(2.1)$ & $139.4(1.8)^{\mathrm{b}}$ & ns \\
\hline Potassium & $5.7(0.6)$ & $4.2(0.4)^{\mathrm{A}}$ & $5.6(0.5)$ & $4.1(0.2)^{a}$ & $\mathrm{~ns}$ \\
\hline total $\mathrm{CO}_{2}$ & $21.7(2.4)$ & $24.3(2.1)^{a}$ & $21.7(3.0)$ & $24.3(1.8)^{\mathrm{a}}$ & ns \\
\hline Urea & $22.7(4.9)$ & $11.3(3.4)^{\mathrm{a}}$ & $23.4(2.8)$ & $11.6(2.2)^{3}$ & ns \\
\hline Osmolaliby & $300.7(10.1)$ & $289.6(8.4)^{\mathrm{a}}$ & $298.4(7.1)$ & $287.6(7.8)^{3}$ & $\mathrm{~ns}$ \\
\hline $\mathrm{COP}$ & $3.4(0.3)$ & $4.2(0.5)^{a}$ & $3.4(0.3)$ & $4.1(0.6)^{\mathrm{a}}$ & ns \\
\hline Noradrenaline & $1.84(0.62)$ & $2.15(0.58)^{b}$ & $1.74(0.76)$ & $1.99(0.57)$ & ns \\
\hline Adrenaline & $0.18(0.08)$ & $0.18(0.12)$ & $0.19(0.08)$ & $0.17(0.09)$ & ns \\
\hline
\end{tabular}

Sodium, Potassium, total $\mathrm{CO}_{2}$ and Urea (mmol/); Osmolality $(\mathrm{mOsm} / \mathrm{kg}) ; \mathrm{COP}(\mathrm{kPa}) ;$ Catecholamines (molld); post vs pre, ${ }^{*}=p<0.01$ and ${ }^{b}=p<0.05$

The blood temperatures are presented in figure $4.3 \mathrm{a}+\mathrm{b}$. The extracorporeal blood temperatures were comparable with no significant changes during either treatment.

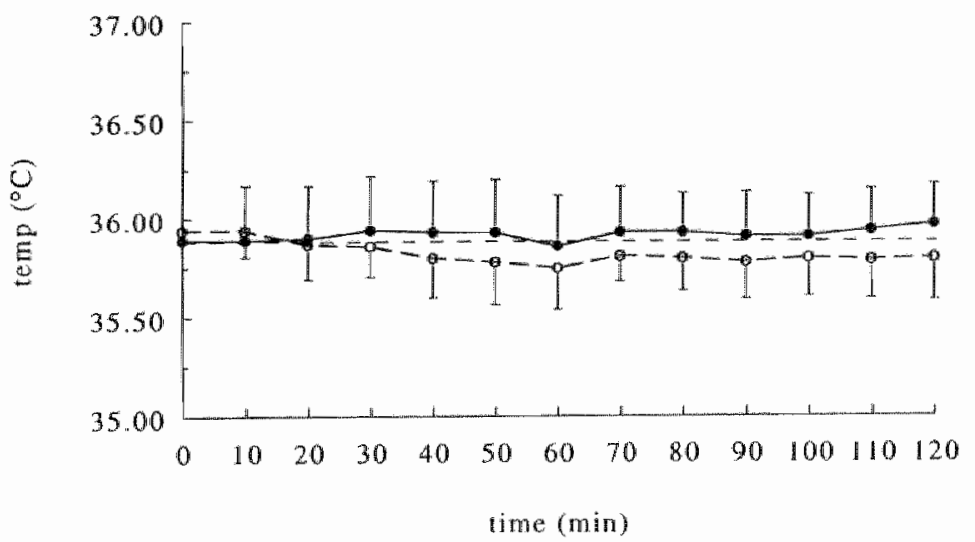

Figure 4.3a Arterial (- $\longrightarrow$ and venous ( . . - ) blood temperature during NS UF $+\mathrm{HD}$ 


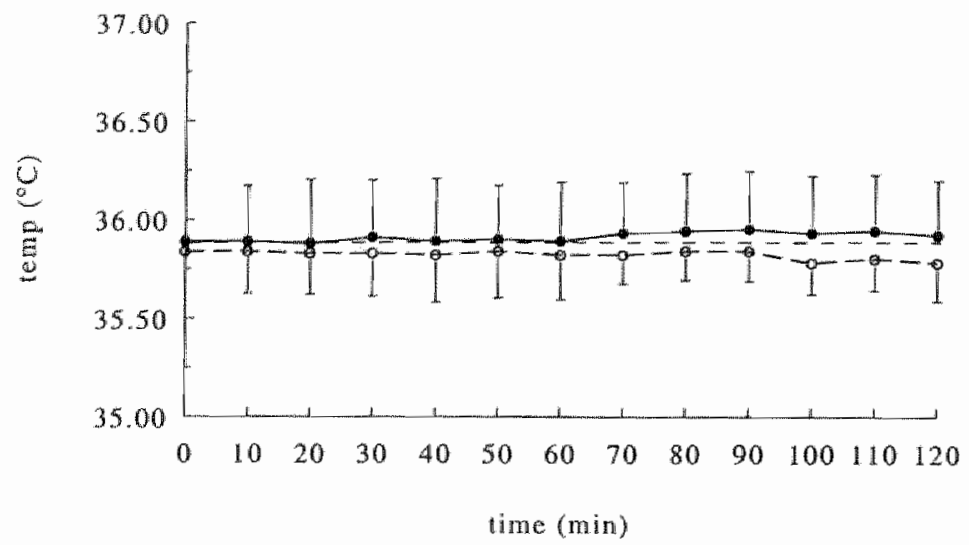

Figure 4.3b Arterial ( - ) and venous (. . . ) blood temperanure during S UF + HD

\section{Discussion}

To study the role of bacteriological contamination of dialysate in the hemodynamic response during dialysis it was investigated whether vascular reactivity during UF + HD could be improved by the use of sterile dialysate. The main conclusion of our results is that both arteriolar and venous reactivity during UF $+H D$ are not improved when sterile dialysate is used.

Ultrapure dialysate was prepared by ultrafiltration of dialysate through two polyamide membranes. The physicochemical characteristics of this hydrophyllic membrane have been shown to completely remove pyrogenic, cytokine-inducing substances from dialysate ${ }^{21.22}$. In agreement, only two out of ten cultures were positive in S UF + HD with a very low count of CFU while all LAL tests were negative. Identification as Acinetobacter and Bacillus species of these two posirive samples is highly suggestive for secondary contamination. Whereas it was not possible to count the number of CFU reliably, samples obtained in NS-UF+HD were all positive in culture with Pseudomonas species being the most dominant genus, present in all samples. Based on the number of CFU in RO-water, at least $200 \mathrm{CFU}$ per $\mathrm{ml}$ can be expected in dialysate. Although all LAL tests were negative in NS UF+HD, presence of pyrogens other than LPS or lipid A that might pass the dialysis membrane such as LPS fragments, peptidoglycans and muramylpeptides is not excluded ${ }^{10}$. A possibility that is excluded in $S$ UF $+H D$ since monocytes in culture are not stimulated by contaminated dialysate after 
filtration of dialysate through polyamide membranes ${ }^{22}$. Moreover, exposition to pyrogens in NS UF +HD is further suggested by a trend towards an increase in BPI which remained unchanged during S UF+HD. In agreement, Schindler et al. have found an increase in BPI during dialysis with either a cuprophane or polysulfone dialyzer. The microbiological contamination of dialysate in their study varied between 20-150 CFU per $\mathrm{ml}^{2 ?}$.

Since the sTNF-Rp75 increased significantly during both treatment modalities stimuli other than pyrogens such as the dialysis membrane could play a role in the release of the sTNF-Rp75 from mononuclear and endothelial cells during dialysis.

Hemodynamics were measured under strictly standardised conditions with comparable pre-dialysis weights and changes in relative blood volume. In addition, changes in laboratory parameters as well as in extracorporeal blood temperature were also comparable. Only in NS UF +HD, the decrease in systolic blood pressure reached statistical significance. However, there were no significant differences in either arterial blood pressure, heart rate or vascular reactivity between NS UF + HD and S UF + HD. Despite the use of sterile dialysate UF+HD was still associated with a decrease in VT while FVR remained unchanged. In addition, HR increased. In previous studies comparable hemodynamic responses have been observed in UF +HD using non-sterile dialysate which contrasts with a clear increase in peripheral vascular tone as observed during hemofiltration and isolated ultrafiltration ${ }^{1,2.6}$. Consequently, our results show that moderate dialysate contamination is not responsible for the impaired vascular response during $\mathrm{UF}+\mathrm{HD}$ as compared to hemofiltration and isolated ultrafiltration. We can however not completely exclude the possibility that high levels of dialysate contamination might lead to a further impairment of the vascular response in $\mathrm{UF}+\mathrm{HD}$. 


\section{References}

1 Baldamus CA, Enst W, Frei U, Koch.KM: Sympathetic and hemodynamic response to volume removal during different forms of renal replacement therapy. Nephron 1982; 31: 324-332.

2 Kooman JP, Gladziwa U, Böcker G, van Bortel LMAB, van Hooff JP, Leunissen KML: Role of the venous system in hemodynamics during ultrafiltration and bicarbonate dialysis. Kidney Int 1992; 42: 718-726.

3 Daugirdas JT: Dialysis hypotension: A hemodynamic analysis.

Kidney Int 1991; 39: 233-246.

4 Henrich WL, Woodard TD, Blachley JD, Gomez-Sanchez C, Pettinger W, Cronin RE: Role of osmolality in blood pressure stability after dialysis and ultrafiltration. Kidney Int 1980; 18: 480-488.

5 Maggiore Q, Pizzarelli F, Sisca S, Zoccalli $C_{n}$ Parlongo S, Nicolò F, Creazzo G: Blood temperature and vascular stability during hemodialyis and hemofiltration Trans Am Soc Artif Intern Organs 1982; 28: 523-527.

6 van Kuijk WHM, Luik.AJ, de Leeuw PW, van Hooff JP, Nieman FHM, Habets HML, Leunissen KML: Vascular reactivity during hemodialysis and isolated ultrafiltration: thermal influences. Nephrol Dial Transplant 1995; (in press).

7 Henderson LW, Koch KM, Dinarello CA, Shaldon S: Hemodialysis hypotension: The interleukin-1 hypothesis. Blood Purif 1983; 1: 3-8.

8 Schindler S, Lonneman G, Shaldon S, Koch KM, Dinarello CA: Transcription, not synthesis, of interleukin-1 and tumor necrosis factor by complement.

Kidney Int 1990; 37: 85-93.

9 Colton CK, Ward RA, Shaldon S: Scientific basis for assessment of biocompatibility in extracorporeal blood treatment. Nephrol Dial Transplant 1994; 9: 11-17.

10 Lonnemann G: Dialysate bacteriological quality and the permeability of dialyzer inembranes to pyrogens. Kidney Int 1993; 43: S195-S200.

11 Laude-Sharp M. Caroff M, Simard L, Pusineri C, Kazatchkine MD, HaeffnerCavaillon N: Induction of IL-1 during hemodialysis: transmembrane passage of intact endotoxins. Kidney [nt 1990; 38: 1089-1094.

12 Herbelin A, Nguyen AT, Zingraff J, Ureña $\mathbf{P}$, Descamps-Latscha B: Influence of uremia and hemodialysis on circulating interleukin- 1 and turnor necrosis factor $\alpha$. Kidney Int 1990; 37: 116-125

13 Tetta C, Camussi G, Turello E, Salomone M, Aimo G, Priolo G, Segoloni G, Vercellone A: Production of cytokines in hemodialysis.

Blood Purif 1990; 8: 337-346.

14 Bingel $M$, Lonnemann G, Koch KM, Dinarello CA, Shaldon S: Plasma interleukin1 during hemodialysis: the influence of dialysis membranes.

Nephron 1988; 50: 273-276. 
15 Haeffner-Cavaillon $\mathbb{N}$, Cavaillon J-M, Ciancioni C, Bacle F, Delons S, Kazatchkine MD: In vivo induction of interleukin-1 during hemodialysis.

Kidney Int 1989; 35: 1212-1218.

16 Beasly D, Bremer BM: Role of nitric oxide in hemodialysis hypotension.

Kidney Int 1992; 42: S96-S100.

17 Leunissen KML, Kouw P, Kooman JP, Cheriex EC de Vries PMJM, Donker AMM, van Hooff JP: New techniques to determine fluid status in hemodialyzed patients. Kidney Int 1993; 43: S50-S56.

18 Dentener MA, Francot GMM, Smit FT, Froon AHM, Pennings H-J, Wouters FFM, Buurman WA: Presence of bactericidal/permeability-increasing protein in disease: detection by ELISA. J Infect Dis 1.995; 171: 739-743.

19 Leeuwenberg JFM, Mat O, Abramowicz D, Gastaldello R, Tielemans $C$, Bumman WA: Increased plasma levels of soluble tumor necrosis factor-receptors in uraemic patients: effects of dialysis, type of membrane, and anticoagulation method.

Nephrol Dial Transplant 1994; 9: 1125-1129.

20 de Vries JPPM, Olthof CG, Viosser V, Kouw PM, van Es A, Donker AJM, de Vries PMJM: Continuous measurement of blood wolume during hemodialysis by an optical method. ASAIO Journal 1992; 38: M181-M185.

21 Lonnemann G, Mahiout A, Schindler R, Colton CK: Pyrogen retention by the polyamide membranes. Contrib Nephrol 1992; 96:47-63.

22 Di Fellice A, Cappelli G, Facchini F, Tetta C, Cornia F, Aimo G, Lusvarghi E: Ultrafiltration and endotoxin removal from dialysis fluids.

Kidney Int 1993; 43: S201-\$204.

23 Schindler R, Marra MN, McKelligon BM, Lonnemann G, Schulzeck P, Schulze M, Oppermann $M$, Shaldon $S$ : Plasma levels of bactericidal/permeability-increasing protein (BPI) and lipopolysaccharide-binding protein (LBP) during hemodialysis. Clin Nephrol 1993; 40: 346-351. 


\section{Chapter 5}

\section{Influence of changes in ionized calcium on cardiovascular reactivity during hemodialysis}

WHM van Kuijk, AW Mulder, CH Peels, GA Harff, KML Leunissen

(submitted for publication) 


\section{Abstract}

\section{Background}

In order to prevent hypercalcemia due to the treatment of secondary hyperparathyrodism it is advocated to use low-calcium dialysate. However, as calcum ions play a pivotal role in both myocardial and vascular smooth muscle contraction, lowering the dialysate calcium concentration might result in a further impaiment of the cardiovascular response during dialysis.

\section{Methods}

Therefore, arterial blood pressure, forearm vascular resistance (FVR) and venous tone (VT) (strain-gauge plethysmography) as well as cardiac dimensions and output (echocardiography) were measured in 10 hemodynamically stable dialysis patients (ejection fraction $>30 \%$ ) during two standardised sessions of three hours combined ultrafiltration-hemodialysis (UF $+H D$ ) at two different dialysate calcium concentrations: 1.25 and $1.75 \mathrm{mmol} / \mathrm{l}$.

\section{Results}

High-calcium UF $+H D$ resulted in a significant increase in plasma ionized calcium $(* 0.19 \pm 0.11 \mathrm{mmol} / \mathrm{l} ; \quad p<0.01)$ while ionized calcium remained unchanged during low-calcium UF +HD $(-0.02 \pm 0.07 \mathrm{mmol} / \mathrm{l})$. As a result, systolic, diastolic and mean arterial blood pressure were respectively $14 \pm 10,5 \pm 7$ and $9 \pm 9 \mathrm{mmHg}$ higher during high-calcium $U F+H D$ as compared to low-calcium UF $+H D(p<0.05)$. There were no significant differences in both FVR and VT between the two treatments. During both treatments FVR increased while VT decreased. In addition, there were no differences in calculated systemic vascular resistance. However, with comparable end-diastolic dimensions, stroke volume $(-18 \pm 13 \mathrm{ml})$ and cardiac output $(-1.3 \pm 1.5 \mathrm{l} / \mathrm{min})$ decreased significandly $(p<0.05)$ only during low-calcium UF $+H D$.

\section{Conclusions}

We conclude that even in hemodynamically slable patients changes in plasma ionized calcium are an important determinant of the blood pressure response during dialysis therapy. Whereas peripheral vascular reactivity is unaffected by changes in ionized calcium, myocardial contractility is improved with higher dialysate calcium concentrations. 


\section{Introduction}

Despite a growing understanding of the underlying pathophysiology, hemodynamic instability with symptomatic hypotension is still one of the most important complications occurring during dialysis therapy. In addition to the patient's cardiovascular status and changes in intravascular volume, hemodynamic stability is also related to the cardiovascular response during dialysis therapy. The importance of the latter factor is illustrated by the fact that on the basis of a more physiological increase in peripheral vascular tone, hemodynamic stability is better during hemofiltration as compared to combined ultrafiltration-hemodialysis ${ }^{2,3}$.

With calcium ions playing a pivotal role in the contractile process of both vascular smooth muscle cells and cardiac myocytes as well as in the release of catecholamines from the synaptic cleft, changes in ionized calcium might play an important role in the cardiovascular response during dialysis. Different authors have indeed found a correlation between changes in ionized calcium and blood pressure during dialysis, with differences in myocardial contractility being the most consistent finding ${ }^{4-8}$. However, it is unknown whether vascular reactivity is also related to changes in ionized calcium. Knowledge about the role of changes in ionized calcium in both blood pressure and cardiovascular responses seems to be especially important as it is advocated to use lower dialysate calcium concentrations in order to prevent or treat hypercalcemia due to the treatment of secondary hyperparathyroidism.

In the present study therefore, blood pressure and both vascular and cardiac reactivity were measured during combined ultrafiltration-hemodialysis at two different dialysate calcium concentrations in the first place to study the influence of changes in plasma ionized calcium on vascular reactivity and secondly to investigate the clinical importance with respect to arterial blood pressure of lowering the dialysate calcium concentration.

\section{Subjects and methods}

\section{Subjects and dialysis}

After obtaining informed consent, two women and eight men on intermittent lhemodialysis were included with a mean age of 47 years (range 25-73) and a mean time on hemodialysis of 64 months (range 6-276). All patients were hemodynamically stable patients who rarely suffered from intradialytic hypotension. Exclusion criteria were severe coronary (NYHA II or more) or valvular heart disease, compromised left ventricular function (ejection fraction $30 \%$ or less) and diabetes mellitus. Patients were studied on the regular day of his or her dialysis 
schedule. By adjusting fluid intake, patients were instructed to achieve a pre-dialysis weight between 2.0 and 3.0 kilograms above their dry-weight that was estimated by echography of the inferior caval vein ${ }^{9}$. All vasoactive medication was stopped 48 hours before the study while patients were not allowed to smoke or drink caffeine containing beverages during 12 hours preceding to the study.

With each patient serving as his or her own control, measurements were performed during two standardised sessions of three hours combined ultrafiltrationhemodialysis that only differed in the dialysate calcium concentration: 1.25 and $1.75 \mathrm{mmol} / \mathrm{l}$. Dialysis was performed with a Monitral-S dialysis monitor (Hospal, France) using hemophane membranes (GFS-16, Gambro, Sweden) in all treatments. The composition of dialysate was: sodium $141 \mathrm{mmol} / 1$, potassium 2.0 $\mathrm{mmol} / \mathrm{l}$, calcium 1.25 or $1.75 \mathrm{mmol} / \mathrm{l}$, bicarbonate $34 \mathrm{mmol} / 1$, acetate $3 \mathrm{mmol} / \mathrm{l}$, magnesium $0.5 \mathrm{mmol} / \mathrm{l}$ and chloride $108 \mathrm{mmol} / 1$. The dialysate temperature was $37.5^{\circ} \mathrm{C}$. Blood flow was $250 \mathrm{ml} / \mathrm{min}$ and dialysate flow was $500 \mathrm{ml} / \mathrm{min}$.

\section{Methods}

Forearm vascular resistance (FVR) and venous tone (VT) were measured as described in chapter 2 . The hand circulation was occluded from one minute before as well as during flow measurements. Arterial blood pressure (BP) and heart rate (HR) were measured as described in chapter 3. Measurements were performed before dialysis and every 30 minutes during dialysis.

Before as well as immediately after dialysis, an echocardiogram was obtained (Hewlett-Packard, Sonos 1000, Andover, MA, USA) with the patient in the left lateral decubitus position using a $2.5 \mathrm{mHz}$ phased array transducer for both imaging and Doppler studies. Left ventricular end-systolic (LVESD, mm) and end-diastolic (LVEDD, $\mathrm{mm}$ ) dimensions were measured on M-mode and two-dimensional echo. The diameter of the left ventricular outflow tract (LVOT) was measured at the aortic annulus in the parasternal long axis view. The LVOT area was calculated assuming circular geometry [LVOT area $\left.=3.14(\mathrm{D} / 2)^{2}\right]^{\mathrm{n}}$. Using pulsed wave Doppler, flow was measured in the LVOT area at the annular level just proximal from the point where aortic leaflet artifacts were observed ${ }^{11}$. By measuring the area under the curve, the mean systolic velocity integral (SVI) was calculated from 3 consecutive cycles. Left ventricular stroke volume ( $\mathrm{SV}, \mathrm{ml}$ ) was calculated from multiplying the LVOT area with SVI. Cardiac output (CO, $1 / \mathrm{min}$ ) was calculated from SV and heart rate. Systemic vascular resistance (SVR, dyne $/ \mathrm{sec} / \mathrm{cm}^{-5}$ ) was calculated from CO and MAP (SVR $=$ MAP/CO x 80). Both temporal and intra-observer variability of flow measurements using the non-invasive Doppler method have been shown to be sufficiently small for the method to be useful in serial hemodynamic measurements ${ }^{10.12}$. 
Changes in relative blood volume (BV) were measured continuously and non-invasively by means of an optical reflection method which operates at a wavelength of $950 \mathrm{~nm}$. The optical sensor was clipped on the arterial line (Haemoguard 2000, Sanofi Sante, The Netherlands)" The baseline value was obtained after two minutes of extracorporeal circulation at a blood flow of 250 $\mathrm{ml} / \mathrm{min}$ without ultrafiltration to exclude the influence of saline (recirculation) present in the blood lines at the start of dialysis.

Before as well as after three hours UF +HD, blood was withdrawn for the estimation of: sodium, potassium, total $\mathrm{CO}_{2}$, urea, osmolality (Osmomat 30, Gonotec, Berlin, Germany) and colloid osmotic pressure. In addition, blood was withdrawn in ice-chilled tubes and directly centrifuged at a temperature of $4^{\circ} \mathrm{C}$ for the estimation of plasma catecholamines (HPLC, fluorescence detection). Plasma ionized calcium was estimated at pre-dialysis as well as every hour during dialysis (Stat profile 6, NOVA biomedical, Waltham, MA, U.S.A.).

\section{Statistical analysis}

Changes in hemodynamic parameters within each treatment as well as differences between treatments were analyzed by repeated measurements MANOVA (SPSS-PC version). If the sphericity of the variance-covariance matrix appeared to be violated, degrees of freedom in the univariate MANOVA tests were corrected by the Greenhouse-Geisser epsilon to avoid Type 1 error in testing the F-ratio. All laboratory parameters were analyzed by Friedmans ANOVA and if appropriate, by the Wilcoxon's signed-rank test. All values are expressed as mean \pm SD.

\section{Results}

The pre-dialysis weights in low- and high-calcium UF+HD were respectively $70.7 \pm 10.7$ and $70.8 \pm 10.6 \mathrm{~kg}(\mathrm{p}=0.13)$. The mean UF-rate was $0.79 \pm 0.10 \mathrm{l} / \mathrm{hr}$ in both treatment modalities. The laboratory data are shown in table 5.1 and figure 5.1. Plasma ionized calcium remained unchanged during low-calcium UF $+H D$ $(-0.02 \pm 0.07 \mathrm{mmol} / 1)$ whereas it increased significantly during high-calcium UF + HD $(+0.19 \pm 0.11 \mathrm{mmol} / \mathrm{l})$. As a result, ionized calcium was significantly higher during the latter treatment as compared to low-calcium UF+HD. All other laboratory parameters as well as relative blood volume changed comparably during both treatments. Plasma adrenaline remained also unchanged during both treatment modalities. However, plasma noradrenaline increased significantly only during high-calcium UF $+\mathrm{HD}$. As compared to low-calcium UF+HD $(+0.37 \pm 0.74$ nmol/l) the increase in plasma noradrenaline was significantly larger during 
high-calcium UF $+\mathrm{HD}(+0.70 \pm 0.53 \mathrm{nmol} / \mathrm{l})$. Relative $\mathrm{BV}$ decreased to $86 \pm 4$ and $85 \pm 5 \%$ in respectivelly low- and high-calcium UF $+H D$ (ns).

Table 5. I Laboratory data

\begin{tabular}{|c|c|c|c|c|c|}
\hline & \multicolumn{2}{|c|}{ Calcium 1.25 mmol/1 } & \multicolumn{2}{|c|}{ Calcium $1.75 \mathrm{mmmol} / \mathrm{l}$} & \multirow{2}{*}{$\begin{array}{l}\text { changes } \\
1.25 \text { vs } 1.75\end{array}$} \\
\hline & pre & posit & pre & post & \\
\hline ionrzed Calcium & $1.13(0.15)$ & $1.11(0.11)$ & $1.13(0.16)$ & $1.33(0.15)^{a}$ & $<0.001$ \\
\hline Sodium & $137.3(1.5)$ & $138.2(2.4)$ & $137.0(3.4)$ & $136.2(3.7)$ & ns \\
\hline Potassium & $5.0(0.8)$ & $3.5(0.3)^{m}$ & 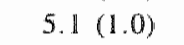 & $3.6(0.3)^{4}$ & ns \\
\hline total $\mathrm{CO}_{2}$ & $23.3(2.9)$ & $28.3(1.8)^{2}$ & $23 . \Downarrow(3.5)$ & $28.2(1.7)^{a}$ & ns \\
\hline Urea & $24.2(5.0)$ & $10.0(2.7)^{\mathrm{ii}}$ & $25.5(5.8)$ & $10.4(3.0)^{\mathrm{a}}$ & $\mathrm{ns}$ \\
\hline Osmolality & $309.0(5.4)$ & $291.9(8.1)^{\mathrm{j}}$ & $308.1(12.7)$ & $292.1(9.6)^{9}$ & nis \\
\hline COP & $3.4(0.6)$ & $4.2(0.6)^{8}$ & $3.3(0.4)$ & $4.2(0.6)^{3}$ & ns \\
\hline Noradrenaline & $1.84(0.61)$ & $2.22(0.81)$ & $1.71(0.60)$ & $2.41(0.78)^{\mathrm{A}}$ & 0.037 \\
\hline Adrenaline & $0.23(0.12)$ & $0.43(0.70)$ & $0.18(0.07)$ & $0.28(0.19)$ & ns \\
\hline
\end{tabular}

ionized Calcium, Sodium, Potassium, total $\mathrm{CO}_{2}$ and Urea (mmol/l); Osmolality (mOsm/kg); $\operatorname{COP}(\mathrm{kPa})$; Catecholamines (nmol/l); post vs pre, ${ }^{\mathrm{a}}=\mathrm{p}<0.01$.

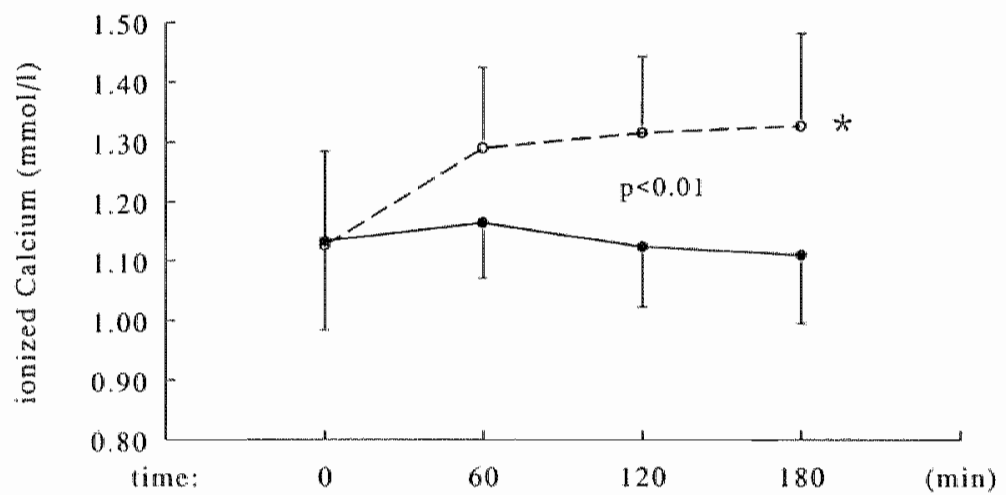

Figure 5.1 Plasma ionized calcimm during low (- - $)$ and high (- - ) calcium $\mathrm{UF}+\mathrm{HD} ; * \mathrm{p}<0,01$ as compared to pre-ireatment level

The data on blood pressure and vascular reactivity are shown in table 5.2 and figure $5.2 \mathrm{a}-\mathrm{c}$. During low-calcium $\mathrm{UF}+\mathrm{HD}$, both systolic and mean arterial $\mathrm{BP}$ decreased significantly while there were no significant changes in the different BP parameters during high-calcium UF+HD. Moreover, both systolic and diastolic as 
well as mean arterial BP were significantly lower during low-calcium UF $+\mathrm{HD}$ as compared to high-calcium UF+HD. After 3 hours UF $+H D$, the differences were respectively $14 \pm 10,5 \pm 7$ and $9 \pm 9 \mathrm{mmHg}$. HR increased significantly and comparably during both low- and high-calcium UF + HD. Concerning vascular reactivity, there were no significant differences in both FVR and VT between لowand high-calcium UF +HD. During both treatments, FVR increased significantly whereas VT decreased significantly.

Table 5.2 Hemodynamic data: blood pressure and vascular reactivity

\begin{tabular}{|c|c|c|c|c|c|}
\hline & \multicolumn{2}{|c|}{ Calcium $1.25 \mathrm{mmol} / 1$} & \multicolumn{2}{|c|}{ Calcium $1.75 \mathrm{mmol} / 1$} & \multirow{2}{*}{$\begin{array}{l}\text { changes } \\
1.25 \vee \mathrm{v} 1.75\end{array}$} \\
\hline & pre & post & pre & post & \\
\hline Systolic BP & $139(20)$ & $121(18)^{a}$ & $140(26)$ & $135(19)$ & 0.010 \\
\hline Diastolic BP & $8(12)$ & $77(13)$ & $81(12)$ & $82(11)$ & 0.022 \\
\hline Mean Arterial BP & $105(16)$ & $96(18)^{6}$ & $105(19)$ & $105(16)$ & 0.021 \\
\hline Heart $\mathbb{R}$ ate & $69(7)$ & $79(10)^{\mathrm{a}}$ & $69(10)$ & $77(13)^{\mathrm{a}}$ & mis \\
\hline FVR & $1626(729)$ & $2480(1205)^{a}$ & $1555(826)$ & $2365(1226)^{\mathrm{b}}$ & ins \\
\hline$V_{T}$ & $16.9(4.6)$ & $14.7(50)^{\mathrm{h}}$ & $16.6(4.5)$ & $14.3(4.0)^{4}$ & ns \\
\hline
\end{tabular}

BP (mmHg), $\mathbb{H R}$ (beats $/ \mathrm{min})$, FVR $(\mathrm{mmHg} / \mathrm{ml} / 100 \mathrm{ml} / \mathrm{sec}), V T$ ( $\mathrm{mmHg} / \mathrm{m} / 100 \mathrm{ml})$; post vs pre, ${ }^{\mathrm{a}}=\mathrm{p}<0.011^{\mathrm{a}}=<0.05$.

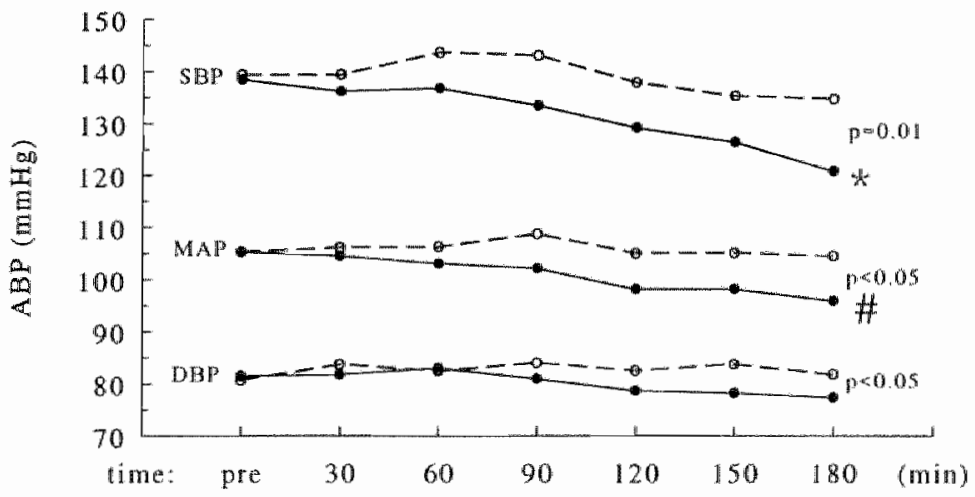

Figure 5.2a Arrerial $\mathrm{BP}$ during low (-) and high (- -) calcium UF +HD

$*=\mathrm{p}<0.01, \#=\mathrm{p}<0.05$ as compared to pre-mreatment level 


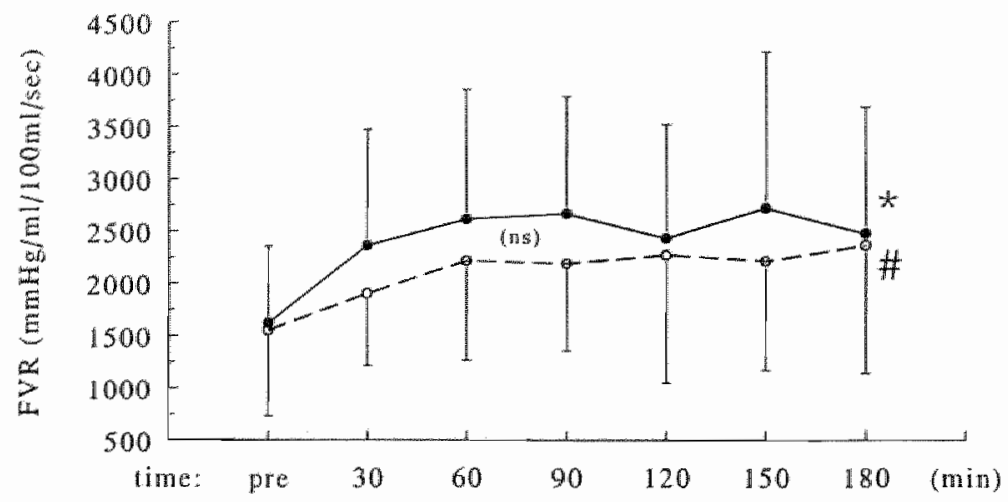

Figure 5.2b FVR during low $(-)$ and high $(\ldots)$ calcium UF $+H D ; *=p<0.01$, $H=p<0.05$ as compared to pre-treatment level

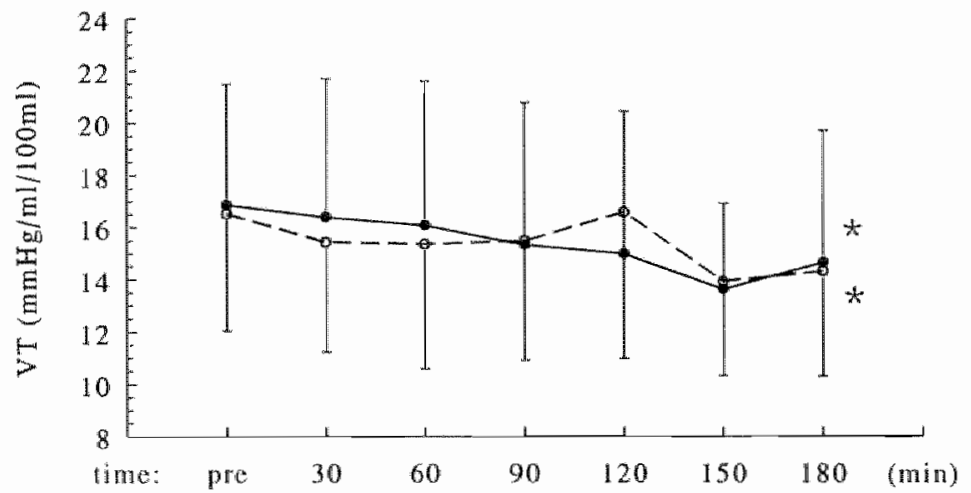

Figure $5.2 \mathrm{c}$ VT during low (-) and high (- - ) calcium UF $+\mathrm{HD} *=0<0.05$ as compared to pre-treatment level

The echocardiographic data are shown in table 5.3. With a comparable pre-dialysis LVEDD in both high- and low-calcium UF + HD there were no significant changes in left ventricular end-diastolic and end-systolic dimensions during both treatment modalities. Both SV $(-18 \pm 13 \mathrm{ml})$ and $\mathrm{CO}(-1.3 \pm 1.5 \mathrm{l} / \mathrm{min})$ decreased significantly during low-calcium UF+HD whereas during high-calcium UF $+\mathrm{HD}$ the decrease in SV $(-8 \pm 11 \mathrm{ml})$ and $\mathrm{CO}(-0.7 \pm 1.2 \mathrm{l} / \mathrm{hr})$ did not reach statistical significance. There were no significant changes in calculated systemic vascular resistance during both treatments. 
Table 5.3 Hemodynamic data: echocardiography before and after UF+HD

\begin{tabular}{|c|c|c|c|c|c|}
\hline & $\begin{array}{l}\text { Calcium } 1.25 \\
\text { pre }\end{array}$ & post & $\begin{array}{l}\text { Calcium } 1.75 \\
\text { pre }\end{array}$ & post & $\begin{array}{l}\text { changes } \\
1.25 \text { vs } 1.75\end{array}$ \\
\hline LVEDD & $48(6)$ & $46(6)$ & $48(6)$ & $46(8)$ & ns \\
\hline LYESD & $33(4)$ & $31(6)$ & $31(5)$ & $30 \cdot(5)$ & ns \\
\hline Heart Rale & $72(10)$ & $72(9)$ & $76(13)$ & $76(12)$ & ns \\
\hline Stroke Volume & $92(22)$ & $73(25)^{\mathrm{a}}$ & $87(20)$ & $79(15)$ & ns \\
\hline Cardiac Output & $6.5(1.5)$ & $5.3(1.7)^{\mathrm{s}}$ & $6.5(1.4)$ & $5.9(0.4)$ & ns \\
\hline Cardiac Index & $3.5(0.7)$ & $2.8(1.0)^{\mathrm{n}}$ & $3.5(0.5)$ & $3.2(0.2)$ & $\mathrm{nss}$ \\
\hline Systemic Vasc Res & $1392(424)$ & $1674(796)$ & $1385(420)$ & $1478(266)$ & $\mathrm{ns}$ \\
\hline
\end{tabular}

LVEDD and LVESD (mm); HR (beats/minute); SV (ml); CO (l/min); $\mathrm{Cl}\left(1 / \mathrm{min} / \mathrm{m}^{2}\right)$ :

SWR (dyne/ $\left./ \mathrm{sec} / \mathrm{cm}^{5}\right)$ ) post ws pre, ${ }^{2}=p<0.05$.

\section{Discussion}

Arterial blood pressure and different cardiovascular parameters were measured during low (1.25) and high (1.75) calcium UF $+\mathrm{HD}$ to study if, in addition to myocardial contractility, vascular reactivity is also influenced by changes in ionized calcium. In addition, the effect of lowering the dialysate calcium concentration on intradialytic blood pressure was assessed. Our results show that even in hernodynamically stable patients, ionized calcium is an important determinant of the blood pressure response during UF +HD. Moreover, it is shown that this relation is exclusively based on changes in myocardial contractility.

Plasma ionized calcium increased significantly and was significantly higher during high-calcium UF+HD. With a dialysate calcium concentration of 1.25 mmol/1 plasma ionized calcium remained more or less unchanged. In high-calcium $U F+H D$, the increase in plasma ionized calcium was largest during the first hour after which it reached a plateau. When comparing our data with previous studies, the data show that dialysate calcium concentrations of \pm 1.35 or higher are associated with a net positive calcium ballance ${ }^{4,8,14,16}$.

With all other dialysis parameters standardised, exactly comparable pre-dialysis weights as well as changes in relative blood volume, systolic, diastolic and mean arterial blood pressure were all substantially and significantly higher during high-calcium UF +HD as compared to low-calcium UF+HD. Only during the latter treatment, both systolic and mean arterial blood pressure decreased significantly. So, even in hemodynamically stable patients selected for their good cardiac function, changes in plasma ionized calcium are a very important determinant of the blood pressure response during dialysis therapy. In agreement with these observations, most authors aiso found a clinically important positive 
correlation between changes in plasma ionized calcium and arterial blood pressure during dialysis therapy ${ }^{4,8}$. At variance, Sherman et al. found only a small but significant decrease in mean arterial BP during low-calcium UF +HD (1.25 mmol/l) as compared to high-calcium UF +HD (1.75 mmol/l). With a maximum mean reduction in mean arterial BP of $4.6 \mathrm{mmHg}$ they concluded that dialysate calcium could be reduced if necessary with only a clinically minor effect on intradialytic blood pressure ${ }^{17}$. A relatively low UF-rate of $\pm 0.56 \mathrm{~J} / \mathrm{hr}$ and differences concerning their methodology might partly explain these findings. However, the bulk of evidence points to an important role of changes in ionized calcium on the blood pressure response during dialysis therapy which should be taken into consideration when lowering the dialysate calcium concentration in treating hypercalcemia in dialysis patients.

A main new finding in the present study is the fact that the peripheral vascular response during UF $+H D$ is not directly influenced by differences in plasma ionized calcium. During both low- and high-calcium UF $+H D$, FVR increased whereas VT decreased with no significant differences between the two treatments. Moreover, calculated SVR was also comparable. However, both SV and CO decreased significantly only during low-calcium $U F+H D$ while changes in $S V$ and $\mathrm{CO}$ were smaller and insignificant during high-calcium UF+HD. So, with comparable changes in relative blood volume and comparable end-diastolic dimensions, indicative of a comparable pre-load, blood pressure was maintained at a higher level during high-calcium UF $+H D$ as a result of an improvement in myocardial contractility only and not on the basis of differences in peripheral vascular resistance or venous tone. In agreement, in isovolemic dialysis as well as in dialysis combined with ultrafiltration different authors also found a positive correlation between changes in plasma ionized calcium and left ventricular contractility ${ }^{4-6}$. Moreover, both Fellner et al. and Lang et al. also found no significant differences in calculated SVR after dialysis at three different dialysate calcium concentrations ${ }^{4,6}$. However, their conclusions are based on post-dialytic echocardiographies only.

Whereas plasma adrenaline remained unchanged during both low- and high-calcium UF +HD, plasma noradrenaline increased significantly only during the latter treatment. The difference between the two treatments was statistically significant. These results suggest that also during dialysis the release of noradrenaline from sympathetic nerve endings is calcium dependent ${ }^{18}$. In healthy volunteers and patients with a mildly impaired renal function, Marone et al. found that infusion of calcium gluconate $(15 \mathrm{mg} / \mathrm{kg}$ body weight) resulted in a small but significant increase in plasma noradrenaline after three hours. Interesting and in contrast with our results, the accompanying increase in systolic and diastolic blood pressure in their study was based on an increase in peripheral resistance whereas 
cardiac output remained unchanged ${ }^{19}$. Therefore, the finding of higher level of plasma noradrenaline with no improvement in the peripheral vascular response could be interpreted as a further confirmation that vascular reactivity is impaired during UF+HD. The present data do not allow us to conclude whether this is due to either a post-receptor defect ${ }^{20}$ or the presence of some disturbing factor such as net heat load ${ }^{21}$ or the effects of dialysate derived contaminants ${ }^{22}$.

In conclusion, lowering the dialysate calcium concentration from 1.75 to 1.25 mmol/1 has a clinically important negative effect on the blood pressure response during combined ultrafiltration-hemodialysis. This relation is based on differences in myocardial contractility only and not on differences in peripheral vascular tone. Especially in cardiac compromised patients, this could be of clinical importance. 


\section{References}

1 Datugirdas $\mathrm{JT}$ : Dialysis hypotension: A hemodynamic analysis.

Kidney Int $1991 ; 39: 233-246$.

2 Baldamus CA, Ernst W, Frei U, Koch.KM: Sympathetic and hemodynamic response to wolume removal during different forms of renal replacement therapy. Nephron 1982; 31: 324-332.

3 Kooman JP, Gladziwa U, Böcker $G$, van Bortel LMAB, van Hooff JP, Leunissen KML: Role of the venous system in hemodynamics during ultrafiltration and bicarbonate dialysis. Kidney Int 1992; 42: 718-726.

4 Fellner SK, Lang RM, Neumann A, Spencer KT, Bushinsky DA, Borow KM: Physiological mechanisms for calcium-induced changes in systemic arterial pressure in stable dialysis patients. Hypert 1989; 13:213-218.

5 Henrich WL, Hunt JM, Nixon JV: Increased ionized calcium and left wentricular contractility during hemodialysis. N Engl J Med 1984; 310: 19-23.

6 Lang RM, Feliner SK, Neumann A, Bushinsky DA, Borow KM: Left wentricular contractility varies dinectly with blood ionized calcium.

Ann Intern Med 1988; 108: 524-529.

7 Leunissen KML, wan den Berg BW, van Hooff JP: Ionized calcium plays a pivotal role in controlling blood pressure during haemodialysis.

Blood Purif 1989; 7: 233-239.

8 Maynard JC, Cruz C, Kleerekoper M, Levin NW: Blood pressure response to changes in serum ionized calcium during hemodialysis.

Ann Intern Med 1986; 104: 358-361.

9 Leunissen KML, Kouw P, Kooman JP, Cheriex EC, de Vries PMJM, Donker AJM, van Hooff JP: New techniques to determine fluid status in hemodialyzed patients. Kidney Int 1993:43: \$50-556.

10 Ihlen H, Endresen K, Myreng Y, Mylure E: Reroducibility of cardiac stroke volume estimated by doppler echocardiography. Am J Cardiol 1987; 59: 975-978.

11 Ditmann $H$, Voelker $W$, Karsch $K-R$, Siepel $L$ : Influence of sampling site and flow area on cardiac output measurements by doppler echocardiography.

J Am Coll Cardiol 1987; 10:818-823.

12 Robson SC, Boys RJ, Hunter S: Doppler echocardiographic estimation of cardiac output: analysis of temporal variability. Eur Heart $J$ 1988; 9: $313-318$.

13 de Vries IPPM, Olthof CG, Viosser V, Kouw PM, van Es A, Donker AJM, de Vries PMIM: Continuous measurement of blood volume during hemodialysis by an optical method. ASAIO Journal 1992; 38; M181-M185.

14 Goldsmith RS, Furszyfer J, Johnson WJ, Beeler GW, Taylor WF: Calcium flux during hemodialysis. Nephron 1978; 20: 132-140.

15 Hou SH, Zhao J, Ellman CF, Hu J, Grifin Z, Spiegel DM, Bourdeau JE: Calcium and phosphorus fluxes during hemodialysis with low calcium dialysate.

Am J Kidney Dis 1991; 18: 217-224. 
16 Argilès A, Kerr PG, Canaud B, Flavier $\mathrm{L}$, Mion $\mathrm{C}$ : Calcium kinetics and the longterm effects of lowering dialysate calcium concentration.

Kidney Int 1993; 43: 630-640.

17 Sherman RA, Bialy GB, Gazinsky B, Bernholc AS, Eisinger RP: The effect of dialysate calcium levels on blood pressure during hemodialysis.

Am J Kidney Dis. 1986; 8: 244-247.

18 Rubin RP: Neurotransmitter substances and hormones.

Pharmacol Rev 1970; 22: 389-428.

19 Marone C, Beretta-Picolli C, Weidmann P: Acute hypercalcemic hypertension in man: role of hemodynamics, catecholamines and renin. Kidney Int 1980;20:92-96.

20 Brodde O-E, Daul A: Alpha- and Beta-adrenoreceptor changes in patients on maintenance hemodialysis. Contrib Nephrol 1984; 41: 99-107.

21 van Kuijk WHM, Luik. AJ, de Leeuw PW, van Hooff JP, Nieman FHM, Habets HML, Leunissen KML: Vascular reactivity during hemodialysis and isolated ultrafiltration: thermal influences. Nephrol Dial Transplant 1995; (in press).

22 Henderson LW, Koch KM, Dinarello CA, Shaldon S: Hemodialysis hypotension: The interleukin-1 hypothesis. Blood Purif 1983; 1:3-8. 


\section{Chapter 6}

\section{Critical role of the extracorporeal blood temperature in the hemodynamic response during hemofiltration}

WHM van Kuijk, D Hillion, C Savoiu, KML Leunissen

(submitted for publication) 


\section{Abstract}

\section{Background}

Impaired vascular reactivity during combined ultrafiltration-hemodialysis (UF+HD) as compared to hemofiltration (HF) remains a rather enigmatic problem of which the causes are still not well understood. Although a number of factors have been claimed to be responsible most recent studies point to a major role of the extracorporeal blood temperature which is normally lower during $\mathrm{HF}$ as compared to UF HD. However, previous studies in which hemodynamics were studied during UF+HD and HF in relation to the extracorporeal blood temperature are limited by the use of acetate in UF H HD while measurements were often confined to blood pressure and heart rate.

\section{Methods}

Therefore, we measured arterial blood pressure and forearm vascular resistance (FVR) and venous tone (VT) (strain-gauge plethysmography) in 11 hemodialysis patients during three hours UF+HD $\left(37.5^{\circ} \mathrm{C}\right)$ and pre-dilution $\mathrm{HF}\left(39.0^{\circ} \mathrm{C}=\right.$ warm $\left.\mathrm{HF}\right)$ resulting in equivalent extracorporeal blood temperatures. In addition, patients were also studied during cold $\mathrm{HF}$ at an infusate temperature of $36.0^{\circ} \mathrm{C}$. UF $+\mathrm{HD}$ and $\mathrm{HF}$ were matched with respect to the dialysate and infusate composition (bicarbonate), biocompatibility factors and small molecule clearance.

\section{Results}

At equivalent temperatures, UF +HD and HF were associated with a comparable vascular and blood pressure response. Only cold MF was associated with a significant increase in FVR. In addition, FVR and VT as well as arterial blood pressure were all significantly higher during cold $\mathrm{HF}^{\mathrm{F}}$ compared to both UF $+\mathrm{HD}$ and warm HF.

\section{Conclusions}

These results indicate that disparity in vascular reactivity between UF H HD and HF is primarily related to differences in the extracorporeal blood temperature. 


\section{Introduction}

With an increasing number of elderly, cardiovascular compromised patients on dialysis therapy hemodynamic instability with symptomatic hypotension will remain an important clinical problem. Since their climical application, convective dialysis treatments such as hemofiltration are considered to be the most optimal treatment modality for hemodynamically unstable patients as blood pressure stability is better during these treatments compared to diffusive treatments such as combined ultrafiltration-hemodialysis'. In previous studies it has been shown that these differences in blood pressure stability are related to the fact that peripheral vascular resistance increases adequately during hemofiltration while peripheral vascular resistance remains more or less unchanged during combined ultrafiltrationhemodialysis ${ }^{2.3}$. In addition, we found that venous reactivity is also impaired during the latter therapy ${ }^{4}$. Although hemofiltration seems to be the most optimal treatment for cardiovascular compromised patients its clinical application is still limited due to the higher cost and limitations in clearance with higher hematocrits as a result of the use of erythropoietin. If we are able to unravel the mechanisms responsible for disparity in vascular reactivity between convective and diffusive dialysis treatments it should be possible to improve hemodynamic stability during the latter treatment modality.

Traditionally, the larger decrease in plasma osmolality during combined ultrafiltration-hemodialysis as a result of a larger small molecule clearance was thought to play a pivotal role in the impaired vascular response ${ }^{s}$. Urea supplemented dialysate, however, did not improve the hemodynamic response in dogs and $\operatorname{men}^{6,7}$. Moreover, we found a comparable vascular response during highand low-sodium dialysis ${ }^{8}$. Henderson et al. suggested that the impaired vascular response during combined ultrafiltration-hemodialysis might be related to bio-incompatibility factors related to the dialysis membrane or to the presence of non-sterile dialysate". However, vascular reactivity did not improve when using sterile dialysate while Aakhus et al. measured comparable central hemodynamics using membranes of low and high biocompatibility ${ }^{10.18}$. Several studies have pointed to the importance of the extracorporeal blood temperature ${ }^{2.14}$ which is normally lower in hemofiltration as a result of the lower infusate flow and the larger extracorporeal circuit. However, results from comparative studies are confounded by the use of acetate as a single buffer in combined ultrafiltration-hemodialysis while hemodynamics and changes in blood volume were not always monitored. In addition, hemodialysis and hemofiltration performed in post-dilution mode were not matched for small molecule clearance and biocompatibility ${ }^{15.16}$.

Therefore, we measured arterial blood pressure as well as vascular reactivity under strictly standardised conditions and in relation to the extracorporeal blood 
remperature comparing combined ultrafiltation-hemodialysis with pre-dilution hemofultration. In both treatments bicarbonate was used as a buffer.

\section{Subjects and methods}

\section{Subjects and dialysis}

After obtaining informed consent, four women and seven men on intermittent hemodialysis were included with a mean age of 43 years (range 26-58) and a mean time on dialysis of 65 months (range 5-252). All patients were hemodynamically stable patients who rarely suffered from intradialytic hypotension. The following exclusion criteria were used: (1) severe coronary (NYHA II or more) or valvular heart disease, (2) compromised left ventricular function (ejection fraction $30 \%$ or less) and (3) diabetes mellitus. By adjusting fluid intake patients were instructed to achieve a predialysis weight in the range from 2.0 to 3.0 kilograms above their dry-weight that was estimated by echography of the inferior caval vein ${ }^{17}$. Vasoactive medication was stopped 48 hours before the study while patients were not allowed to drink caffeine containing bewerages during 12 hours preceding the study. Recinculation was less that $10 \%$ in the studied population.

With each patient serving as his or her own control, measurements were performed during three consecutive dialysis treatments in randomised order. Blood flow was set at $300 \mathrm{ml} / \mathrm{min}$ in all treatments while the same ultrafilltration rate was used within the same patient. One session consisted of three hours combined ultrafiltration-hemodialysis (UF+HD) using a polyamide dialyser (Polyflux 160, Gambro, Sweden), a dialysate temperature of $37.5^{\circ} \mathrm{C}$ and a dialysate flow of 500 $\mathrm{ml} / \mathrm{min}$. The other two sessions consisted of three hours pre-dilution hemofiltration (HF) using a polyamide hemofilter (FH $88 \mathrm{H}$, Gambro, Sweden) and an infusate flow of $350 \mathrm{ml} / \mathrm{min}$ to obtain an almost comparable small molecule clearance as in UF $+\mathrm{HD}$. In one session the infusate temperature was set at $39.0^{\circ} \mathrm{C}$ (warm $\mathrm{HF}$ ) to obtain the same blond temperature in the efferent, venous line as during UF-HD. On the basis of former experiments, the intusate temperature was set at $36.0^{\circ} \mathrm{C}$ in cold hemofiltration (cold HE) to obtain a comparable extracorporeal blood temperature as in post-dilution $\mathrm{HF}^{*}$.

UF +HD and HF were performed with an AK-100 Ultra monitor (Gambro, Sweden) to prepare on-line sterile infusate and dialysate. The composition of both dialysate and infusate was: sodium $141 \mathrm{mmol} / 1$, potassium $2.0 \mathrm{mmol} / \mathrm{l}$, calcium $1.75 \mathrm{mmol} / \mathrm{l}$, bicarbonate $34 \mathrm{mmol} / \mathrm{l}$, acetate $3 \mathrm{mmol} / \mathrm{l}$, magnesium $0.5 \mathrm{mmol} / \mathrm{l}$ and chloride $108 \mathrm{mmol} / \mathrm{l}$. 


\section{Methods}

The luminal blood temperature was measured in the arterial and venous line with needle thermometers (Hewlett-Packard $78214 \mathrm{C}$ temperature monitor). Connectors with a built-in adaptor were placed in the arterial and venous line under sterile conditions at a distance of about 15 centimetres from the patient. There was no direct contact between blood and thermometer.

Forearm vascular resistance (FVR) and venous tone (VT) were measured as described in chapter 2 . The hand circulation was occluded from one minute before as well as during flow measurments. Arterial blood pressure (BP) and heart rate (HR) were measured as described in chapter 3. All hemodynamic measurements were performed before and every 30 minutes during dialysis.

Changes in relative blood volume (BV) were measured continuously and non-invasively by means of an optical reflection method which operates at a wavelength of $950 \mathrm{~nm}$. The optical sensor was clipped on the arterial line (Haemoguard 2000, Sanofi Sante, The Netherlands) ${ }^{18}$. The baseline value was obtained after two minutes of extracorporeal circulation at a blood flow of 250 $\mathrm{ml} / \mathrm{min}$ without ultrafiltration to exclude the influence of saline (recirculation) present in the blood lines at the start of dialysis.

Both before and after dialysis, blood was withdrawn for the estimation of: sodium, potassium, ionized calcium (NOVA 8, NOVA Biomedical, Waltham, MA, USA) total $\mathrm{CO}_{2}$, urea, osmolality (Wescor, vapour pressure monitor) and colloid osmotic pressure. In addition, blood was withdrawn in ice-chilled tubes and directly centrifuged at a temperature of $4^{\circ} \mathrm{C}$ for the estimation of plasma catecholamines (HPLC, fluorescence detection).

\section{Statistical analysis}

Changes in hemodynamic parameters within each treatment as well as differences between treatments were analyzed by repeated measurements MANOVA (SPSS-PC version). If the sphericity of the variance-covariance matrix appeared to be violated, degrees of freedom in the univariate MANOVA tests were corrected by the Greenhouse-Geisser epsilon to avoid Type 1 error in testing the F-ratio. All laboratory parameters were analyzed by Friedmans ANOVA and if appropriate, by the Wilcoxon's signed-rank test. All values are expressed as mean $\mathbb{S}$ SD. 


\section{Results}

The pre-dialysis weights in UF+HD, warm HF and cold HF were respectively $69.2 \pm 10.8,69.3 \pm 11.1$ and $69.5 \pm 10.9 \mathrm{~kg}$ (ns) while the mean ultrafiltration rate was $0.92 \pm 0.12 \mathrm{l} / \mathrm{hr}$. The blood temperatures are shown in figure $6.1 \mathrm{a}-\mathrm{c}$. UF $+\mathrm{HD}$ and warm HF resulted in an almost comparable arterial and venous blood temperature. After three hours, the arterial blood temperature increased by $0.4 \pm 0.2^{\circ} \mathrm{C}$ in both treatments $(p<0.01)$. In addition, the wenous blood temperature increased by $0.2 \pm 0.2(\mathrm{p}<0.05)$ and $0.3 \pm 0.2^{\circ} \mathrm{C} \quad(\mathrm{p}<0.01)$ respectively. In cold-HF, blood cooled down during extracorporeal circulation by $1.2^{\circ} \mathrm{C}$ while after three hours the arterial blood temperature had increased by $0.1 \pm 0.2^{\circ} \mathrm{C}(\mathrm{p}<0.05)$ without significant changes in the venous blood temperature.

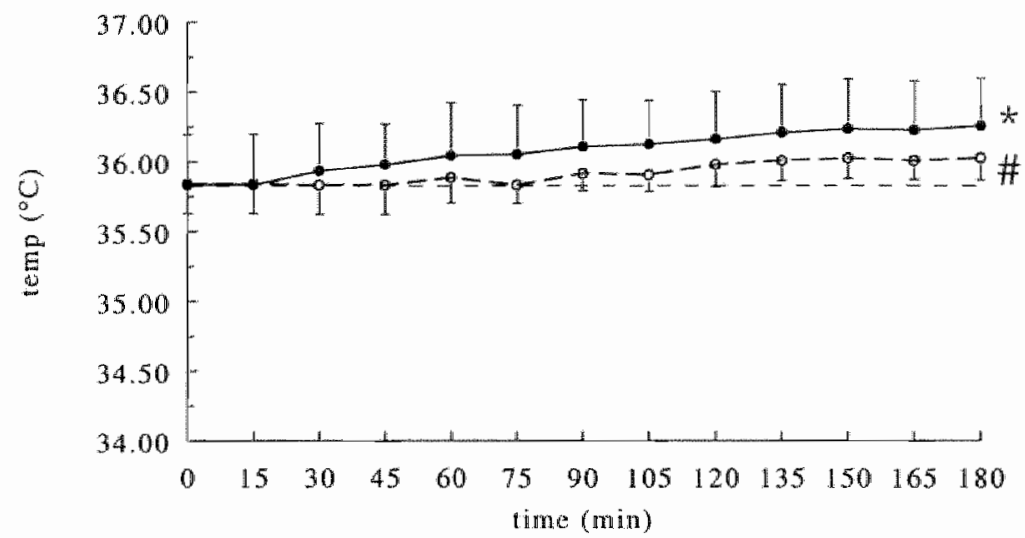

Figure 6.1a Arterial ( $\longrightarrow$ ) and venous (- - ) blood temperatures in UF + HD $*=p<0.01=p<0.05$ as compared to $t=0 \mathrm{~min}$.

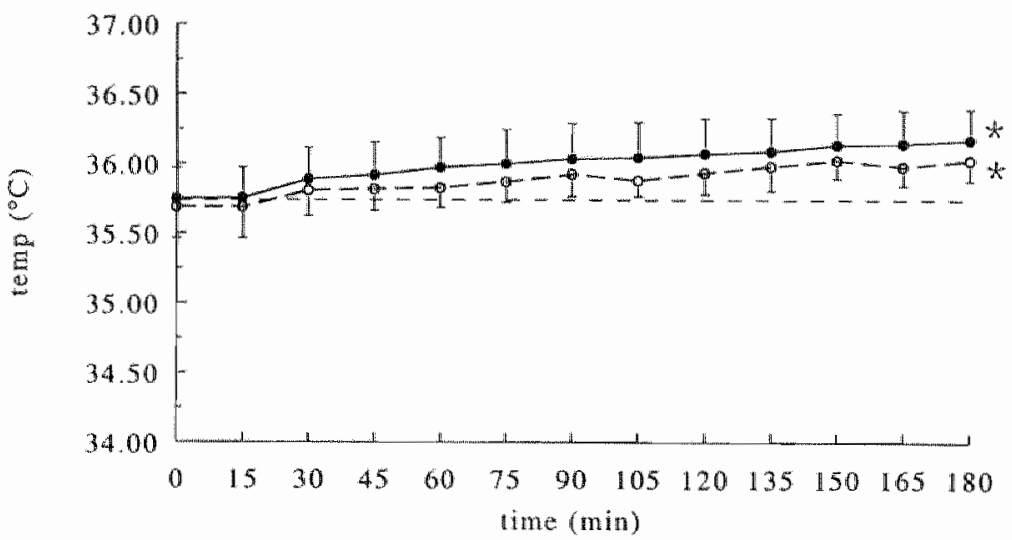

Figure 6.16 Arerial (_- and wenous ( $\ldots$ ) blood temperatures in warm HF $*=p<0.01$ as compared $10 t=0 \mathrm{~min}$. 


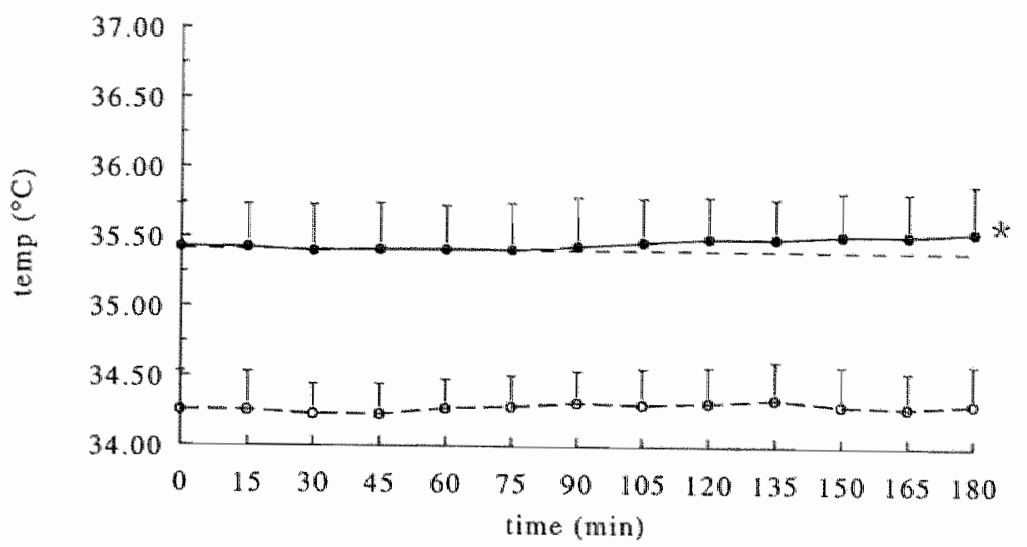

Figure 6.1c Arterial (- - ) and venous (- - ) blood temperatures in cold HF $*=p<0.05$ as compared to $t=0 \mathrm{~min}$.

The laboratory data are shown in table 6.1. All laboratory parameters changed comparably during the different treatment modalities. The decrease in plasma Potassium, Urea and Osmolality and the increase in total $\mathrm{CO}_{2}$ tended to be smaller during both warm and cold HF as compared to UF +HD but these differences did not reach statistical significance. In addition, differences in the urea reduction ratio (URR) were not statistically significant. There were no significant changes in plasma adrenaline or noradrenaline. Relative blood volume decreased significantly $(p<0.01)$ and comparably to $86 \pm 6,84 \pm 6$ and $85 \pm 6 \%$ during respectively $\mathrm{UF}+\mathrm{HD}$, warm $\mathrm{HF}$ and cold $\mathrm{HF}$.

The hemodynamic data are presented in table 6.2 and figure $6.2 \mathrm{a}-\mathrm{c}$. UF $+\mathrm{HD}$ and warm HF were associated with comparable vascular and blood pressure responses with no significant differences between the two treatments. In both, FVR tended to increase during the first hour $(\mathrm{p}>0.05)$ after which it stabilised while VT decreased significantly. In contrast, Cold HF was associated with a significant increase in FVR, especially during the first two hours while VT remained unchanged. As compared to both UF+HD and warm HF, FVR $(\mathrm{p}<0.01)$ and VT $(p<0.05)$ were significantly higher during cold HF. There were no significant changes in arterial blood pressure during UF $+\mathrm{HD}$. During warm HF, only systolic blood pressure decreased significantly while heart rate increased significantly during both UF $+\mathrm{HD}$ and warm HF. In cold $\mathrm{HF}$, all three blood pressure parameters increased significantly while heart rate decreased. Mean arterial BP was significantly higher as compared to both UF+HD and warm HF $(p<0.05)$. Differences in systolic $(p<0.05)$ and diastolic BP $(p<0.05)$ reached statistical significance only between warm and cold HF. 
Table 6.1 Laboratory data

\begin{tabular}{|c|c|c|c|c|c|c|}
\hline & \multicolumn{2}{|c|}{$\mathrm{UF}+\mathrm{HD} 37.5^{\circ} \mathrm{C}$} & \multicolumn{2}{|l|}{$\mathrm{HF} 390^{\circ} \mathrm{C}$} & \multicolumn{2}{|l|}{$\mathrm{HF} 36.0^{\circ} \mathrm{C}$} \\
\hline & pre & posi & pre & posi & pre & post \\
\hline Sodium & $139.0(2.1)$ & $140.1(2.1)^{4}$ & $137.4(2.5)$ & $139.6(1.9)^{\mathrm{a}}$ & $138.2(3,0)$ & $139.6(2.1)^{2}$ \\
\hline Polassium & $4.7(0.6)$ & $3.5(0.4)^{\mathrm{x}}$ & $4.7(0.5)$ & $3.8(0.4)^{3}$ & $4.8(0.7)$ & $3.7(0.4)^{\sqrt{a}}$ \\
\hline ionized Calcium & $1.17(0.13)$ & $1.40(0.08)^{\mathrm{a}}$ & $1.14(0.13)$ & $1.37(0.07)^{\mathrm{s}}$ & $1.14(0.11)$ & $1.34(0.07)^{2}$ \\
\hline lotal $\mathrm{CO}_{2}$ & $22.7(2.8)$ & $25.6(1.4)^{x}$ & $23.1(3.2)$ & $24.8(1.5)^{\mathrm{bh}}$ & $23.0(3.0)$ & $24.9(1.6)$ \\
\hline Urea & $25.0(7.3)$ & $9.7(3.5)^{x}$ & $25.9(6.5)$ & $11.9(3.4)^{3}$ & $23.9(5.5)$ & $11.8(2.8)^{3}$ \\
\hline URR & & $59.5(15.9)$ & & $53.5(10.4)$ & & $53.5 \cdot(6.8)$ \\
\hline Osmolality & $295.3(7.7)$ & $283.2(5.6)^{3}$ & $297.4(7.3)$ & $288.7(6.1)^{3}$ & $296.0(7.1)$ & $286.4(4.5)^{\mathrm{b}}$ \\
\hline COP & $2.9(0.3)$ & $4.4(0.4)^{x}$ & $2.9(0.3)$ & $4.4(0.6)^{\mathrm{n}}$ & $2.9(0.2)$ & $4.3(0.3)^{n}$ \\
\hline Noradrenaline & $1.27(0.47)$ & $1.58(0.51)$ & $1.10(0.87)$ & $1.46(0.52)$ & $1.24(0.46)$ & $1.69(0.85)$ \\
\hline Adrenaline & $0.12(0.11)$ & $0.13(0.10)$ & $0.15(0.12)$ & $0.17(0.16)$ & $0.13(0.07)$ & $0.16(0.15)$ \\
\hline
\end{tabular}

Sodium, Potassium, ionized Calcium, total $\mathrm{CO}^{2}$ and Ura (mmol/1); URR ( W); Osmolality (mOsm/kg); $\operatorname{COP}(\mathrm{kPa}) ;$ Cattecholamines (nmol/1); post vs pre: ${ }^{a}=\mathrm{p}<0.01,{ }^{b}=p<0.05$

Table 6.2 Hemodynamic data

\begin{tabular}{|c|c|c|c|c|c|c|}
\hline & \multicolumn{2}{|c|}{$\mathrm{UF}+\mathrm{HD} 37.5^{\circ} \mathrm{C}$} & \multicolumn{2}{|c|}{$\mathrm{HF} 39.0^{\circ} \mathrm{C}$} & \multicolumn{2}{|c|}{$\mathrm{HF}=36.0^{\circ} \mathrm{C}$} \\
\hline & pre & post & pre & post & pre & post \\
\hline Systalic BP & $129(17)$ & $126(25)$ & $133(20)$ & $125(18)^{a}$ & $131(20)$ & $137(26)^{3}$ \\
\hline Diastollic BP & $779)$ & $80(10)$ & $80(11)$ & $82(9)$ & $79 \cdot(10)$ & $85(9)^{3}$ \\
\hline Mean Arterial BP & $97(12)$ & $98(17)$ & $101(15)$ & $100(12)$ & $98(15)$ & $106(15)^{\mathrm{a}}$ \\
\hline Heari Rate & $74(7)$ & $78(16)^{13}$ & $70(6)$ & $75(14)^{114}$ & $72(7)$ & $68(12)^{a}$ \\
\hline FVR & $1524(606)$ & $2186(2318)$ & $1704(664)$ & $2366(1282)$ & $1588(602)$ & $5110(2688)^{2}$ \\
\hline $\mathrm{VT}$ & $18.6(5.2)$ & $15.7(5.0)^{\mathrm{a}}$ & $19.2(3.3)$ & $15.2(2.8)^{\circ}$ & $17.9(5.0)$ & $18.0(4.8)$ \\
\hline
\end{tabular}

BP (nmHg); HR (beats/min); FVR ( $\mathrm{mmHg} / \mathrm{ml} / 100 \mathrm{~mL} / \mathrm{sec})$ VT) (mmHg/ml/o0mls: post vs pre: " $=p<0.01$. $^{k}=p<0.05$ 


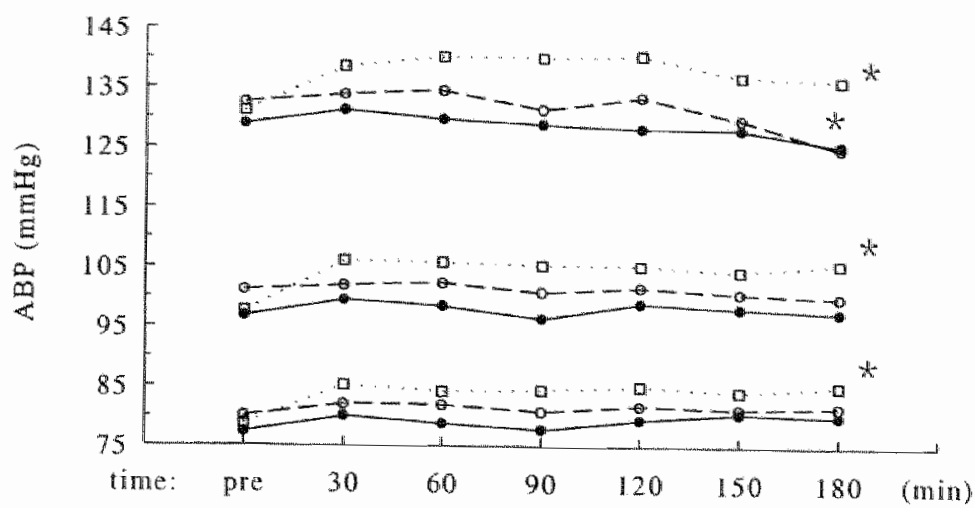

Figure 6.2a Arterial BP during UF+HD(-), warm HF (- - ) and cold $\mathrm{HF}(\cdots):=\mathrm{p}<0.01$ as compared to pre-treament level

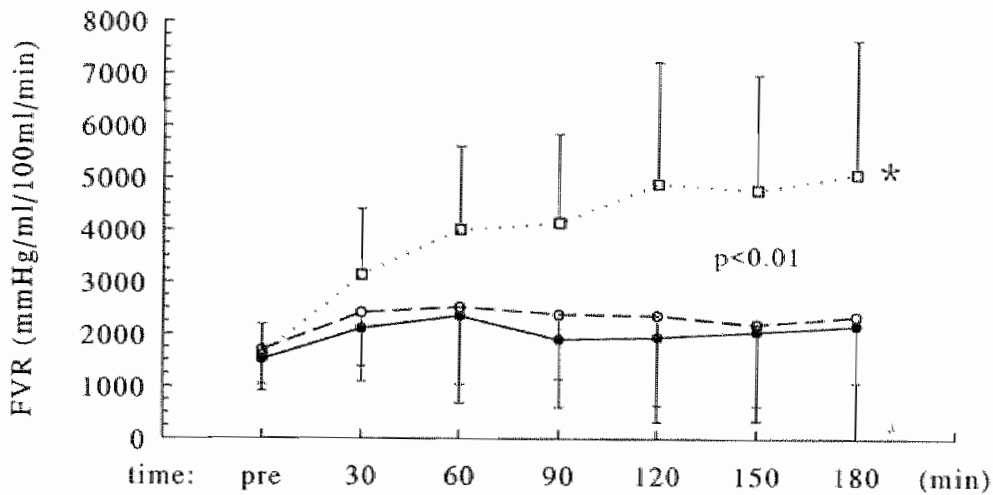

Figure 6.2b FVR during UF $+\mathrm{HD}(--)$, warm HF $(\cdots)$ and cold $\mathrm{HF}(\cdots)$ $*=p<0.01$ as compared to pre-treatment level

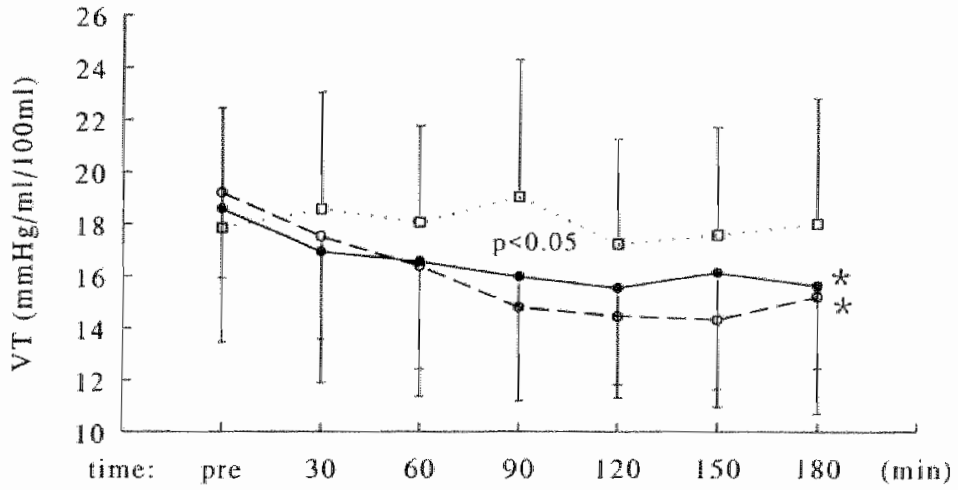

Figure 6.20 VT during $U F+H D(-\infty)$, wam HF $(\ldots)$ and cold $H F(\cdots)$ $*=p<0.01$ as compared to pre-treatment level 


\section{Discussion}

Our study is the first to show that at equivalent extracorporeal blood temperatures the vascular and blood pressure responses are comparable between UF $+\mathrm{HD}$ and $\mathrm{HF}$. Only during extracorporeal blood cooling, $\mathrm{HF}$ is associated with an increase in peripheral resistance and a more stable venous tone resulting in a higher blood pressure.

To match UF+HD and HF with respect to the extracorporeal blood temperature the intusate temperature was increased to $39.0^{\circ} \mathrm{C}$ in pre-dilution $\mathrm{HF}$ which resulted in an almost comparable temperature of blood in the arterial and venous line. In contrast, $\mathrm{HF}$ at an infusate temperature of $36.0^{\circ} \mathrm{C}$ was associated with cooling of blood in the extracorporeal circuit. The significant increase in the arterial blood temperature after three hours UF H HD and warm HF indicates that the net thermal balance was positive in both treatments which is in agreement with previous studies ${ }^{1 \%, 20}$. Although very little, the arterial blood temperature increased significantly also during cold HF. This suggests that despite extracorporeal blood cooling the patient's body temperature increased which might be related to either dialysis induced catabolism ${ }^{21}$ or to a decrease in heat loss as a result of baroreceptor mediated vasoconstriction of the skin vasculature.

At comparable pre-dialysis weights and changes in intravascular volume and with UF + HD and HF matched for the buffer substrate, small molecule clearances and biocompatibility factors, only cold HF was associated with a physiological hemodynamic response to compensate for the decrease in circulating blood volume. FVR and VT were significantly different during cold HF compared to both UF $+H D$ and warm HF without significant differences between the latter two treatments. These results indicate that the well described differences in hemodynamics between UF $+H D$ and HF are primarily related to thermal differences. The curves in FVR suggest that even UF+HD and warm HF were associated with an increase in peripheral vascular tone during the first hour. Thereafter this increase seems to be counteracted most probably as a result of the net positive thermal balance. In agreement, Baldamus et al. also found an increase in TPR during the first two hours of bicarbonate dialysis after which it tended to decrease during the following two hours (dialysate temperature is not given) ${ }^{3}$. In contrast, the cold stimulus during cold HF initiated an instantaneous increase in peripheral resistance as well as in mean arterial pressure of which the former continued to increase during the second hour.

Our results are at variance with results obtained by Maggiore et al and Fox et al. who concluded that differences in the extracorporeal blood temperature are only partially responsible for disparity in hemodynamic stability. However, Maggiore et al. only measured blood pressure and heart rate while acetate was used as a single 
buffer in UF $+H D$ while using lactate in $H F^{15}$. The vasodilatory capacities of acetate are well described. In the study of Fox et al. differences in the extracorporeal blood temperature are not excluded, as in their study temperature measurements were confined to measurements of core body temperature while the same temperature was used for dialysate and substitution fluid. In addition, acetate was used in both $\mathrm{UF}+\mathrm{HD}$ and $\mathrm{HF}^{16}$.

Although plasma catecholamines only weakly reflect overall sympathetic activity $^{22}$ our data on plasma catecholamines do not confirm that improved vascular reactivity in cold HF is the result of an increase in sympathetic tone ${ }^{13,2 \pi}$. More direct measurements of sympathetic activity are necessary to be more conclusive on this subject ${ }^{24}$. In addition, it is unknown whether the effects of temperature on vascular tone are more generalised or remain confined to the skin vascular bed ${ }^{25,26}$.

In conclusion, the present study shows that disparity in vascular reactivity between UF $+\mathrm{HD}$ and $\mathrm{HF}$ is primarily related to differences in the extracorporeal blood temperature which indicates that it should be possible to obtain a comparable hemodynamic stability in UF +HD as in HF by lowering the dialysate temperature. Future studies are necessary to determine the optimal dialysate and infusate temperature and to investigate the possible adverse effects of cold dialysis on the incidence of cardiac arrhythmias and tissue oxygenation. 


\section{References}

1 Qucllhorst $E$, Doh B. Schueneman B: Hemofiltration: treament of renal failure by Wliraflitration and substitution. J Dial 1977; 1: $529-543$.

2 Hampl H, Paeprer $H$, Unger $V$, Fischer C. Resa I, Kessel M. Hemodynamic changes during hemodialysis, sequential ultrafiltration, and hemofiltration.

Kidney Int $1980 ; 18: \$ 83-\$ 88$.

3 Baldamus CA, Ernst W. Frei U, Koch.KM: Sympathetic and hemodynamic response to volume removal during different forms of renal replacement therapy. Nephron 1982; $31: 324-332$.

Kooman JP, Gladziwa U, Böcker $G$, van Bortel LMAB, van Hooff JP, Leunissen KML: Role of the venous system in hemodynamics during ultrafiltration and bicarbonate dialysis. Kidney Int 1992; 42: 718-726.

5 Henrich WL, Woodard TD, Blachley JD, Gomez-Sanchez C, Pettinger W, Cronin RE: Role of osmolality in blood pressure stability after dialysis and ultrafiltration. Kidney Int $1980 ; 18: 480-488$.

6 Wehle B, Asaba $H$, Castenfors J, Gunnarsson B, Bergström J: Influence of dialysate composition on cardiowascular function in isovolemic haemodialysis.

Proc EDTA 1981; 18: 153-159.

7 Daugirdas JT, Ing TS, Chen W-T, Vestal RE, Hano JE, AI-Kudsi RR: Ultrafiltration hemodynamics in conscious, uremic dogs: Effect of a decreasing plasma urea level. Mineral Electrolyte Metab 1985; 11: 79-84.

8 van Kuijk WHM, Wirtz JJM, Grave W, de Heer F, van Hoofl JP, de Leeuw PW, Leunissen KML: The effect of high and low sodium dialysate on vascular reactivity during hemodialysis (abstract). Nephrol Dial Transplant 1995; 10; 1028.

9 Henderson LW, Koch KM, Dinarello CA, Shaldon S: Hemodialysis hypotension: The interleukin-1 hypothesis. Blood Purif 1983; 1: 3-8.

10 van Kuijk WHM, Bumman WA, Gerlag PGG, Leunissen KML: Is vascular reactivity improved by using ultrapure dialysate? (abstract).

Nephrol Dial Transplant 1995; 10; 1028.

11 Aakhus $S_{i}$ Bjoernstad $K$, Jorstad $S$ : Systemic cardiovascular response in hemodialysis withoul and with ultrafiltration with membranes of high and low biocompatibility. Blood Purif 1995; 13: $229-240$.

12 Coli U. Landini S, Lucatello S, Fracasso A, Morachiello P, Righeto F, Scanferta $\mathbb{F}$, Onesti $\mathrm{G}$. Bazzato $\mathrm{G}$ : Cold as cardiovascular stabilizing factor in hemodialysis: hemodynamic evaluation. Trans Am Soc Artif Intern Organs 1983; 29: 71-75.

13 Mhida $3 \mathrm{H}$, Dumler $\mathrm{F}$, Zasuwa $\mathrm{G}$, Fleig $\mathrm{G}$, Levin $\mathrm{NW}$ : Effect of cooler dialysate on serum catecholamines and blood pressure stability.

Trans Am Soc Artif Intern Organs 1983; 24: 384-389.

14 Jost CMT, Agarwal R, Khair-El-Din T, Grayburn PA, Victor RG. Henrich WL: Effects of cooler temperaure dialysate on hemodynamic stability in "problem" dialysis patients. Kidney Int 1993; 44:606-612. 
15 Maggiore Q, Pizzarelli F, Sisca S, Zoccalli C, Parlongo S, Nicolò F, Creazzo G: Blood temperature and vascular stability during hemodialyis and hemofiltration. Trans Am Soc Artif Intern Organs 1982; 28: 523-527.

16 Fox SD. Henderson LW: Cardioxascular response during hemodialysis and hemofiltration: thermal, membrane, and catecholamine influences.

Blood Purif 1993; 11: 224-236.

17 Leunissen KML., Kouw P, Kooman JP, Cheriex EC, de Vries PMIM, Donker AJM. van Hooff JP: New techniques to determine fluid status in hemodialyzed patients. Kidney Int 1993; 43: S50-S56.

18 de Vries JPPM, Olthof CG, Viosser V, Kouw PM, wan Es A. Donker AJM, de Vries PMMM: Continuous measurement of blood volume during hemodiaiysis by an optical method. ASAIO Journal 1992; 38: M181-M185.

19 Lindholm T, Thysell H, Yamamoto Y, Forsberg B, Gullberg CA: Temperature and vascular stability in hemodialysis. Nephron 1985; 39: 130-133.

20 van Kuijk WHM, Luik. AJ, de Leeuw PW, van Hooff JP, Nieman FHM, Habets HML, Leunissen KML: Vascular reactivity during hemodialysis and isolated ultrafiltration: thermal influences. Nephrol Dial Transplant 1995; (in press).

21 Gutierrez A, Alvestrand A, Bergström J, Beving H, Lantz B, Henderson LW: Biocompatability of hemodialysis membranes: A study in healthy subjects.

Blood Purif 1994; 12: 95-105.

22 Esler MD, Hasking GJ, Willett IR, Leonard PW, Jennings GL: Noradrenaline release and sympathetic nervous system activity. J Hypert 1985; 3: 117-129.

23 Bergström $\mathrm{J}$ : Catecholamines and control of blood pressure during hemodialysis and hemofiltration. Kidney Int 1988; 34: S110-S114.

24 Converse RL, Jacobsen TN, Jost CMT, Toto RD, Graybum PA, Obregon TM, Fouad-Tarazi F, Victor RG: Paradoxical withdrawal of reflex vasoconstriction as a cause of hemodialysis-induced hypotension. J Clin Invest 1992; 90: 1657-1665.

25 Rowell BR: Cardiovascular adjustment to thermal stress; in Shepherd IT, Abboud FM (ed.): Handbook of Physiology, sect 2, Cardiovascular system, vol 3, Peripheral circulation and organ blood flow. Bethesda, American Physiological Society, 1983, 3, pp. 967-1023

26 Vanhoutte PM: Physical factors of regulation; in Bohr DF, Somlyo AP (ed.): Handbook of Physiology, sect 2, Cardiovascular System, vol 2, Vascular smooth muscle. Bethesda, American Physiological Society, 1980,2, pp. 443-474 


\section{Chapter 7}

Summary and concluding remarks 


\section{Summary}

Hemodynamic instability with symptomatic hypotension is still one of the main problems in dialysis therapy. Therefore it is of the utmost importance to improve dialysis with respect to intradialytic blood pressure regulation especially since the number of elderly, cardiovascular compromised patients on dialysis therapy is still increasing. In this respect, it is well established that blood pressure stability is better when fluid is withdrawn during either isolated ultrafiltration or hemofiltration compared to combined ultrafiltration-hemodialysis. In chapter 1 the literature is reviewed on the possible role of plasma volume preservation and cardiovascular compensatory mechanisms in differences in hemodynamic stability among different dialysis strategies. Both mechanisms play a central role in blood pressure regulation during dialysis therapy. From the bulk of evidence it can be concluded that disparity in hemodynamic stability between different dialysis strategies is primarily related to differences in vascular reactivity. Isolated ultrafiltration and hemofiltration are associated with a physiological increase in peripheral vascular tone when circulating blood volume decreases whereas both arteriolar and venous reactivity are impaired during combined ultrafiltration-hemodialysis. However, the mechanism responsible for these differences in vascular reactivity is still not well understood. The present studies were designed to investigate pathophysiologic mechanisms responsible for disparity in vascular reactivity between different dialysis strategies. In all studies, forearm vascular reactivity was measured during dialysis therapy (bicarbonate) in cardiovascular stable patients using strain-gauge plethysmography.

The extracorporeal blood temperature has been shown to be an important determinant of the blood pressure response during dialysis therapy. In chapter 2 the role of differences in extracorporeal blood temperature in the vascular response during isolated ultrafiltration and combined ultratiltration-hemodialysis was studied (protocol A). During combined ultrafiltration-hemodialysis measurements were performed at two different dialysate temperatures: 37.5 and $35.0^{\circ} \mathrm{C}$. Isolated ultrafiltration was associated with cooling of blood during extracorporeal circulation $\left(-1.7^{\circ} \mathrm{C}\right)$. In contrast, extracorporeal blood cooling was compensated by heat transfer from dialysate $\left(37.5^{\circ} \mathrm{C}\right)$ to blood during combined ultrafiltrationhemodialysis which resulted in a significant increase of the arterial blood temperature after four hours treatment. Ai a dialysate temperature of $35.0^{\circ} \mathrm{C}$ extracorporeal blood temperatures were comparable between isolated ultrafiltration and combined ultrafiltration-hemodialysis. The hemodynamic data confirm that both arteriolar and venous reactivity are impaired during combined ultrafiltrationhemodialysis: in contrast to isolated ultrafiltration vascular resistance remained unchanged while venous tone even decreased, resulting in secondary tachycardia. 
Compared to warm dialysis, venous tone was significantly higher while heart rate was significantly lower during cold dialysis while vascular resistance was not significantly different. Therefore, we conclude that impaired vascular reactivity during combined ultrafiltration-hemodialysis compared to isolated ultrafiltration is only partially explained on the basis of differences in extracorporeal blood temperature which suggests that additional factors should play a role. In protocol $\mathbf{B}$ blood pressure was measured during both warm and cold combined ulliafiltrationhemodialysis as well as during 22 post-dialysis hours to investigate whether cold dialysis is associated with rebound hypotension. Mean arterial blood pressure was significantly higher during cold dialysis compared to warm dialysis. However, in the post-dialytic period, blood pressure was comparable between warm and cold dialysis while none of the patients experienced rebound hypotension. Therefore, lowering the dialysate temperature seems to be a safe method to improve blood pressure stability without inducing post-dialytic hypotension.

Traditionally, a decrease in plasma osmolality is considered to play an important role in the impaired vascullar response during combined ultrafiltration-hemodialysis. In this respect, it is well established that hemodynamic stability can be improved by the use of high dialysate sodium concentrations. Moreover, a relation has been suggested between hemodynamic instability during low-sodium dialysis and an increase in plasma prostaglandin $\mathbb{E}_{2}$. In chapter 3 therefore, vascular reactivity as well as changes in plasma prostaglandin $E_{2}$ were measured during combined ultrafiltration-hemodialysis using high $(144 \mathrm{mmol} / \mathrm{l})$ and low (134 mmol/l) sodium dialysate. High-sodium dialysis resulted in a significantly higher plasma sodium level. Continuous measurements of relative blood volume confirmed results obtained in previous studies showing a significantly larger decrease in intravascular volume during low-sodium dialysis. Prostaglandin $E_{2}$ increased significantly only during low-sodium dialysis. However, there were no significant differences in vascular reactivity between high- and low-sodium dialysis. In addition, we found no relation between changes in prostaglandin $E_{2}$ and changes in arterial blood pressure or vascular tone. Consequently, better hemodymamic stability in high-sodium dialysis is only related to a better preservation of plasma volume and not to an improvement in vascular reactivity. Moreover, the data indicate that impaired vascular reactivity during combined ultrafiltration hemodialysis is not related to changes in plasma osmolality.

Theoretically, hemodynamic instability during combined ultrafiltrationhemodialysis could be related to release of cytokines by monocyles in the presence of dialysate derived contaminants as suggested by Henderson and colleagues. Better hemodynamic stability during isolated ultrafiltration and hemofiltration would then result from the absence of dialysate and contaminants and the use of sterile substitution fluid in hemofiltration. In chapter 4 , however, we found no 
differences in vascular reactivity during combined ultrafiltration-hemodialysis with either non-sterile and sterile dialysate. Despite use of pyrogen free dialysate, combined ultraflltration-hemodialysis was sill associated with a decrease in venous tone while vascular resistance remained unchanged. Although we cannot exclude that high levels of dialysate contamination may further impair vascular reactivity during combined ultrafiltration-hemodialysis, our results show that disparity in vascular reactivity between different dialysis strategies is not primarily related to differences in pyrogenic exposition.

Since calcium ions play a pivotal role in the contraction of vascular smooth muscle cells and cardiac myocytes, changes in plasma ionized calcium might be of importance with respect to the hemodynamic response during dialysis therapy. As a metter of fact, a relation has been found in previous studies between changes in ionized calcium and the blood pressure response during dialysis therapy. In this respect, an increase in myocardial contractility with higher dialysate calcium concentrations has been a consistent finding. However, it is unknown whether vascular reactivity also depends on changes in ionized calcium. In chapter 5 both vascular and myocardial reactivily were studied during combined ultrafiltrationhemodialysis with high $(1.75 \mathrm{mmol} / \mathrm{l})$ and low-calcium $(1.25 \mathrm{mmol} / \mathrm{l})$ dialysate. Plasma ionized calcium increased significantly only during high-calcium dialysis which resulted in a significantly higher blood pressure as compared to low-calcium dialysis. Although we found no significant differences in both arteriolar and venous reactivity between the two treatment modalities, cardiac output decreased significantly only during low-calcium dialysis. Consequently, while confirming the pivotal role of changes in plasma ionized calcium in the blood pressure response during dialysis therapy our data indicate that this relation is based on differences in myocardial contractility only.

According to the results of the first four studies, the extracorporeal blood temperature appears to be the most important factor with respect to the vascular response during dialysis therapy. In chapter 6 therefore, vascular reactivity was measured in relation to the extracorporeal blood temperature comparing combined ultrafiltration-hemodialysis with hemofiltration. To obtain a comparable extracorporeal blood temperature in hemofiltration just as in combined ultrafiltration-hemodialysis $\left(37.5^{\circ} \mathrm{C}\right)$, the infusate temperature was set at $39.0^{\circ} \mathrm{C}$. In addition, measurements were also performed during hemofiltration at an infusate temperature of $36.0^{\circ} \mathrm{C}$. Treatments were matched with respect to the buffer substrate (bicarbonate), small molecule clearance and biocompatibility. The results show that at equivalent extracorporeal blood temperatures, combined ultrafiltration-hemodialysis and hemofiltration are associated with a comparable hemodynamic response. Vascular resistance increased significantly only during cold hemofiltration while venous tone remained unchanged. In contrast, both warm 
hemofiltration and combined ultrafiltration-hemodialysis were associated with a similar decrease in venous tone while vascular resistance remained unchanged. As a result, mean arterial blood pressure was significantly higher in cold hemofiltration compared to both combined ultrafiltration-hemodialysis and warm hemofiltration.

\section{Concluding remarks}

In the present thesis the pathophysiology of disparity in vascular reactivity between different dialysis strategies was investigated. In general it can be concluded that vascular reactivity during dialysis therapy is especially influenced by changes in the extracorporeal blood temperature. The results obtained in chapter 6 even indicate that compared to hemofiltration, impaired vascular reactivity during combined ultrafiltration-hemodialysis is primarily related to differences in extracorporeal blood temperature. The normal hemodynamic response to a decrease in circulating blood volume seems to be counteracted by an increase in core body temperature during combined ultrafiltration-hemodialysis, resulting in peripheral vasodilation. This suggests that it should be possible to obtain comparable hemodynamic stability in combined ultrafiltration-hemodialysis like in hemofiltration by lowering the dialysate temperature. To investigate this hypothesis, the blood pressure response and the incidence of hypotensive episodes should be studied in a prospective clinical study in cardiovascular compromised patients during hemofiltration and (cold) combined ultrafiltration-hemodialysis at equivalent extracorporeal blood temperatures. In addition, studies are necessary to investigate the possible adverse effects of cold dialysis. 
Chapter 8

Samenvatting 


\section{Samenvatting}

Hemodynamische instabiliteit met symptomatische hypotensie is nog steeds een van de belangrijkste dialyse gerelateerde complicaties. Met een toenemend aantal oudere, cardiovasculair gecompromitteerde dialyse patiënten is het van groot belang hemodialyse als therapie te optimaliseren met betrekking tot de intradialytische bloeddrukregulatie. Ten aanzien hiervan is het algemeen bekend dat het onttrekken van vocht beter wordt getolereerd door de patiënt wanneer dit plaats vindt tijdens geïsoleerde ultrafiltratie of hemofiltratie dan tijdens gecombineerde ultrafiltratiehemodialyse. De laatste therapie wordt ook wel klassieke hemodialyse genoemd. In hoofdstuk 1 wordt een overzicht van de literatuur gegeven betreffende plasma volume preservatie en cardiovasculaire compensatie mechanismen in relatie tot de verschillende vormen van nierfunctievervangende therapie. Beide mechanismen spelen een centrale rol in de bloeddrukregulatie tijdens hemodialyse. Geconcludeerd kan worden dat verschillen in hemodynamische stabiliteit tussen verschillende vormen van nierfunctievervangende therapie primair zijn gerelateerd aan verschillen in vasculaire reaktiviteit. Zowel geïsoleerde ultrafiltratie als hemofiltratie zijn geassocieerd met een normale fysiologische toename in perifere vaattonus indien het circulerend bloedvolume daalt. In tegenstelling hiermee is zowel de arteriolaire als de veneuze reaktiviteit gestoord tijdens gecombineerde ultrafiltratie-hemodialyse. Het is echter nog steeds onduidelijk welke mechanismen hiervoor verantwoordelijk zijn. In de huidige studies werd daarom de pathofysiologie van verschillen in vasculaire reaktiviteit tijdens verschillende vormen van nierfunctievervangende therapie bestudeerd. Middels veneuze occlusieplethysmografie werd de vasculaire reaktiviteit van de onderarm gemeten bij cardiovasculair stabiele patiënten tijdens hemodialyse in relatie tot een aantal factoren.

Het is bekend dat de extracorperale bloedtemperatuur een belangrijke rol speelt in de bloeddrukregulatie tijdens hemodialyse. In hoofdstuk 2 werd de rol van verschillen in de extracorperale bloedtemperatuur in de vasculaire reakties tijdens geisoleerde ultratiltratie en gecombineerde ultrafiltratie-hemodialyse bestudeerd (protocol A). Tijdens gecombineerde ultrafiltratie-hemodialyse werd gebruik gemaakt van twee verschillende dialysaattemperaturen. Tijdens geïsoleerde ultrafiltratie koelde het bloed tijdens extracorporale circulatie af met $1.7^{\circ} \mathrm{C}$. Tijdens gecombineerde ultrafilltratie-hemodialyse met een dialysaattemperatuur van $37.5^{\circ} \mathrm{C}$ werd afkoeling van bloed voorkomen door verwarming van bloed door het warme dialysaat. Als gevolg hiervan nam de arteriële bloedtemperatuur tijdens 4 uur behandeling significant toe. Bij een dialysaattemperatuur van $35.0^{\circ} \mathrm{C}$ was de extracorperale bloedtemperatuur tijclens gecombineerde ultrafiltratie-hemodialyse exact gelijk aan geïsoleerde ultrafiltratie. De hemodynamische gegevens bevestigen 
dat zowel de arteriolaire als veneuze reaktiviteit gestoord is tijdens gecombineerde ultrafiltratie-hemodialyse: in tegenstelling tot geïsoleerde ultrafilltratie bleef de vasculaire weerstand onveranderd terwijl de veneuze tonus zelfs daalde, hetgeen resulteerde in een secundaire toename van de hartfrequentie. Tijdens koude gecombineerde ultrafiltratie-hemodialyse was alleen de veneuze tonus significant hoger en de hartfrequentie significant lager dan tijdens warme gecombineerde ultrafiltratie-hemodialyse. Dit impliceert dat de verminderde vasculaire reaktiviteit tijdens gecombineerde ultrafiltratie-hemodialyse in vergelijking met geïsoleerde ultrafiltratie slechts ten dele wordt verklaard door verschillen in de extracoperale bloedtemperatuur. Dit suggereert dat additionele factoren hierin een rol moeten spelen. In protocol $\mathbf{B}$ werden de effecten van koude dialyse op de post-dialytische bloeddruk bestudeerd door zowel tijdens als 22 uur na warme en koude gecombineerde ultrafiltratie-hemodialyse de bloeddruk te meten. Koude hemodialyse was alleen tijdens de behandeling geassocieerd met een significant hogere bloeddruk. In de post-dialytische periode bestonden er geen verschillen in bloeddruk tussen warme en koude hemodialyse. Post-dialytische lrypotensie na koude dialyse trad evenmin op. Het verlagen van de dialysaattemperatuur lijkt daarom een veilige methode om de hemodyanamische stabiliteit tijdens gecombineerde ultrafiltratie-hemodialyse te doen toenemen.

Een daling in plasma osmolaliteit wordt traditioneel gezien als een belangrijke factor in de gestoorde hemodynamische reaktiviteit tijdens gecombineerde ultrafiltratie-hemodialyse. Het is bekend dat de hemodynamische stabiliteit tijdens hemodialyse kan worden verbeterd door gebruik te maken van een hogere dialysaatnatriumconcentratie. Tevens wordt er een relatie gesuggereerd tussen hemodynamische instabiliteit bij gebruik van lage dialysaatnatriumconcentraties en een stijging van het plasma prostaglandine $E_{2}$. In hoofdstuk 3 werd daarom zowel de vasculaire reaktiviteit als veranderingen in prostaglandine $E_{2}$ bestudeerd tijdens gecombineerde ultrafiltratie-hemodialyse bij zowel een hoge (144 mmol/l) als een lage $(134 \mathrm{mmol} / \mathrm{l})$ dialysaatnatriumconcentratie. Hoog natrium dialyse resulteerde in een significant hogere plasma natriumconcentratie. Continue meting van veranderingen in bloedvolume toonde een grotere afname in het intravasculaire volume tijdens laag natrium dialyse hetgeen resultaten van eerdere studies bevestigde. Prostaglandine $\mathrm{E}_{2}$ nam alleen tijdens laag natrium dialyse significant toe. De vasculaire reaktiviteit was echter volledig vergelijkbaar tussen hoog en laag natrium dialyse. Tevens werd geen relatie gevonden tussen veranderingen in plasma prostaglandine $E_{2}$ en veranderingen in arteriële bloeddruk of vasculaire tonus. Deze resultaten tonen aan dat de verbeterde hemodynamische stabiliteit bij gebruik van hogere dialysaatnatriumconcentraties wordt bepaalld door een betere preservatie van plasma volume en niet door een verbetering van de vasculaire reaktiviteit. Verder duiden zij erop dat de verminderde vasculaire reaktiviteit tijdens gecombineerde 
ultrafiltratie-hemodialyse niet is gerelateerd aan veranderingen in plasma osmolaliteit.

In aanwezigheid van niet steriel dialysaat zou hemodynamische instabiliteit tijders gecombineerde ultrafiltratie-hemodialyse gerelateerd kunnen zijn aan de produktie van cytokinen door monocyten zoals wordt gesuggereerd door Henderson en anderen. Betere hemodynamische stabiliteit tijdens geisoleerde ultrafiltratie en hemofiltratie zou dan het gevolg zijn van de afwezigheid van dialysaat (en pyrogenen) en het gebruik van een steriel substitutievloeistof tijdens hemofiltratie. In hoofdstuk 4 konden wij echter geen verschil aantonen in vasculaire reaktiviteit tijdens gecombineetde ultrafiltratie-hemodialyse tussen gebruik van niet-steriel en steriel dialysaat. Gecombineerde ultrafiltratie-hemodialyse was nog steeds geassocieerd met een afname in veneuze tonus en een onveranderde perifere weerstand ondanks gebruik van dialysaat vrij van pyrogenen. Deze resultaten tonen aan dat verschillen in vasculaire reaktiviteit tussen verschillende vormen van nierfunctievervangende therapie niet primair zijn gerelateerd aan verschillen in expositie aan pyrogenen. Het is echter niet uitgesloten dat expositie aan een hogere graad van pyrogenen zou kunnen leiden tot een verdere verstoring van de vasculaire reaktiviteit tijdens gecombineerde ultrafiltratie-hemodialyse.

Aangezien calcium ionen een belangrijke rol spelen in de contractie van zowel vasculaire gladde spiercellen als van cardiale myocyten kunnen veranderingen in plasma geïoniseerd calcium van grote invloed zijn op de hemodynamische reaktie tijdens hemodialyse. In eerdere studies werd reeds een relatie gevonden tussen veranderingen in geioniseerd calcium en de bloeddruk tijdens hemodialyse. Een toename in myocardiale contractiliteit bij gebruik van hogere dialysaat calcium concentraties is hierbij meendere malen aangetoond. Onbekend is echter of de perifere vasculaire reaktiviteit tevens wordt beïvloed door veranderingen in geioniseard calcium. In hoofdstuk $\mathbf{5}$ werd daarom zowel de vasculaire als myocardiale reaktiviteit gemeten tijdens gecombineerde ultrafiltratie-hemodialyse met een lage (1.25 mmol/l) en een hoge $(1.75 \mathrm{mmol} / \mathrm{l})$ dialysaatcalciumconcentratie. Het plasma geioniseerd calcium nam alleen tijdens hoog calcium dialyse significant toe hetgeen resulteerde in een significant hogere bloeddruk. Terwijl de cardiale output alleen tijdens laag calcium dialyse significant afnam werden geen verschillen in perifere weerstand en veneuze tonus gevonden tussen laag en hoog calcium dialyse. Deze resultaten tonen aan dat de belangrijke rol die veranderingen in geioniseerd calcium spelen in de bloeddrukregulatie tijdens dialyse primair zijn gerelateerd aan veranderingen in myocardiale contractiliteit.

Op basis van de resultaten van de eerste vier studies kan geconcludeerd worden dat de extracorperale bloedtemperatuur een belangrijke rol speelt in de vasculaire reaktiviteit tijdens hemodialyse. In hoofdstuk 6 werd daarom de vasculaire reaktiviteit bestudeerd in relatie tot de extracorperale bloedtemperatuur tijdens 
zowel gecombineerde ultrafiltratie-hemodialyse als hemofiltratie. Om een vergelijkbare bloedtemperatuur te verkrijgen tijdens hemofiltratie als tijdens gecombineerde ultrafiltratie-hemodialyse $\left(37.5^{\circ} \mathrm{C}\right)$ werd de temperatuur van de substitutievloeistof verhoogd naar $39.0^{\circ} \mathrm{C}$. Dezelfde metingen werden tevens verricht tijdens hemofiltratie met een temperatuur van de substitutievloeistof van $36.0^{\circ} \mathrm{C}$. Beide behandelingen waren gematched met betrekking tot de gebruikte buffer (bicarbonaat), klein moleculaire klaring en biocompatibiliteit. Bij een exact gelijke extracorperale bloedtemperatuur waren gecombineerde ultrafiltratiehemodialyse en hemofilltratie geassocieerd met een vergelijkbare hemodynamische reaktiviteit. Alleen tijdens koude hemofiltratie bleef de veneuze tonus onveranderd terwijl de perifere weerstand significant toenam. Tijdens zowel warme hemofiltratie als gecombineerde ultrafiltratie-hemodialyse nam de veneuze tonus significant af terwijl de perifere weerstand onveranderd bleef. Een en ander resulteerde in een significant hogere bloeddruk tijdens koude hemofiltratie in vergelijking met zowel warme hemofiltratie als gecombineerde ultrafiltratie-hemodialyse.

\section{Conclusie}

In het voorliggende proefschrift werd de pathofysiologie van verschillen in vasculaire reaktiviteit tijdens verschillende vormen van nierfunctie vervangende therapie bestudeerd. In het algemeen kan worden geconcludeerd dat de vasculaire reaktiviteit tijdens dialyse met name wordt beïnvloed door de extracorperale bloedtemperatuur. De resultaten van hoofdstuk 6 laten zelfs zien dat verschillen in vasculaire reaktiviteit tussen gecombineerde ultrafiltratie-hemodialyse en hemofiltratie primair worden bepaald door verschillen in de extracorperale bloedtemperatuur. Tijdens gecombineerde ultrafiltratie-hemodialyse wordt de normale fysiologische hemodynamische reaktie op een afname in circulerend bloedvolume verstoord door een toename in lichaamstemperatuur, resulterend in perifere vasodilatatie. Dit suggereert dat het mogelijk moet zijn on een vergelijkbare hemodynamische stabiliteit te verkrijgen tijdens gecombineerde ultrafiltratie-hemodialyse als tijdens hemofiltratie door verlaging van de dialysaattemperatuur. Het is van belang on deze hypothese te bestuderen in een prospectieve meer klinische georienteerde studie. Hierin zouden hemodynamische parameters en de incidentie van hypotensieve episodes gemeten moeten wordlen bij cardiovasculair gecompromitteerde patiënten tijdens hemofiltratie en (koude) gecombineerde ultrafiltratie-hemodialyse bij een vergelijkbare extracorperale bloedtemperatuur. Tevens lijkt het noodzakelijk om de mogelijk nadelige gevolgen van koude dialyse te bestuderen. 


\section{Dankwoord}




\section{Dankwoord}

Het verrichten van klinisch-wetenschappelijk onderzoek is voor een belangrijk deel gebascerd op een goede samenwerking met meerdere mensen. Zo heb ook ik de afgelopen jaren velerlei mensen mogen ontmoeten, waarvan eenieder op zijn of haar wijze aan de totstandkoming van dil proefschrift heeft bijgedragen. Zonder woord van dank is de afsluiting van drie jaar onderzoek niet compleet.

Door het praktisch-klinische karakter van de verschillende studies was de medewerking van patiënten onontbeerlijk. Met veel geduld ondergingen zij de verschillende metingen, waarbij 'stil zitten' een vaak uitgesproken verzoek mijnerzijds was. Ik wil hen graag hartelijk danken woor het getoonde vertrouwen en hun bereidwilligheid om aan de studies deel te nemen.

De meeste studies zijn uitgevoerd op de afdeling hemodialyse van het Academisch Ziekenhuis Maastricht. Deze afdeling fungeerde de afgelopen jaren voor mij als een soort thuisbasis. Ik kan terugkijken op een bijzonder prettige samenwerking met het voltallige personeel. Een dag op de dialyse begon meestal met een kopje koffie en een praatje met Marleen Dresens. Verder stond Pierre Waterval altijd open voor een nieuw verzoek mijnerzijds. Ook in tijden wanneer de ruimte binnen de afdeling bijzonder beperkt was. Voor vragen of problemen van technische aard kon ik altijd bij Piet Claessens terecht. De door eenieder getoonde interesse heb ik altijd bijzonder op prijs gesteld.

Dr. F. de Heer (Masland ziekenhuis, Sittard) was bereid on mij een aantal van zijn patiènten voor het onderzoek toe te vertrouwen. Verder waren Dr. W. Grave en Dr. J.J.J.M. Wirtz (St.Laurentius ziekenhuis, Roermond) alsook Dr. P.G.G. Gerlag en Dr. A.W.L. van den Wall Bake (St.Joseph ziekenhuis, Veldhoven) en Dr. A.W. Mulder en Dr. S.J. Hoorntje (Catharina ziekenhuis, Eindhoven) bereid de deuren van hun afdeling voor mij te openen. In Veldhoven was de medewerking van de afdeling medische microbiologie onder leiding van Dr. M. Haverkorn van bijzonder belang. Dhr. A. van Dorst moet onit gedacht hebben dat aan de stroom van te analyseren dialysaatmonsters geen einde meer zou komen. In Eindhoven werd het echocardiografisch onderzoek verricht door medewerkers van de afdeling Hartfunctie onder leiding van Dr. C.H. Peels. Het verrichten van onderzock elders gaf aan de verschillende studies een extra dimensie. Dankzij de medewerking van de verschillende internist-nefrologen, vele verpleegkundigen, technici, laboranten en secretaresses was het mogelijk om in vaak korte tijd een schat aan informatic te verkrijgen. I also would like to thank Dr. D. Hillion and his co-workers (CHI Poissy, France) for their French hospitality and cooperation in performing the last study. Dr. Hillion, it was a great pleasure for me to share your experience with convective dialysis treatments.

In Maastricht werd het onderzoek vanuit verschillende hoeken ondersteund. Centraal in alle studics stond de plethysmograaf van Janssen Scientific Instruments. Luc van Bortel maakte de beschikking hierover zowel binnen als buitenshuis mogelijk. De medewerkers van het hypertensie laboratorium en het laboratorium klinische farmacologie stonden garant voor een nauwkeurige en snelle bepaling van catecholaminen. Het laboratorium voor klinische chemie verzorgde de vele klinisch chemische bepalingen waarbij 
Ing. H.M.L. Habets een altijd coöperatief aanspreekpunt vormde. Dr. P.P.C.A. Menheere was bereid zich te verdiepen in de bepaling van prostaglandinen hetgeen geen sinecure bleek te zijn. Op het laboratorium wan Dr. W.A. Butuman en in het bijzonder door Gaby Francot werden de immunologische bepalingen verricht. De uitvoering en verslaglegging waren altijd bijzonder accuraat. Dr. F.H.M. Nieman verzorgde in de beginfase de statistische bewerking van de verkregen gegevens en gaf mij in korte tijd een spoedcursus statistiek. Fred, het feit dat ik loch nog regelmatig bij je moest aankloppen geeft an dat MANOVA voor mij nog steeds een aantal geheimen heeft. Bij de uiteindeligke afronding van mijn proefschrift waren zowel de positieve inzet als ervaring van "Tiny Wouters voor mij wan bijzondere betekenis. Om met Karel te spreken, bij Tiny brandt nog het heilig veur.

Zonder uitzondering wil ik alle leden vam de Werkgroep Nefrologie (klein maar fijn) graag bedanken voor de bijzonder prettige samenwerking van de afgelopen jaren. Wat mij betreft zullen onze paden elkaar de komende jaren nog meerdere malen kruisen.

The financial support of the Department of Research of Gambro $A B$, Sweden, coordinated by Dr. I. Ledebo, is also greatly acknowledged. Deat Ingrid, at many meetings and congresses we have been able to discuss the progress of our mutual project. Your critical and constructive comments have always been of great help.

Tevens wil ik Gambro Nederland danken voor hun logistieke ondersteuning bij in het bijzonder mijn exercitie in Veldhoven.

De leden van de beoordelingscommissie, Prof.Dr. P.J.E.H.M. Kitslatar, Prof.Dr. M.P. van Diejen-Visser en Prof.Dr. H.A.J. Struyker Boudier wil ik danken voor de kritische beoordeling van mijn proefschrift, waarin een voor hen niet alledaags onderwerp centraal staat.

I. also would like to thank Prof.Dr. C. Baldamus and Prof.Dr. J. Bergström for their willingness to critically review my manuscript. The present thesis is in fact based on their scientific work.

Mijn promotor, Prof.Dr. J.P. van Hooff wil ik graag danken voor zijn constructieve bijdrage aan de afronding van mujn proefschrift. Zijn intelligente en praktische benadering van problemen werkte vaak bijzonder verhelderend.

Een bijzonder woord van dank gaat wit naar mijn co-promotor, Dr. K.M.L. Leunissen. Beste Karel, ondanks een zich woor jou opstapelend aantal functies en taken heb ik de afgelopen jaren nooit vergeefs een beroep op je gedaan. Zowel je immer opbouwende kritiek als je heldere ideeën en enthousiasme waren voor mij van bijzondere betekenis en vormden een drijvende kracht achter de totstandkoming van dit proefschrift. Gelukkig beperkte jou begeleiding zich niet tot het onderzoek alleen. Met name dankzij jou was de achterliggende periode voor mij op vellerlei gebied bijzonder leenaam. Ik wil je hiervoor hartelijk danken.

Tot slot wil ik mijn ouders danken, voor de mogelijkheden die zij mij altijd hebben geboden. Bouwen begint bij een goed fundament. 


\section{Curriculum Vitae}




\title{
Curriculum Vitae
}

\author{
Willibrord van Kuijk
}

16-11-1965 Geboren te Waalwijk

1978-1984 atheneum-B, Dr. Mollercollege te Waalwijk

1984-1991 studie Geneeskunde aan de Rijksuniversiteit Limburg te Mastricht

1991-1992 vervulling militaire dienstplicht als eerste luitenant arts, Koninklijke Militaire School te Weert

1992-1995 assistent-in-opleiding aan de Rijksuniwersiteit Limburg te Maastricht (begeleider: Dr. K.M.L. Leunissen)

1995-1996 arts-assistent Intensive Care, Catharina Ziekenhuis te Eindhoven

01-10-1997 aanvang opleiding tot internist, Catharina Ziekenhuis te Eindlioven (opleider: Dr. W.P.M. Breed) 